\title{
Electrochemical Reverse Engineering: A Systems-Level Tool to Probe the Redox-Based Molecular Communication of Biology
}

Jinyang Li, ${ }^{1,2}$ Yi Liu, 1,2 Eunkyoung Kim, ${ }^{1,2}$ John C. March, ${ }^{3}$ William E. Bentley ${ }^{1,2}$ and Gregory F. Payne ${ }^{1,2}$

1. Fischell Department of Bioengineering, University of Maryland, College Park, MD, USA

2. Institute for Bioscience and Biotechnology Research, University of Maryland, College Park, MD, USA

3. Department of Biological and Environmental Engineering, Cornell University, Ithaca, NY, USA

* Corresponding author

Email: gpayne@umd.edu

Phone: 301-405-8389

FAX: $\quad 301-314-9075$ 


\begin{abstract}
The intestine is the site of digestion and forms a critical interface between the host and the outside world. This interface is composed of host epithelium and a complex microbiota which is "connected" through an extensive web of chemical and biological interactions that determine the balance between health and disease for the host. This biology and the associated chemical dialogues occur within a context of a steep oxygen gradient that provides the driving force for a variety of reduction and oxidation (redox) reactions. While some redox couples (e.g., catecholics) can spontaneously exchange electrons, many others are kinetically "insulated" (e.g., biothiols) allowing the biology to set and control their redox states far from equilibrium. It is well known that within cells, such non-equilibrated redox couples are poised to transfer electrons to perform reactions essential to immune defense (e.g., transfer from $\mathrm{NADH}$ to $\mathrm{O}_{2}$ for reactive oxygen species, ROS, generation) and protection from such oxidative stresses (e.g., glutathione-based reduction of ROS). More recently, it has been recognized that some of these redox-active species (e.g., $\mathrm{H}_{2} \mathrm{O}_{2}$ ) cross membranes and diffuse into the extracellular environment including lumen to transmit redox information that is received by atomically-specific receptors (e.g., cysteine-based sulfur switches) that regulate biological functions. Thus, redox has emerged as an important modality in the chemical signaling that occurs in the intestine and there have been emerging efforts to develop the experimental tools needed to probe this modality. We suggest that electrochemistry provides a unique tool to experimentally probe redox interactions at a systems level. Importantly, electrochemistry offers the potential to enlist the extensive theories established in signal processing in an effort to "reverse engineer" the molecular communication occurring in this complex biological system. Here, we review our efforts to develop this electrochemical tool for in vitro redox-probing.
\end{abstract}

\title{
I. Redox Biology of Intestine
}

\section{Intestinal Anatomy and Physiology}

\subsection{Eukaryotic}

Figure 1a shows that the intestine is comprised of small intestine and large intestine (also called colon). The small intestine is divided into duodenum (connected to stomach), jejunum and ileum. The large intestine begins at cecum (connected to small intestine), followed by ascending colon, transverse colon, descending colon and the rectum[1]. Both the large and small intestines are lined with a layer of columnar epithelial cells. As shown in Figure $\mathbf{1 b}$, the epithelium of the small intestine is extensively folded with distinct crypt and villi morphology to provide maximal absorptive surface area for efficient nutrient acquisition. In contrast, Figure 1c shows the epithelial surface in the large intestine is flatter and lacks the distinct villi structure.

The intestinal epithelium is composed of different cell types that perform various functions. Figure $\mathbf{1 b}$ shows that in the small intestine, the epithelium of the villi consists 
primarily of enterocytes with intermittent goblet cells (which increase in number from the proximal to distal small intestine) and enteroendrocrine cells, while the epithelium of the crypt is comprised of stem cells and Paneth cells. In the small intestine, the multi-potent intestinal stem cells (ISC) reside in the crypt and are shielded by invaginations. ISC proliferate into progenitor cells and then further differentiate into absorptive (enterocyte) and secretory (goblet and enteroendocrine cells) lineages. As indicated in Figure 1b, as these cells differentiate - with the exception of Paneth cells - they also tend to migrate from the crypt to the villus tip until they detach from the epithelial layer or undergo apoptosis. In contrast to the small intestine, Figure 1c shows the surface of the large intestine lacks villus projections and Paneth cells.

The various cell types in Figure 1b are believed to perform various functions. Absorptive enterocytes, which account for over $80 \%$ of the intestinal cells, not only participate in the digestive process, but also exert a barrier function via tight junctions. They also generate reactive oxygen species (ROS)[2] as signaling molecules to maintain homeostasis. Goblet cells constantly secrete highly glycosylated mucin to maintain a mucus barrier (approximately $100 \mu \mathrm{m}$ thick) to protect against adhesion and invasion by microorganisms. Enteroendocrine cells release gastrointestinal hormones to initiate communication for both local and more distant responses (e.g., at a systemic level) [3]. Paneth cells, which differentiate and remain within the crypt, produce substantial quantities of antimicrobial peptides (AMP) including lysozyme, defensins and cathelicidins to protect the host from enteric pathogens and to shape the composition of luminal commensal microbiota [4]. The high concentration of AMP in the mucous layer can maintain the zone adjacent the epithelium free of bacteria.

While Figure 1b and Figure 1c provide an overview, it is important to note that the intestinal epithelium is a dynamic system with continuous ISC differentiation and renewal[5].

\subsection{Prokaryotic}

The human intestine is a complex but highly stable system in which the epithelium coexists with biologically and metabolically active microbiota. The gut microbiota possesses enormous microbial diversity with a bacterial cell population 1.3 times greater than the number of somatic cells in the human body[6], and 100-times more encoded genes than the human genome[7,8]. It is well accepted that luminal microorganisms perform important functions for the host by extracting nutrients and energy from diet, protecting against enteropathogens, and promoting the development and maturation of normal immune functions.

Molecular biological analysis of the microbiota has expanded our knowledge of the community composition of the gut microbiota and offers the potential for correlating the microbial composition to health or disease. Efforts to characterize the composition of gut microbiota have revealed that for healthy adults, Firmicutes (38.8\%) and Bacteroidetes 
(27.8\%) usually dominate the microbiota, whereas Actinobacteria (8.2\%), Proteobacteria $(2.1 \%)$ and Verrucomicrobia are found as minor constituents[9,10]. Despite consistencies in the main components, the species can vary markedly across individuals, making it difficult to define a core set of species in the microbiota[11]. However, recent studies indicate that microbial genetic function is preserved (e.g., some minor species share common functions) $[9,12]$. Thus, a definition of a "normal" human gut may need to include information of both microbial composition and microbial activities and functions within the context of host function.

A variety of interventions have been used to alter the microbial composition in the gut with the goal of maintaining or restoring health. One type of intervention is the use of prebiotics or food ingredients that stimulate the growth and/or activity of beneficial intestinal bacteria[13,14]. A second type of intervention is probiotics or living organisms in an attempt to directly alter the gut's microbial composition. Recent research is even considering the use of synthetic biology to purposefully-engineer probiotic bacteria to encourage healthy microbial interactions and suppress pathogenic interactions[15,16]. A third intervention is fecal transplantation which is the introduction of fecal bacteria from a healthy donor in order restore healthy microbial function[17-20].

(a) Anatomy

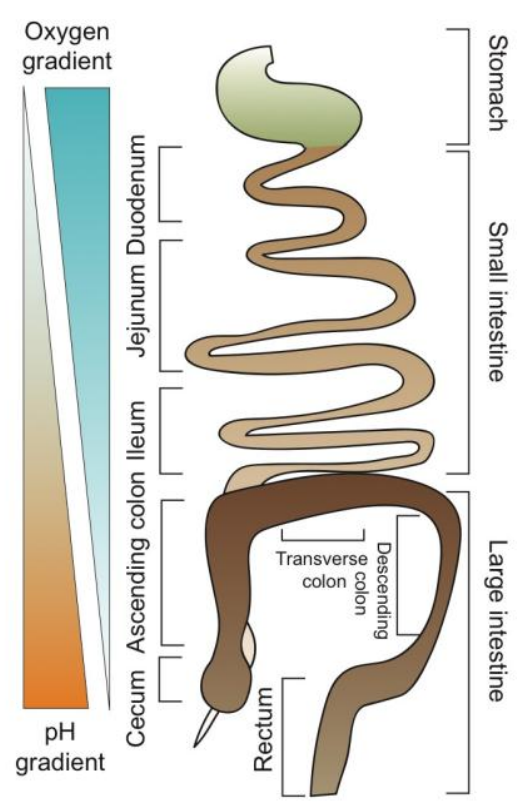

(b) Small Intestine

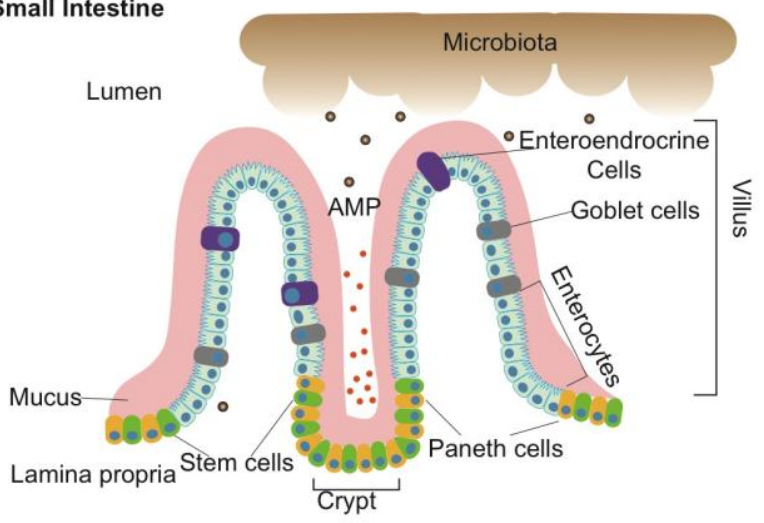

(c) Large Intestine

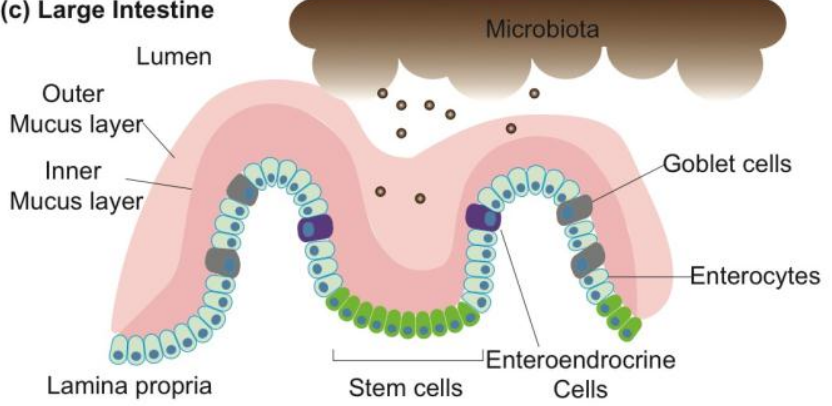

Figure 1. (a). Overview of gastrointestinal anatomy. (b). Organization of the small intestinal epithelium with a loose, non-adherent mucus layer separating the epithelium from luminal microbiota. (c). Organization of the large intestinal epithelium where the mucus separates the epithelium from a much denser microbiota. 


\subsection{Mucus}

As illustrated in Figure $\mathbf{1 b}$ and Figure 1c, the intestinal epithelium and luminal microbiota are physically separated by a mucus layer, which is generated by epithelial goblet cells. The mucus of the small intestine is composed of a single layer. In contrast, the mucus in the colon has a two-layered structure: the inner layer is attached to the epithelium and impervious to bacteria, while the outer layer is unattached, looselyorganized, and a habitat and partial food source for commensal bacteria. The main component of mucus is the proteoglycan Mucin2 (MUC2), which is highly glycosylated with over $80 \%$ carbohydrate content. The glycan chains contribute a large negative charge to mucin giving this proteoglycan considerable water-binding capabilities and therefore hydrogel-like properties[21]. Host defense molecules (e.g. AMP and $\lg A$ ) and even bacteriophages are believed to be trapped in the mucus. Therefore, the mucus layer can provide a highly selective environment for survival of nonpathogenic gut colonizers that have evolved resistance to host AMP[22].

\subsection{Homeostasis and dysbiosis}

To maintain homeostasis, the commensal bacteria, the mucus lining, the intestinal epithelial and lamina propria comprise the host's first line of defense against pathogens. Commensal bacteria inhibit colonization by pathogens through competition for nutrients and for mucosal binding sites. In addition, commensal bacteria are believed to secrete antimicrobial substances (e.g., the protein bacteriocins). The mucus layer serves as a physical barrier to separate and trap invading microorganisms. Epithelial cells exert a barrier function through the formation of tight junctions[23] and also immune function by production of reactive oxygen species (ROS) and antimicrobial peptides (AMP) and trafficking of IgA from the submucosa. AMP are produced by all intestinal epithelial cell lineages (e.g. enterocytes, goblet cells and Paneth cells)[24]. ROS were observed to be generated in intestinal epithelium via enterocyte NADPH oxidase[25]. If bacteria do transport across epithelium and reach the lamina propria, significant immune responses can be triggered and these include phagocytic killing by macrophages and $\mathrm{T}$ cell activation. Further details of intestinal inflammatory immune responses can be found in recent reviews[1,24,26]).

The disruption of intestinal flora leads to quantitative and qualitative changes of the microbial community, and such maladaptive disruptions are termed dysbacteriosis or dysbiosis. Dysbiosis can be induced by infections, dietary factors, immune deficits or the administration of antibiotics. Dysbiosis is characterized by decreases in microbial diversity and the number of commensal bacteria, increases in the number of pathological bacteria, disruption of the mucosal barrier and intestinal inflammation[8]. For example, the administration of antibiotics has been shown to disrupt the homeostatic balance of the normal intestinal flora and this has been implicated in the development of serious Clostridium difficile infections [27]. Dysbiosis is also implicated in a variety of pathologies of the gut such as inflammatory bowel disease[28] and colorectal cancer[29]. More 
broadly, imbalances in the gut microbiota have been suggested for a diverse range of diseases that include diabetes[30], multiple sclerosis[31], atherosclerosis[32], obesity[33], rheumatoid arthritis[34] and non-alcoholic fatty liver disease[35]. These observations have motivated intense investigation to understand the role of intestinal flora (i.e., the microbiome) and its interaction with host in health and disease.

\section{Chemical Dialogues}

Figure 2 illustrates that there is extensive chemical communication among the different bacteria in the lumen and between microbiome and host cells. Considerable current research aims to characterize these chemical signaling interactions to understand their roles in homeostasis and disease. Do specific chemical signals characterize symbiotic vs pathogenic interactions? Are there chemical signatures that characterize the microbial imbalances of dysbiosis? Can causal relations be discerned between chemical signals and pathogenic responses? And, can purposeful interventions (e.g., functional foods or therapeutics) promote favorable chemical signaling interactions and/or suppress unfavorable interactions?

\subsection{Bacterial communication: quorum sensing}

Bacterial Quorum Sensing (QS) is a chemical communication strategy that allows bacteria to coordinate population-level responses. As suggested in Figure 2a, QS signals are small molecules that are synthesized and released by bacteria, and the bacteria can also detect and respond to these same signals. Because the local concentration of QS signals depends on the population of QS-synthesizers, this signal provides information of the number and type of bacteria in this local environment [36,37]. Bacterial QS is reported to be important for: aiding or resisting biofilm formation[38] which is associated with colorectal tumors[39,40], pathogen colonization [41], tolerance to host immune action [42], facilitating bacterial movement[43], and production of virulence factors[44]. For instance, bacterial pathogens may use QS to delay the expression of virulence until after a threshold population is generated. This strategy may prevent the elicitation of a robust host immune response until after an infection has been established[41].

As shown in Figure 2a, three major QS paradigms have been described that use separate autoinducers (Al): acyl homoserine lactones ( $\mathrm{AHL}$ ) are used by Gram-negative bacteria, autoinducing oligopeptide (AIP) is used by Gram-positive bacteria, and auntoinducer-2 (Al-2) is reported to be a universal system for communication across species as it is synthesized by numerous types of bacteria.[45]. The term autoinducer has been used because QS signals can induce genes responsible for their own biosynthesis which leads to feedback loop that amplifies the QS chemical signal. Considerable research aims to "decode" the QS language of bacteria with translational goals of guiding bacterial behaviors, restoring colonization resistance and (re)shaping of microbiota composition[46,47]. 


\subsection{Communication between eukaryotic \& prokaryotic cells}

Figure $\mathbf{2 b}$ and $\mathbf{2 c}$ shows that there is a mutual relationship between the intestinal microbiota and its host, which is believed to be crucial determinant of health and disease. The host provides their intestinal bacteria a protected nutrient-rich environment, while the bacteria make essential contributions for polysaccharide digestion[48], defense against infections and synthesis of vitamins[24]. Studies using germ-free animals show that the acquisition of symbiotic microbes is critical for the normal function of the intestine[49,50]. Disruption of a symbiotic host-microbiota interactions can cause serious health challenges both locally (e.g., at the intestine) and systemically (e.g., other organs)[51].

The environmental factors controlled/contributed by the host include oxygen, $\mathrm{pH}, \lg \mathrm{A}$ and antimicrobial peptides (AMPs) and these serve to shape and maintain the microbial community[52]. Physiological conditions change dramatically throughout the digestive tract as illustrated in Figure 1a. The stomach has a high oxygen concentration and is strongly acidic $(\mathrm{pH} \approx 2-5[53])$, and as a result, the microbial load is relatively small $\left(10^{2}\right.$ $10^{3} / \mathrm{g}$ content [1]). In the duodenum, the oxygen concentration is lower and the acidity has been partially neutralized by the bicarbonate ions secreted by Brunner's glands and as a result, the microbiota increases in both diversity and density (103/g content). The duodenum's slightly oxygenated and acidic $\mathrm{pH}$ limits microbial colonization to oxygenand acid -tolerant bacteria, such as Lactobacillus, Streptococcus and Veillonella. Due to the low oxygen [54] and richness of host-indigestible polysaccharides[55] in colon, the colonic bacterial load increases to $10^{12} / \mathrm{g}$ content and $99 \%$ of bacterial species are strict anaerobes. In addition to providing $\mathrm{O}_{2}$ and controlling $\mathrm{pH}$, the host's intestinal cells may initiate immune responses (e.g., the generation of AMPs and ROS) that further exert selective pressure on the microbiota.

In addition to the host providing conditions to shape the intestinal microbiota, Figure 2c also shows that the microbes can signal to host and perform essential functions [8]. The commensal microbiota convert dietary components into metabolites that exert signaling function[56]. These metabolites range from peroxides to other metabolites and have been shown to support epithelial growth, nutrient adsorption, barrier function and angiogenesis[57-59]. Perhaps the best-known example is the short chain fatty acids (SCFA) that are produced by a wide variety of bacteria at concentrations of $50-150 \mathrm{mM}$ in the large intestine[60]. SCFA signal through a pair of G-protein-coupled receptors, modulating host processes such as $T$ cell function[61], mucin production[62] and tight junction integrity [63].

The above discussion considered the exchange of chemicals (e.g., for nutrition and signaling) as unidirectional. Figure $\mathbf{2} \mathbf{d}$ also shows the intestine and microbiota can interact through complex bidirectional signaling networks, termed inter-kingdom signaling. For instance, a range of metabolic products are coproduced by both the host and microbiota and are believed to play important roles in shuttling information between 
host cells and microbial symbionts as well as among different microbial species. Further details have been reviewed by Pettersson et al.[51].

Notably, quorum sensing was previously considered to be a bacteria-to-bacteria signaling mechanism to shape community structure, but now there is evidence indicating that QS may also be involved in the inter-kingdom signaling among symbiotic microbiota, pathogenic microbiota and the host[64-66]. Examples include a host synthesis of QSmimics to communicate with bacteria [67] and host responses to bacterial QS signals [68-70]. Moreover, bacteria have also been reported to sense and respond to host signals (e.g., hormones[71]).

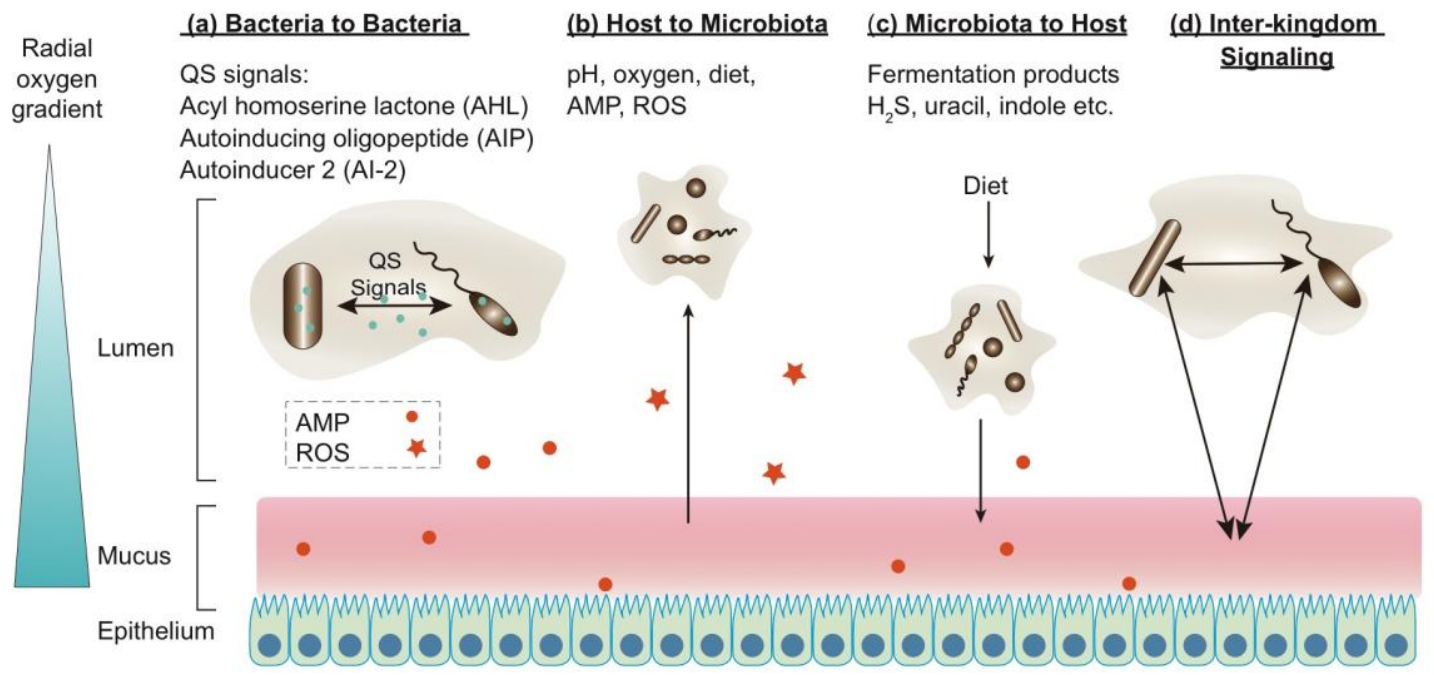

Figure 2. Chemical dialogues in the intestine. (a) Bacteria in intestine use Quorem Sensing (QS) to coordinate activities. (b) Environmental factors provided by the host can shape the composition and maintain homeostasis of microbial community. (c) Microbiota convert dietary components into metabolites that sometimes serve as signaling effectors for the host. (d) The host and microbiota also communicate through complex bidirectional signaling networks that span the kingdoms (e.g. inter-kingdom signaling).

\section{Relevance of Redox Chemistry in Intestine}

\subsection{Oxygen gradient}

Figure 2 shows that there are steep radial oxygen gradients in the intestines. The intestine is highly vascularized to provide oxygen to the epithelium but the oxygen 
concentration decreases precipitously from relatively high submucosal levels to near anoxic levels at the midpoint of the lumen. Importantly, these radial oxygen gradients are not constant over time, but change through daily cycles as a result of the ingestion of food which stimulates intestinal blood flow to meet increases in local metabolic demands for oxygen. Such steep radial oxygen gradients contribute to the microbial biogeography[72], with enrichment of oxygen-tolerant bacteria (e.g., facultative anaerobes, Helicobacter and Treponema) in the mucosa and obligate anaerobes (e.g., Firmicutes) in the lumen.[73,74]. The oxygen gradient not only provides an important context for the gut biology (e.g., the radial partitioning of intestinal microbiota[75]), but it also impacts the chemistry of the gut by modulating redox effectors such as nitric oxide, hydrogen sulfide and the reactive oxygen species that may be of either host or bacterial origin[54]. These biologically-generated redox effectors, or the oxygen gradient itself, may further influence redox-active chemical components introduced in the diet (e.g., antioxidants).

\subsection{Reactive Oxygen Species (ROS)}

Historically, reactive oxygen species (ROS) have played a prominent role in studies of oxidative stress (e.g., the free radical theory of aging[76]) and antioxidant protection. Figure 3a and Table 1 shows that ROS-generation can be initiated by a partial reduction of $\mathrm{O}_{2}$ to generate free radical superoxide $\left(\mathrm{O}_{2} \cdot-\right)$. Two well-established mechanisms for $\mathrm{O}_{2} \cdot-$-generation are "leakage" from the mitochondrial electron transport chain and the enzymatic electron transfer from NADPH (e.g., by NADPH oxidases, NOXs). Once formed, $\mathrm{O}_{2}$ - can be further converted to hydrogen peroxide $\left(\mathrm{H}_{2} \mathrm{O}_{2}\right)$ by the superoxide dismutase enzymes (SOD) and to the highly reactive hydroxyl radical $(\cdot \mathrm{OH})$ via nonenzymatic Fenton and/or Haber-Weiss reactions. The hydroxyl radical is highly reactive and believed to be one of the most damaging ROS as it is capable of reacting with cellular proteins, lipids and DNA. Biology uses a variety of defenses to limit oxidative damage associated with ROS and Table 2 lists various ROS protection strategies.

It is well-known that high levels of ROS are generated during a host immune inflammatory response to provide antimicrobial function. However, increasing evidence indicates that basal levels of ROS generated by intestinal epithelium act as signaling effectors to maintain homeostasis [2,77,78]. It has also been reported that some intestinal bacteria can induce transient ROS-production by enterocytes, and this ROS can exert its effects through redox-responsive cell signaling mechanisms[79-83]. Such bacterial-stimulated ROS generation has been shown to affect a wide range of physiological processes, including the differentiation[84] and proliferation[85] of intestinal stem cells, and the migration of epithelial cells for epithelium restitution/repair[86]. Thus this emerging work indicates that ROS are more than protective antimicrobials but may be central participants for the development and homeostasis of the intestine[2,87,88]. 
Table 1 Reactive Oxygen Species

\begin{tabular}{ll}
\hline Species & Reaction \\
\hline Superoxide $\left(\mathrm{O}_{2} \cdot{ }^{-}\right)$ & $\mathrm{O}_{2}+\mathrm{e}^{-} \stackrel{\text { mitochondria }}{\longrightarrow} \mathrm{O}_{2}^{\cdot-}$ \\
Hydrogen peroxide $\left(\mathrm{H}_{2} \mathrm{O}_{2}\right)$ & $\mathrm{O}_{2}^{\cdot-}+2 \mathrm{H}^{+}+\mathrm{e}^{-} \stackrel{\mathrm{SOD}}{\longrightarrow} \mathrm{H}_{2} \mathrm{O}_{2}$ \\
Hydroxyl radical $(\cdot \mathrm{OH})$ & $\mathrm{H}_{2} \mathrm{O}_{2}+\mathrm{Fe}^{2+} \stackrel{\text { Fenton reaction }}{\longrightarrow} \mathrm{OH} \cdot+\mathrm{OH}^{-}+\mathrm{Fe}^{3+}$ \\
\hline
\end{tabular}

Table 2 Antioxidant systems

\begin{tabular}{|c|c|c|}
\hline Anti-oxidant protein & Reactions & Ref \\
\hline Superoxide dismutase (SOD) & $\mathrm{O}_{2}^{--}+2 \mathrm{H}^{+}+\mathrm{e}^{-} \stackrel{\mathrm{SOD}}{\longrightarrow} \mathrm{H}_{2} \mathrm{O}_{2}$ & [90] \\
\hline Catalase (CAT) & $2 \mathrm{H}_{2} \mathrm{O}_{2} \stackrel{\text { CAT }}{\longrightarrow} 2 \mathrm{H}_{2} \mathrm{O}+\mathrm{O}_{2}$ & [91] \\
\hline Glutathione Peroxidase (GPx) & $2 \mathrm{GSH}+\mathrm{ROOH} \stackrel{\mathrm{GPx}}{\longrightarrow} \mathrm{GSSG}+\mathrm{ROH}+\mathrm{H}_{2} \mathrm{O}$ & [92] \\
\hline Peroxiredoxin (Prdx) & $\mathrm{Trx}-(\mathrm{SH})_{2}+\mathrm{ROOH} \stackrel{\text { Prxd }}{\longrightarrow} \mathrm{Trx}-\mathrm{S}_{2}+\mathrm{ROH}+\mathrm{H}_{2} \mathrm{O}$ & [93] \\
\hline Glutaredoxins(Grx) & Grx- $(\mathrm{SH})_{2}+$ Protein- $\mathrm{S}_{2} \longrightarrow$ Protein- $(\mathrm{SH})_{2}+\mathrm{Grx}-\mathrm{S}_{2}$ & [94] \\
\hline Thioredoxin (Trx) & Trx- $(\mathrm{SH})_{2}+$ Protein- $\mathrm{S}_{2} \longrightarrow$ Protein- $(\mathrm{SH})_{2}+\operatorname{Trx}-\mathrm{S}_{2}$ & [95] \\
\hline Thioredoxin Reductase (TrxR) & $\operatorname{Trx}-\mathrm{S}_{2} \stackrel{\operatorname{TrxR}}{\longrightarrow} \operatorname{Trx}-(\mathrm{SH})_{2}$ & [95] \\
\hline
\end{tabular}

\subsection{Reactive Nitrogen Species (RNS)}

Other biologically important reactive species are reactive nitrogen species (RNS) that include nitric oxide radical ( $-\mathrm{NO}$ ), peroxynitrite (ONOO-), nitrogen dioxide radical $\left(\cdot \mathrm{NO}_{2}\right)$ and dinitrogen trioxide $\left(\mathrm{N}_{2} \mathrm{O}_{3}\right)$. As illustrated by the reactions in Table 3, $-\mathrm{NO}$ can be produced by the host from the $\mathrm{O}_{2}$-dependent metabolism of $\mathrm{L}$-arginine via nitric oxide synthases (NOS) [89]. Under hypoxic conditions, commensal microbiota can reduce dietary nitrate into nitrite while non-enzymatic reductions by ascorbate or phenols can also reduce nitrite into nitric oxide. [96,97] Intestinal anaerobic bacteria are also able to produce - NO by dissimilatory nitrate reduction to ammonium[98]. Therefore the concentration of - NO in gut can be significant (220 ppb) [99]. 
Table 3. Reactive Nitrogen Species

\begin{tabular}{|c|c|c|}
\hline Species & Reaction & Ref \\
\hline \multirow[t]{6}{*}{ Nitric oxide $(\cdot \mathrm{NO})$} & Host pathway (high oxygen tension) & [100] \\
\hline & L-arginine $+\mathrm{O}_{2} \stackrel{\text { NOS }}{\longrightarrow} \cdot \mathrm{NO}$ & \\
\hline & Host \& microbiota pathway (low oxygen tension) & \\
\hline & $\mathrm{NO}_{3}{ }^{-}+\mathrm{e}^{-} \stackrel{\text { Microbiota }}{\longrightarrow} \mathrm{NO}_{2}^{-} \stackrel{\text { Host }}{\longrightarrow} \cdot \mathrm{NO}$ & \\
\hline & Microbiota pathway & [101] \\
\hline & $\mathrm{NO}_{3}^{-}+\mathrm{e}^{-} \longrightarrow \mathrm{NO}_{2}^{-} \longrightarrow \cdot \mathrm{NO}+\mathrm{NH}_{3}$ & \\
\hline Nitrogen dioxide $\left(\cdot \mathrm{NO}_{2}\right)$ & $\cdot \mathrm{NO}+1 / 2 \mathrm{O}_{2} \longrightarrow \cdot \mathrm{NO}_{2}$ & [102] \\
\hline Dinitrogen trioxide $\left(\mathrm{N}_{2} \mathrm{O}_{3}\right)$. & $\cdot \mathrm{NO}+\cdot \mathrm{NO}_{2} \longrightarrow \mathrm{N}_{2} \mathrm{O}_{3}$ & [102] \\
\hline Peroxynitrite (ONOO-) & $\cdot \mathrm{NO}+\mathrm{O}_{2}^{\cdot-} \longrightarrow \mathrm{ONOO}^{-}$ & [96] \\
\hline
\end{tabular}

Nitric oxide ( • NO) was the first identified gasotransmitter[103] and has been shown to be an important messenger molecule in the gastrointestinal tract. - NO has been reported to modulate a wide range of host physiological functions that include maintenance of mucosal integrity and vascular tone[104-106], immune response [107109], and an inhibition of apoptosis [110]. In the presence of low oxygen tension, the respiration and growth of certain bacteria has also been shown to be suppressed by $\cdot \mathrm{NO}[111]$. As indicated in Table 3 , under aerobic conditions when $\mathrm{O}_{2}$ - - levels are comparatively low, $-\mathrm{NO}$ and $\mathrm{O}_{2}$ can react to form dinitrogen trioxide $\left(\mathrm{N}_{2} \mathrm{O}_{3}\right)$. In the presence of $\mathrm{O}_{2} \cdot$ and comparatively lower - NO levels, - $\mathrm{NO}$ and $\mathrm{O}_{2} \cdot$ - can react to generate $\mathrm{ONOO}^{-}$[112]. Both dinitrogen trioxide $\left(\mathrm{N}_{2} \mathrm{O}_{3}\right)$ and peroxynitrite (ONOO-) are highly reactive RNS that induce nitrosation (i.e. the formation of RSNO)[112] and direct oxidation of cellular thiol-containing compounds such as Cys residues (i.e. to form $\mathrm{RSOH}$ ) [113]. Peroxynitrite is a very potent oxidant with a half-life of seconds. Although the link between peroxynitrite and intestinal barrier dysfunction is still unclear, it has been suggested that peroxynitrite may contribute to colitis[114].

\subsection{Thiols}


Sulfur has emerged as a central element in redox biology, and S-containing biomolecules can undergo a range of reactions. Prominent among these reactions is the oxidation of biothiols to their disulfides as indicated by the three redox couples in Figure 3b. Cysteine/cystine (Cys/CySS) is the most abundant low-molecular weight biothiol in extracellular fluids and levels of Cys and CySS have been measured to be $40 \mu \mathrm{M}$ and 8$10 \mu \mathrm{M}$, respectively[115]. The Cys/CySS redox couple is believed to contribute to extracellular/luminal redox homeostasis[116] as well as the redox status of extracellular proteins. The tripeptide L- $y$-glutamyl-L-cysteinylglycine (glutathione; GSH), is the most abundant small molecule thiol in aerobic cells and therefore plays an important role in modulating intracellular redox environment. GSH participates in the efficient removal of various ROS through a GPx-catalyzed oxidation into the glutathione disulfide (GSSG) [92]. In fact, the ratio of the reduced to oxidized forms (i.e., GSH/GSSG) has often been used as a measure of the balance of pro-oxidative and anti-oxidative activities[117,118]. Thioredoxins (Trxs) are small proteins that regulate protein redox status through reduction of cysteine disulfides. It should be noted that while there can be interactions between these biothiols, these couples are not in thermodynamic equilibrium which enables them to be used to perform regulatory functions.

Cysteine is the only thiol among the common amino acids and the Cys residues of proteins confer redox-properties[119] that are important for antioxidant defense as well as for cellular signal transduction. Figure $\mathbf{3 c}$ outlines the various thiol oxidative reactions that are important for the regulatory role of the Cys residues. A two-electron oxidation of the Cys residues $\left(\mathrm{R}_{1} \mathrm{SH}\right.$ ) can yield sulfenic acid $\mathrm{R}_{1} \mathrm{SOH}$ (often present as $\mathrm{R}_{1} \mathrm{SO}^{-}$), which can rapidly react with other thiols (e.g., free Cys, GSH or thiol protein) to generate disulfides $\left(\mathrm{R}_{1} \mathrm{SSR}_{2}\right)$. Reduction of these protein disulfides (e.g., by thioredoxin and GSH reductants) can regenerate these protein thiols. As indicated in Figure $3 \mathbf{c}$, these oxidation/reduction reactions of protein thiols provides a functionally reversible S-based switching mechanism that can be important for oxidative stress[83], redox-based regulation of cellular signal transduction[120], and a structural transitions of proteins (e.g., example keratin[121,122]). Figure 3c shows that further oxidation of thiols leads to the formation of reversible sulfinic acids $\left(\mathrm{R}_{1}-\mathrm{SOOH}\right.$, reduced by sulfiredoxin[123]) and irreversible sulfonic acids $\left(\mathrm{R}_{1}-\mathrm{SO}_{3} \mathrm{H}\right)[124]$.

As indicated in Figure 3c, sulfur switching can be initiated by ROS and this provides a mechanism for ROS signals to mediate the changes in protein structure/function that underlie redox-based cellular signal transduction[125]. Such redox sensor proteins are integral to the regulation of various physiological processes, such as antioxidant defense, pro-survival activities and apoptosis [126-130]. 


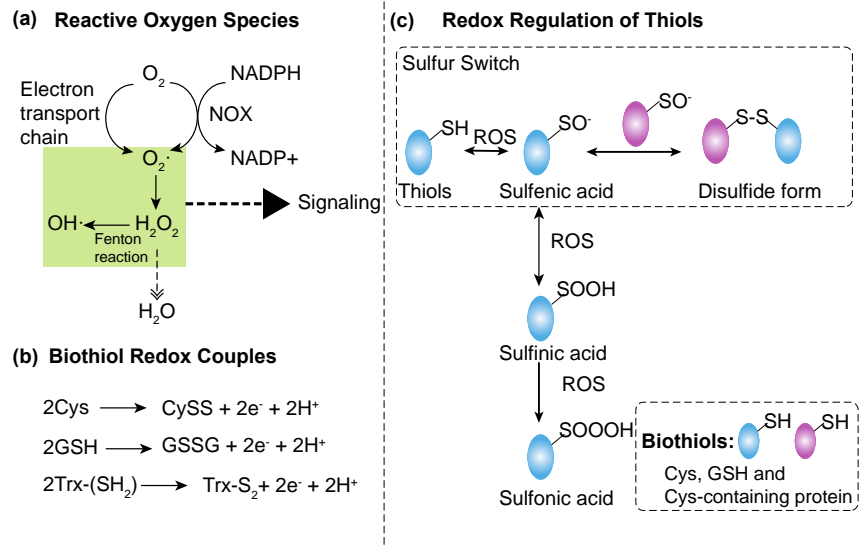

Figure 3. Reactive oxygen species (ROS) interact with biothiols. (a). The production and interconversion of ROS (see Table 1 for further details). (b) Common biothiol redox couples. (c) ROS-mediated redox regulation of thiols including the S-switches of cysteine-containing proteins.

\subsection{Oxidative stress}

Historically, it was believed that oxidative stress resulted from elevated levels of ROS that damaged lipids, proteins and DNA, and therefore disrupted cellular functions[131]. Over time, oxidative stress began to be viewed as an imbalance between the production of ROS and antioxidant defenses[132]. As it became clear that other reactive species could cause cellular damage, the definition of oxidative stress was expanded beyond ROS. More recently, with the recognition of redox-based signaling pathways it has become clear that consequences of oxidative stress may not simply result from macromolecular damage, but may involve redox signaling and redox-regulation responsible for homeostasis. In summary, emerging evidence indicates that our understanding of oxidative stress is incomplete and this may explain why antioxidant therapeutic interventions that aim to suppress ROS have been generally disappointing. [133]

\section{Redox Regulation in Intestine}

Over the last 20 years there has been an emerging understanding of the role of redox in biological regulation [134] and also a recognition of the spatiotemporal complexity of the gut's redox context[54]. Specifically, Figure 4a illustrates that gradients exist both in oxygen and the redox status of the biothiol couples but these redox species are not in equilibrium. These gradients may be integral to the redox signaling that occurs within the intestinal microbiota as well as the interactions between host and microbiota.

4.1. Evidence for redox regulation of prokaryotes: quorum-sensing example 
Figure 4b shows that two QS systems, LuxS/AI2 and Agr QS, are reported to be redoxsensitive. For instance, Dong et al. [135] carried out a proteome-level disulfide mapping and proposed that $\mathrm{H}_{2} \mathrm{O}_{2}$-dependent inter-molecular disulfide bond formation of LuxS results in decreased synthesis of Al-2. Delisa et al. [136] showed that oxidative stressors influenced the synthesis rate of Al-2. Also, He et al. [137] showed that the DNA-binding domain of AgrA is redox sensitive with an $\mathrm{H}_{2} \mathrm{O}_{2}$-dependent formation of an intramolecular disulfide that abolishes DNA binding and a DTT-reduction that recovers DNA binding capability. Such redox-responsiveness of QS may enable intestinal bacteria to recognize and respond to dynamic changes in redox environment and overcome oxidative stresses imposed by host immune responses. These studies provide molecular-level evidence for a linkage between redox and quorum signaling which could have important implications both for redox biology and for understanding the bacteria-tobacteria communication responsible for population-level responses (e.g. biofilm formation).

\subsection{Evidence for redox regulation of host cells}

Intestinal epithelial cells generate ROS to function as signaling intermediates and maintain homeostasis. ROS is generated by the NOX1 and DUOX2 members of the NADPH oxidase family which are highly expressed in colonic intestinal epithelia. The redox status in intestine is tightly regulated to ensure rapid self-renewal and avoid excessive proliferation [138]. Ogier-Denis et al.[139] showed that ROS regulated the proliferation and differentiation of stem cells in the colon, as well as a modulating the balance between absorptive and secretory cell types. Figure $\mathbf{4 c}$ shows that stem cells exist in low ROS and progenitor cells migrate to higher ROS where differentiation occurs[140], which is consistent with the $\mathrm{NADH} / \mathrm{NAD}^{+}$ratio gradient along the crypt-villus axis[141]. Accordingly, proliferating stem cells have a more reducing extracellular environment than differentiated cells, as indicated by the redox potential (e.g. a thermodynamic measure of the extent of reduction) of extracellular Cys/CySS [142]. Interestingly, Figure 4c shows the localized gradients in ROS and Cys/CySS redox potential are opposite to those expected from the $\mathrm{O}_{2}$ gradient. This contradiction emphasizes that redox reactions are not equilibrated but rather cellular activities that generate ROS and adjust the status of redox couples can exert independent control of localized redox conditions. 
(a) Redox Environment

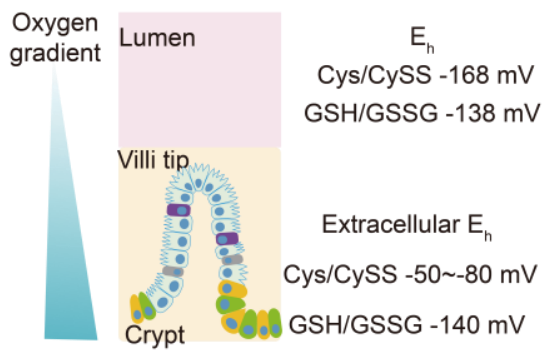

(b) Microbiota: Quorum Sensing

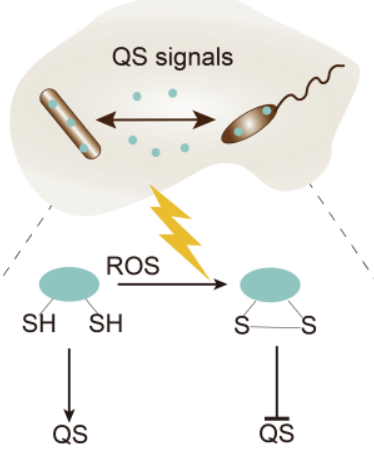

(c) Host

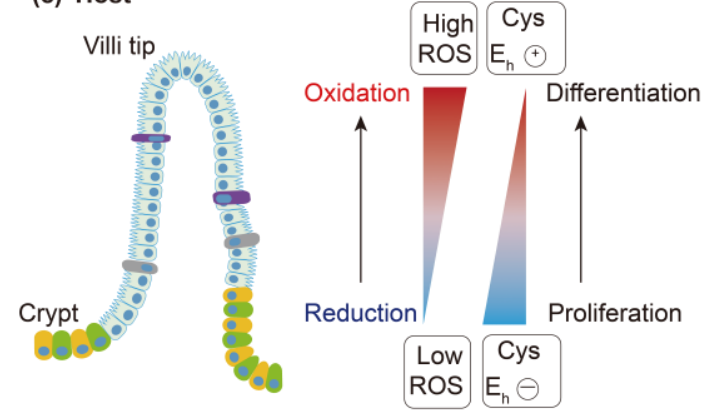

(d) Host-Microbiota

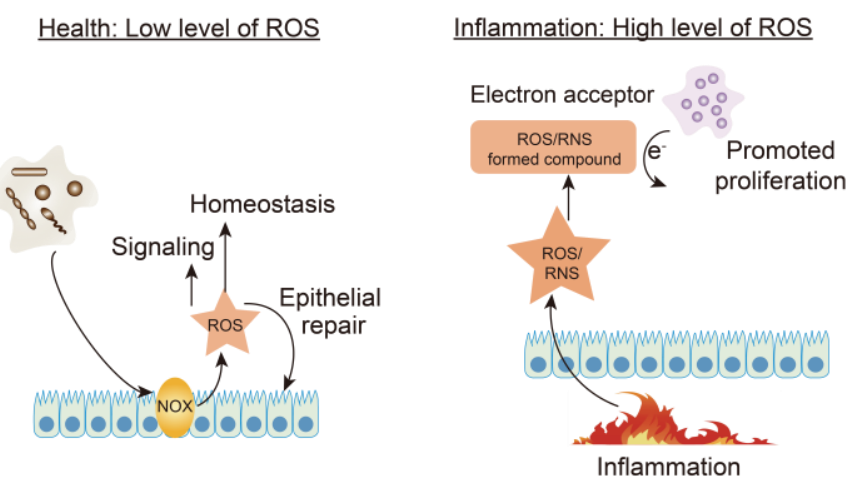

Figure 4. Examples of redox regulation in the intestine. (a). Intestine is characterized by complex redox environment. (b). Quorum sensing can be regulated by redox as ROSmediated disulfide bond formation leads to downregulation of QS signaling pathways. (c). The crypt-to-villus cell migration is under redox regulation with pluripotent stem cells tending to exist in the more reducing environment of the crypt and differentiation occuring in the viili. (d). ROS plays a crucial role in the interaction between host and microbiota in both health and inflammation.

\subsection{Evidence for redox regulation of host-microbiome interaction}

It is increasingly recognized that enterocytes and intestinal stem cells generate ROS in response to microbial signals, both symbiotic and pathogenic[2]. As shown in Figure 4d, basal low-levels of ROS generated by epithelial cells are crucial for the maintenance of homeostasis and immunosuppression in the host. Neish et al. proposed that luminal bacteria produce and shed small formylated peptides, which can be recognized by the formyl peptide receptors (FPR) on the apical surface of gut epithelia and activate the NOX[25]. The generated ROS signals are reported to regulate a series of cellular activities, including proliferation[85], motility[86], immune signaling[77], and restitution of damaged mucosa [143] and these activities are typically regulated by the oxidative regulation of related proteins. For example, oxidation of Cys in tyrosine phosphatases enhances the turnover of focal adhesions and promoted cell migration and 
proliferation[25,144]. These results suggest that microbiota could possibly contribute to the restitution of injured epithelia barrier by stimulating ROS generation[86].

Gut microorganisms have developed a series of mechanisms to respond to the ROS and RNS generated by host inflammation as illustrated in Figure 4d. Examples include $E$. coli's use of RNS-generated nitrate for anaerobic respiration[145], and Salmonella's use of tetrathionate (a compound formed by ROS and thiosulphate) as a terminal electron acceptor [146]. In addition to ROS-mediated interactions, other redox active molecules are reported to be involved in microbiota-host communication as well as inter-kingdom signaling are summarize in Table 4.

Table 4. Redox active molecules involved in host-microbiota interaction

\begin{tabular}{|c|c|c|}
\hline $\begin{array}{l}\text { Redox active } \\
\text { molecules }\end{array}$ & Regulation effect & Ref \\
\hline Hydrogen sulfide & $\begin{array}{ll}\text { - } & \text { Promote mucus granules production and protect mucosal integrity; } \\
\text { - } & \text { Restore microbiota biofilm; } \\
\text { - } & \text { Regulate antioxidant response et al. }\end{array}$ & $\begin{array}{l}{[103,147-} \\
151]\end{array}$ \\
\hline Nitric oxide & $\begin{array}{l}\text { - Increase mucus secretion; } \\
\text { - } \quad \text { Increase formation of new blood vessels; } \\
\text { - } \quad \text { Reduce secretion and adherence of neutrophils. }\end{array}$ & {$[152][151]$} \\
\hline Pyocyanin & $\begin{array}{l}\text { - Signals through the Pseudomonas aeruginosa quorum sensing } \\
\text { network } \\
\text { - Induce oxidative damage to eukaryotic host. }\end{array}$ & [153-156] \\
\hline Indole & $\begin{array}{l}\text { - Increase epithelial barrier function, attenuate inflammation } \\
\text { - } \quad \text { Modulate hormone secreting } \\
\text { - } \quad \text { Protect against oxidative stress. }\end{array}$ & [157-161] \\
\hline Uracil & $\begin{array}{l}\text { - Balance the immune tolerance to symbiotic bacteria and immune } \\
\text { response to pathogenic bacteria. }\end{array}$ & {$[162,163]$} \\
\hline
\end{tabular}

\subsection{Redox regulation in mucus}

Figure 5 indicates that redox may also be important for the structural integrity and biological activity in the mucus layer. Intestinal mucus is composed predominantly of gelforming mucin MUC2. As shown in Figure 5, MUC2 has cysteine-rich $\mathrm{N}$ - and $\mathrm{C}$ - termini as well as internal cysteine residues. The C-termini form disulfide-linked dimers, the $\mathrm{N}$ termini generate disulfide-linked trimers, and internal cysteines form disulfide-linked sidelinks[164]. These disulfide bonds may confer redox-responsiveness to mucin's network properties[165] possibly through interactions with biothiols (e.g., GSH and Nacetylcysteine) $[166,167]$. For instance, Fahy et al. [168] proposed that oxidative stress induces the mucin cross-linking that reduces the compliance of the mucus layer in cystic fibrosis [169,170] while a similar response might occur in the intestine given the similarities of the cysteine-rich mucins of the lung (MUC5AC and MUC5B) and intestine 
(MUC2) [171,172]. Figure 5 also illustrates the recent work of Meer et al. [173], in which $\mathrm{H}_{2} \mathrm{~S}$-induced reduction of mucin's disulfides disrupted the mucus barrier function leading to exposure of epithelium to bacteria. In addition to redox modulating the structural properties of the mucin layer, redox may also affect its immune properties[174] through a thioredoxin-responsive unmasking of the antimicrobial activities of the peptide $\beta$-defensin 1 [175].

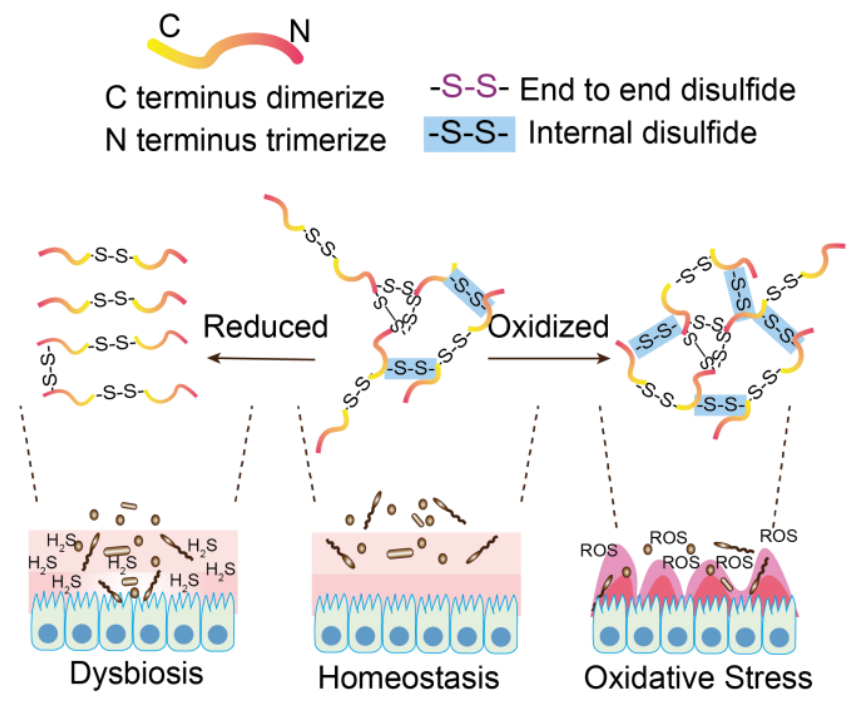

Figure 5. The permeability of mucin is under redox regulation. Under reducing conditions (e.g., with high $\mathrm{H}_{2} \mathrm{~S}$ concentrations), the cross-linked mucin gels are reduced and become permeable for bacteria. Under oxidative conditions (e.g., oxidative stress), more internal disulfide linkages are formed resulting in an over-crosslinking of mucus.

\section{Redox Imbalance, Intestinal Pathology and Dietary Intervention}

\subsection{Redox imbalance and intestinal pathology}

There has been considerable effort to understand possible linkages between ROS generation and oxidative stress, and the onset and development of intestinal dysbiosis and inflammation[176-178]. Significantly lower levels of GSH were found in: inflamed ileal mucosa from patients with Crohn's disease [179], colonic mucosa of active ulcerative colitis patients [180], and mucosa of inflammatory bowel disease patients [181]. Elevated GSSG concentrations have been correlated to the severity of mucosal inflammation [182]. Increased fecal redox potential and decreased total bacterial number were observed in Severe Acute Malnutrition[183]. However, it is still debated whether intestinal redox imbalances alter the microbiome composition and induce inflammation or vice versa. Excessive ROS as a defense against invading pathogens is well known in immune response. However, Aw et al [116,184]reported that GSH/GSSG imbalance temporally preceded mucosal inflammation and clinical symptoms of colitis, suggesting 
redox imbalance is a cause rather than consequence of inflammation. Another viewpoint is that inflammation is caused by oxidative stress but also increases oxidative stress, which further contribute to up-regulation of pro-inflammatory gene expression and active inflammation[185].

\subsection{Dietary intervention}

Polyphenols have drawn much attention as health-promoting food components[186-188] and treatments for intestinal inflammation[189-192]. As illustrated by representative structures in Figure 6, phenolics are a complex group of compounds that have been reported to contribute diverse properties (e.g., anti-oxidative and anti-inflammatory) which may rely on the phenolic's abilities to donate and accept electrons[193,194]. The microbiota may play an important role in the phenolic's activities as few polyphenols are absorbed directly in small intestine (e.g., low bioactivity) but may transit to the colon and undergo microbial metabolism. The polyphenols and their metabolites may influence the gut's microbial composition $[195,196]$ and stimulate growth of beneficial bacteria while inhibiting growth of pathogenic bacteria[197-201]). It should be noted however that antioxidant therapies including ascorbic acid and vitamin $\mathrm{E}$ do not always show healthpromoting benefits but may lead to less benign pro-oxidant activities. [202-204].

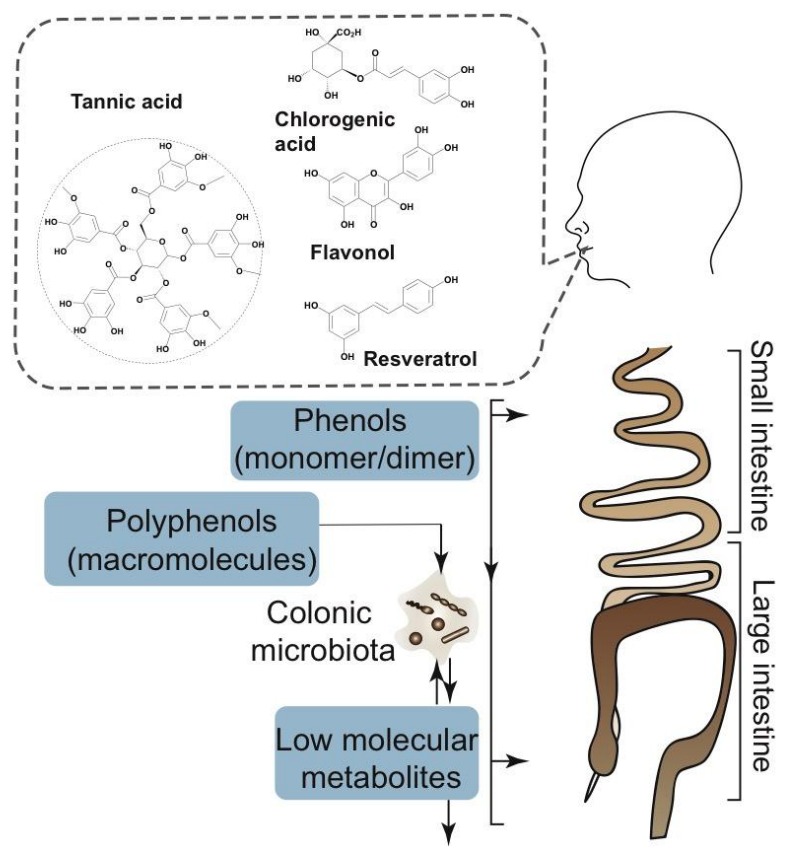

Figure 6. Phenolics are among the most important dietary antioxidants and have complex structures and interactions with the microbiota.

\section{II.ELECTROCHEMISTRY AS A TOOL FOR REDOX BIOLOGY}

\section{Overview of Electrode Measurements}


In the above discussion, we have highlighted the importance and complexity of redox interactions in the gut. We suggest that understanding this complexity will require new experimental tools. In the remainder of this review we describe our efforts to develop electrochemistry as a tool for redox biology.

\subsection{Historical Perspective: The Contribution of Electrode Measurements}

Historically, electrodes have been important tools in biology, medicine, and biotechnology. Electrodes can be used to control/measure currents and potentials, and the often-cited advantages of electrode measurements are their speed (msec), sensitivity and convenience (instruments can be inexpensive and portable). Electrodes have contributed to biology by accessing information either at a global systems level or at a specific chemical level.

At a systems level, electrodes allow measurements of a global electrical modality that is integral to neural communication and muscle actuation. The ability of electrodes to access this electrical modality is illustrated by two examples. Figure 7a illustrates the success of the early neuroscientists who used the speed and sensitivity of electrode measurements to discern important features of the electrical signaling of nerve cells (i.e., the action potentials and voltage gated ion channels)[205]. Figure $\mathbf{7 b}$ illustrates the clinical use of electrodes for electrocardiogram (EKG) measurements that generate a signature pattern that characterizes the functioning of a complex organ (the heart) and detects abnormalities associated with disease. In addition to these historical examples, the developments in electronics and telemetry are enabling the development of implantable devices for physiological monitoring. Applications for implantable electrode probes include electromyography[206], electroencephalography[207], electrocardiography[208] and sensors for measuring glucose[209], oxygen[210] and $\mathrm{pH}[211]$.

An often-cited limitation of electrodes is selectivity: an electrode measurement includes contributions from many chemical species and it can be difficult to discern the relative contributions of the individual chemical species to the measured signal. One approach to confer selectivity to an electrode measurement is to couple a molecular recognition element (e.g., an enzyme, antibody or nucleic acid) to the electrode. The classic example of this approach is the glucose biosensor illustrated in Figure 7c, which transformed the management of diabetes and serves as a landmark in personalized medicine. 
(a) Action Potential

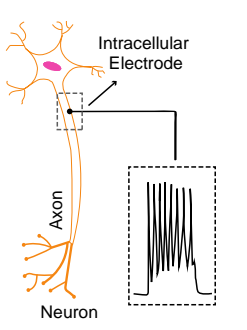

(b) EKG

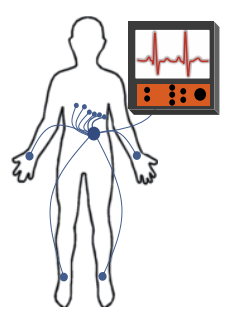

(c) Glucose Biosensor
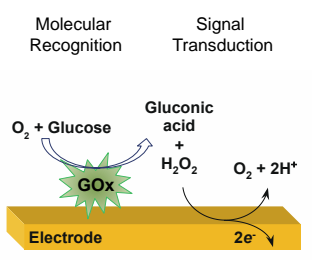

Figure 7. Electrodes have been valuable tools by providing access to global electrical signaling modalities either at (a) cellular levels (neuronal action potentials) or (b) systems levels (electrocardiogram; EKG). (c) Electrodes can also provide access to chemically specific information especially if molecular recognition elements (e.g., enzymes) are coupled to a signal transduction mechanism.

\subsection{Conventional Limitations of Electrochemistry}

Besides their limited selectivity, there are other intrinsic features of electrode measurements that will limit their applications. To access specific chemical information from an electrode measurement, the electrode will generally require direct access to the chemical species. Typically, such chemical species are detected by electrochemical measurements of redox reactions in which electrons are directly exchanged between the chemical species and the electrode surface. For example, Figure 8a shows the electrochemical reduction of the bacterial quorum sensing and virulence factor pyocyanin. This electron exchange is detected as a flow of electrons across the solutionelectrode interface (i.e., an electronic current is measured). Such electron-based measurements of redox reactions will be more invasive compared to alternative imaging methods based on optical, acoustic or magnetic modalities. In addition, detection of the electron-based charge transfer (i.e., electronic currents) of redox reactions will be more invasive compared to measurements of the electrical potential associated with ion flow (i.e., ionic currents). For instance, EKG measurements of ionic potentials and currents are performed noninvasively by a set of electrodes that are placed on the skin.

Since the electrochemical detection of redox information will typically require electron exchange at the electrode-solution interface, then the reacting chemical species must be transported to the electrode surface (often by diffusion) and this requirement can have several important implications. First, it may not be possible to detect species that cannot diffuse (e.g., insoluble particulates). Further, it may not be possible to detect diffusible species with inaccessible redox-sites (e.g., redox-enzymes with a metal center buried within the globular structure). Finally, complex mathematical theories are generally required to relate the measured electrical signal (i.e., current) to the underlying chemical mechanisms (i.e., diffusion followed by electron transfer at the interface). 
Another very important feature of redox measurements is that they generally do not reflect equilibrium conditions. Rather, the electron exchange of redox reactions may have significant kinetic barriers (i.e., activation energies may prevent redox reactions from reaching thermodynamic equilibrium). These kinetic barriers make redox reactions (the transfer of electrons) quite different from typical acid/base reactions (the transfer of protons) as illustrated in Figure $\mathbf{8 b}$. Acid/base reactions are generally considered to be rapid and reversible, and thus a single $\mathrm{pH}$ measurement is sufficient to know the protonation state of acids and bases in that sample. For the simple acid in Figure $\mathbf{8 b}$, the Henderson-Hasselbalch equation allows calculation of the relative concentrations of the protonated and deprotonated states from knowledge of the acid's pKa and the measured $\mathrm{pH}$.

If the electrochemical redox reaction in Figure $\mathbf{8 b}$ achieves equilibrium, then the Nernst equation could be used to calculate the relative concentrations of the reduced and oxidized states from knowledge of the reacting species' redox potential ( $\mathrm{E}^{\circ}$; an equilibrium value associated with the redox reaction) and the imposed electrode potential (E). However, because of the kinetic barriers to electron transfer, redox reactions are seldom in equilibrium. From an electrochemist's perspective, an overpotential must be imposed (the electrode potential $E$ must be significantly different from $\mathrm{E}^{\circ}$ ) to encourage electron transfer. From a biologist's perspective, the kinetic barriers to electron transfer provides the kinetic "insulation" that allow redox species to exist far from their equilibrium state. The lack of equilibrium means that redox couples may be independent if the activation energies for interconversion are high, but may be equilibrated if enzymes are available to catalyze their interconversion. For instance, it is thermodynamically favorable for $\mathrm{NADH}$ to transfer its electrons to $\mathrm{O}_{2}$ to generate ROS yet, because of kinetic barriers, enzymes (e.g., NADPH oxidase) are required to catalyze this electron transfer redox reaction.

\subsection{Perspective}

On balance, electrode measurements have been historically important because they provided access to the global electrical modality of biological ionic currents and potentials, and in some cases electrodes provided access to specific chemical information (e.g., glucose biosensors). While there are advantages, there are also significant limitations to the use of electrodes which we believe have limited the broader use of electrochemistry in biology. From a biologist's perspective, electrochemists use uncommon instruments, represent data in unfamiliar ways (cyclic voltammograms), use specialized terminology, and employ complex quantitative theories that are effective primarily for simple experimental systems. For more complex biological systems it would seem that the non-specific nature of electrode measurements will constrain their usefulness. In particular, the focus of much of modern biology has been on unraveling the molecular details of complex biological phenomena. As a result of this focus, the common analytical tools are designed for chemical selectivity (e.g., immunoassays and -omic methods). In addition, biological researchers are more familiar with optical readouts (e.g., fluorescence-based detection) rather than the electrical outputs of 
electrochemistry. Despite the above limitations, we believe electrochemistry has much to offer for studies in redox biology.

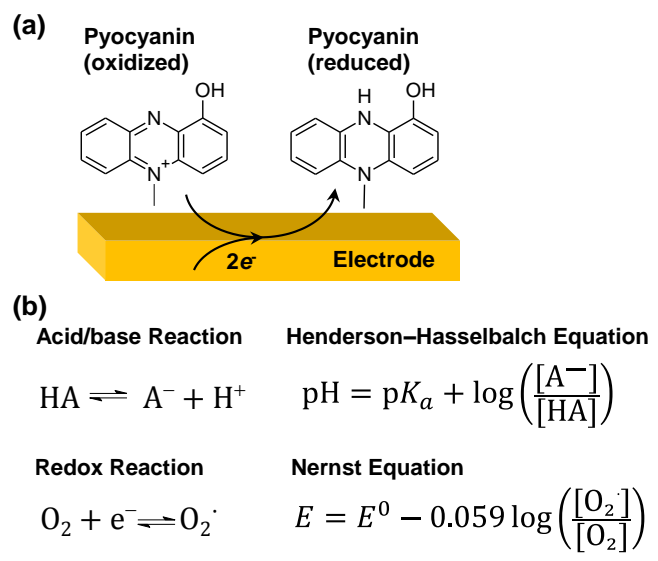

Figure 8. (a) Electrochemistry provides access to redox information as illustrated by the reduction of pyocyanin. (b) While there are similarities between acid/base reactions (proton exchange) and redox reactions (electron exchange), redox reactions often have significant kinetic barriers that prevent redox couples from equilibrating with their environmental context.

\section{Redox: Another Global Biological Modality?}

Over the last decade redox has emerged as a critical component of homeostasis, stress (i.e., oxidative stress) and disease, and this has stimulated the development of a variety of new experimental tools (e.g., fluorescent probes[212], immunosensors [213], and electron paramagnetic resonance[214]). We contend that electrochemistry offers a unique set of capabilities that are well suited for in vitro studies in redox biology. In particular, electrodes can be precisely set to impose specific potentials (i.e., voltages) which enable the controlled study of oxidation and reduction reactions: a capability that seems intuitively well matched to the experimental needs in redox biology. For instance, electrochemical oxidation reactions have been used to mimic the cytochrome P450 catalyzed oxidative metabolism of drugs[215-218], while electrochemical reduction reactions have been used to model the bioreduction of prodrugs[219,220]. Also, electrodes are integral to the shuttling of electrons in bio-based fuel cells which aim to enlist biological mechanisms to convert chemical into electrical energy[221]. In addition, electrodes have been used to generate gradients (e.g., in $\mathrm{pH}[222], \mathrm{O}_{2}$ or redox potential[223]) and this may provide a means to experimentally recapitulate the gradients that exist in complex biological environments (e.g., the gut). Finally, electrode potentials do not need to be maintained at constant values, but electrodes can be switched between oxidative and reductive conditions through any arbitrarily complex sequence of imposed potentials. Such a sequence may be able to mimic biological changes over time (e.g., diurnal variations). 
More broadly, it seems possible that the ability of electrodes to controllably transfer electrons between electrodes and redox couples may provide access to a global signaling modality of biology. As highlighted in Figure 7, it is well-established that biology uses a global electrical modality associated with the flow of ions. Emerging evidence in redox biology suggests that the "flow of electrons" through redox reactions may provide an independent global modality for biology[224]. For instance, the flow of electrons from $\mathrm{NADH}$ to $\mathrm{O}_{2}$ to generate ROS can result in diffusible signaling molecules (e.g., $\mathrm{H}_{2} \mathrm{O}_{2}$ ) that can be received through atomically-specific mechanisms (sulfur switches)[119,225-228] that may exist on multiple regulatory proteins. Thus these redox signals may be able to access multiple independent cellular signal transduction pathways and thus induce global biological responses[224,229-231]. The underlying hypothesis of our research is that electrode measurements that can access such an electron-based biological redox modality could provide rapid access to important global biological information.

\subsection{Electrochemical Probing for Redox Information}

Our approach for using electrochemistry to probe for biological redox information is approximately analogous to the use of sonar to probe for physical information in an environment. As illustrated in Figure 9, there are two broad components of this analogy. First, is the use of complex electrical inputs/outputs to probe the local environment for information. For the case of sonar, sound waves are transmitted to probe the local environment for physical information (size, shape, distance and motion of objects) and this information is extracted from the reflected waves using well-developed methods from signal processing and control theory. We believe an under-utilized feature of electrochemistry is that the data is available in a format that is readily accessible for analysis by such advanced methods in information processing[232-240]. Thus, we envision that electrochemical probing using complex voltage inputs will generate complex response currents that are rich in redox information[241,242]. We suggest that this redox information can be analyzed using approaches adapted from signal processing.

The second component of the sonar analogy is the use of mediators (i.e., diffusible electron shuttles). In redox-based molecular communication system, mediators function as the carriers of information [243-246] by (i) exchanging electrons with the electrode and thus transduce the complex electrical input into a redox input; (ii) diffusing into the local environment to probe for redox interactions (i.e., to exchange electrons with redoxactive species) and thereby collect redox information; and (iii) diffusing back to the electrode where they exchange electrons with the electrode to transduce this historical redox information into complex electrical outputs (i.e., currents). Thus, the mediators serve both to transduce electrical $1 / O$ into redox $1 / O$, and to transmit the redox signals into the local environment.

We anticipate that modest redox inputs should provide access to biological redox information without influencing the biology. In this case, interactive redox probing could 
discern redox contexts and "eavesdrop" on redox based communication. Potentially, more aggressive redox inputs could influence the biology (e.g., by imposing oxidative stresses) and allow participation in redox-based communication. Initial reports have already demonstrated such redox-based interventions in biological system[247-249] and shown that synthetic biology allows biological systems to be designed to interface with devices through redox modalities[250,251].

In the following, we provide initial evidence to support our hypothesis that electrochemical probing can access important biological information that is not readily available through alternative experimental methods.

(a) Sonar's Interactive Probing

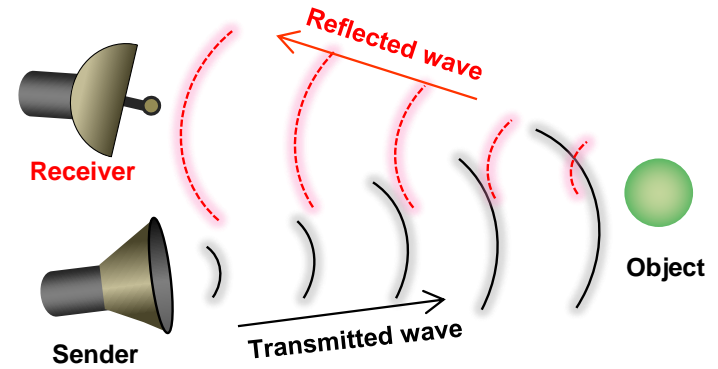

(b) Electrochemical Interactive Probing

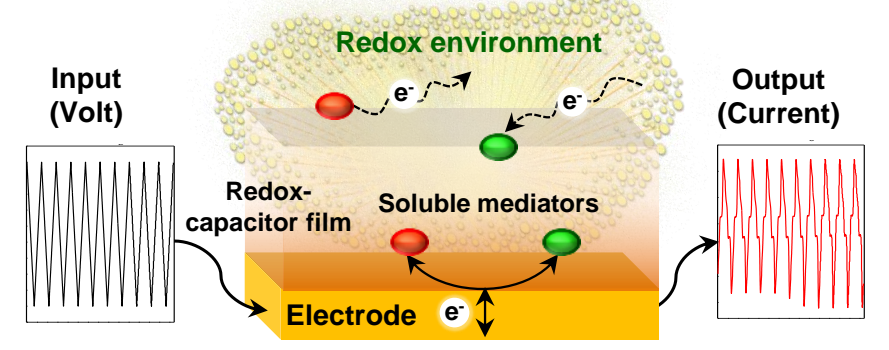

Figure 9. Interactive probing of redox activity. (a) Analogy to sonar. (b) Electrochemical probing using (i) complex inputs/outputs to tailor the interactive probing, and (ii) redox mediators to both transduce electrical inputs/outputs to redox $\mathrm{I} / \mathrm{O}$ and to transmit diffusible redox signals into local environment.

\section{Probing for Redox Properties of Dietary Antioxidants}

Epidemiological evidence has routinely shown that diets rich in antioxidants confer health benefits. However, interventional trials with antioxidants have been less definitive[252-256]. Because phenolics are among the most abundant dietary antioxidants[199,257] they have been the subject of intensive research on their potential health benefits[258-262]. However, the molecular mechanisms that could enable such benefits remain elusive[263,264]. For instance, expectations that phenolics confer systemic antioxidant protection have been difficult to demonstrate as a large fraction of dietary phenolics pass through the small intestine in an insoluble form[186,265,266] and there can be limitations on how readily phenolics are absorbed into the bloodstream[267-269]. The gut may be a major site of action for these 
antioxidants[270,271], and protective effects may involve both insoluble antioxidants and antioxidants that are solubilized by partial digestion[272]. In fact, it has been reported that there is a synergistic effect between soluble antioxidants and dietary-fiber bound insoluble antioxidants[273,274] with suggested mechanisms involving the oxidative grafting of soluble phenolics to fiber-based amines[275].

\subsection{Detecting Redox-Activity}

In initial studies we used electrochemical methods to probe whether insoluble antioxidant phenolics possess redox activities[276]. We selected clove as our model because this spice has been reported to be one of the densest sources of dietary antioxidants[277,278]. As illustrated in Figure 10a, we entrapped the insoluble fraction of clove in a hydrogel film that was formed at an electrode surface. This film was prepared by first blending insoluble clove into a slightly acidic solution of the $\mathrm{pH}$ responsive film-forming aminopolysaccharide chitosan ( $0.5 \%$ chitosan $\mathrm{pH} 5.5)$, casting this clove-chitosan solution onto an electrode surface, and then drying and neutralizing (phosphate buffer; $\mathrm{pH}$ 7.0) the film. The redox activities of the entrapped clove were probed by immersing the film-coated electrode into a buffered solution $(0.1 \mathrm{M}$ phosphate; $\mathrm{pH} 7.0)$ along with reference $(\mathrm{Ag} / \mathrm{AgCl})$ and counter electrodes as illustrated in Figure 10b. The input potential ( $\mathrm{E}$; volts) imposed to the underlying gold electrode was cycled between reductive values (more negative E's) and oxidative values (more positive E's) as illustrated in Figure 10b. If chemical species can diffuse through hydrogel film and exchange electrons with the electrode, then currents will be detected. Traditionally electrochemists represent data from such experiments as a cyclic voltammogram (CV) in which the measured current is plotted against the imposed potential without explicitly showing time.

The first control in Figure 10c is a clove-chitosan film probed while immersed in buffer without diffusible mediators. The CVs for this control show no discernable current peaks indicating that no diffusible redox-active species could access and exchange electrons with the electrode. This observation is consistent with expectations that chitosan is not redox-active and the entrapped clove particles are too far from the electrode surface to exchange electron. The second control in Figure 10c is an electrode coated with a chitosan film (without entrapped clove) that was immersed in a buffered solution containing two standard electrochemical mediators. One mediator, $\mathrm{Ru}\left(\mathrm{NH}_{3}\right)_{6} \mathrm{Cl}_{3}\left(\mathrm{Ru}^{3+}\right.$ : $\mathrm{E}^{\circ}$ $=-0.2 \mathrm{~V}$ vs $\mathrm{Ag} / \mathrm{AgCl}$ ), can be reversibly reduced at a reductive potential, while the other mediator, ferrocene dimethanol $\left(\mathrm{Fc}^{\circ} \mathrm{E}^{\circ}=+0.25 \mathrm{~V}\right.$ vs $\left.\mathrm{Ag} / \mathrm{AgCl}\right)$, can be reversibly oxidized at an oxidative potential. As shown in Figure 10c, when the input potential for this chitosan-coated control electrode was cycled to impose reducing conditions, a small reduction peak current was observed $(\approx-0.27 \mathrm{~V})$ associated with $\mathrm{Ru}^{3+}$ reduction. When the input potential was cycled to impose oxidative conditions, a small oxidation peak current was observed $(\approx+0.27 \mathrm{~V})$ associated with the oxidation of the Fc mediator. These results are consistent with expectations that both the $\mathrm{FC}$ and $\mathrm{Ru}^{3+}$ mediators can diffuse through the chitosan hydrogel film to access and exchange electrons with the electrode. 
The experimental film in Figure 10c is a chitosan film with entrapped clove probed using the $\mathrm{Fc}$ and $\mathrm{Ru}^{3+}$ mediators. The results in Figure 10c show considerable amplification of the peak currents associated with both Fc-oxidation and $\mathrm{Ru}^{3+}$-reduction. Figure $\mathbf{1 0 d}$ shows that amplification of these mediator currents increases with increasing amounts of clove entrapped in this chitosan film. This amplification of the mediator currents provides initial evidence that some moieties in the insoluble fraction of clove are redox-active and can undergo redox-interactions with added mediators.

(a)
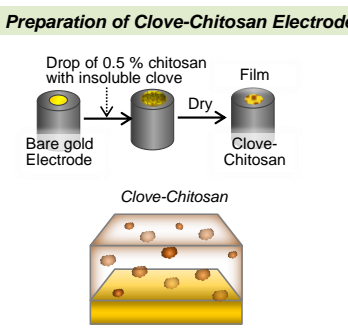

(b) Electrochemical Experimental Apparatus Counter Electrode Working Electrode Reference $\|\downarrow\|$ Tube for $\mathrm{N}_{2}$ Electrode $-1-1<$
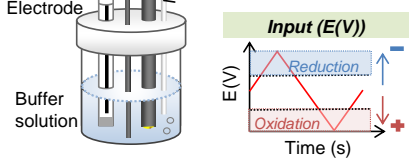

(c)

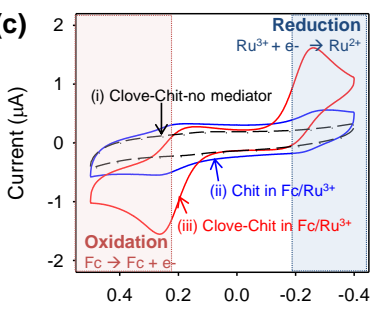

(d)

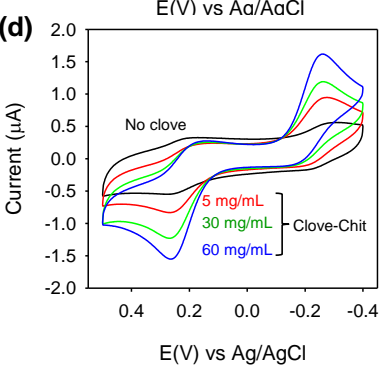

(e) Putative Reductive Putative Oxidative

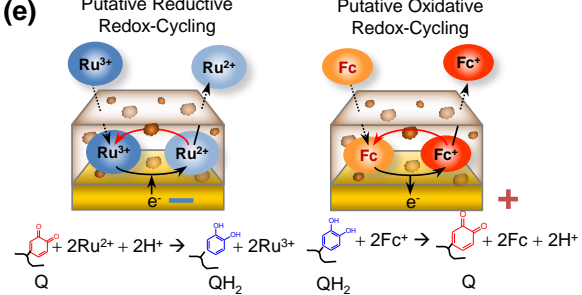

(f)

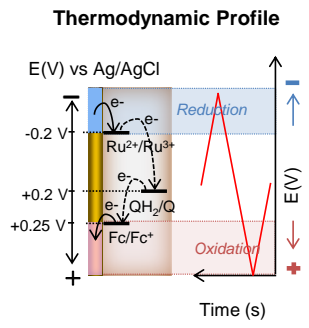

Figure 10. Probing for redox activity of insoluble dietary antioxidants[276]. (a) The preparation of film with insoluble clove entrapped within a chitosan matrix. (b) Electrochemical system used for interactive probing of insoluble clove. (c) Cyclic voltammograms (CVs) for electrodes coated with clove-containing chitosan films compared to controls. Clove-chitosan incubated with both mediators shows amplified peak currents consistent with redox cycling activities of clove. (d) CVs for electrodes coated with chitosan films containing varying clove levels show amplified peak currents increase with increasing clove levels. (e) Proposed mechanism for redox cycling of clove-chitosan film. (f) Thermodynamic plot of electrochemical mediators ( $\mathrm{Fc}$ and $\mathrm{Ru}^{3+}$ ) and clove illustrating the driving forces for redox cycling.

The mechanistic explanations for these amplified mediator currents is provided in Figure 10e. The left schematic shows that amplification of the $\mathrm{Ru}^{3+}$ reduction current results from its reductive redox-cycling with the entrapped clove. In this case, the oxidized $\mathrm{Ru}^{3+}$ mediator accepts an electron at the electrode, the reduced $\mathrm{Ru}^{2+}$ diffuses from the electrode into the film where it donates the electron to the entrapped clove, and then the oxidized $\mathrm{Ru}^{3+}$ returns to the electrode to be re-reduced. This reductive redox-cycling reaction serves to transfer electrons from the electrode to the insoluble clove (i.e., it "charges" the clove with electrons). The right schematic in Figure 10e shows that amplification of Fc's oxidation current results from its oxidative redox-cycling with clove. 
In this case, the reduced $\mathrm{Fc}$ donates electrons to the electrode to generate the oxidized $\mathrm{Fc}^{+}$species, the oxidized $\mathrm{Fc}^{+}$diffuses into the film where it can accept an electron from the insoluble clove to regenerate the reduced Fc, and then the reduced Fc diffuses back to the electrode where it donates this electron. This oxidative redox-cycling reaction serves to transfer electrons from insoluble clove to the electrode (i.e., it "discharges" the clove). These oxidative and reductive redox-cycling reactions explain the amplified mediator currents observed in Figure 10d and provide evidence that clove is redox active (i.e., it can exchange electrons with the mediators).

It is important to note two important requirements for sustained redox-cycling and these are suggested by the thermodynamic plot in Figure 10f. First, sustained redox-cycling requires that the imposed electrode potential be cycled between reducing conditions (that induce $\mathrm{Ru}^{3+}$ reductive redox-cycling that transfers electrons to clove) and oxidizing conditions (that induce Fc oxidative redox-cycling that transfers electrons from clove). Second, sustained redox-cycling requires that the redox potentials of the mediators bracket the redox potential of the insoluble redox-active clove. Thus the thermodynamic plot in Figure 10f suggests that the redox activity of insoluble clove that is being probed by the $\mathrm{Fc}$ and $\mathrm{Ru}^{3+}$ mediators must be between +0.25 and $-0.2 \mathrm{~V}$. One possibility is that this redox activity is associated with catechol-quinone moieties of clove (the redox potential of catechols is typically $\mathrm{E}^{\circ} \approx 0.2 \mathrm{~V}$ vs $\mathrm{Ag} / \mathrm{AgCl}$ )[279]. Catechols are among the most abundant redox-active moieties in dietary phenolics.

\subsection{Coupling Electrochemistry and Signal Processing}

To experimentally probe for sustained redox activity, we immersed an electrode coated with the clove-chitosan film into a buffered solution containing both the $\mathrm{Fc}$ and $\mathrm{Ru}^{3+}$ mediators and imposed cyclic potential inputs over multiple cycles. If the clove's redoxactivity is fully reversible, then the observed amplification of the mediator currents would be expected to be time-invarying (i.e., "steady") over the multiple cycles. Figure 11a shows the input potential imposed to the electrode and the output current observed during this experiment. Visual inspection of Figure 11a suggests that output currents remain steady over the 8 cycles tested. Figure 11a also compares output currents for the clove-containing film to those for a control chitosan film (lacking clove). This comparison again shows amplified mediator currents in the presence of clove. Thus the results in Figure 11a indicate that not only is clove redox-active, but that it can be repeatedly oxidized and reduced. Further, the steady nature of this output suggests redox probing is benign in that it probes an activity (redox activity) without permanently altering this activity.

To provide a more quantitative analysis of this steady amplification, we analyzed the current vs potential (i.e., the CV) curves for each cycle as illustrated in Figure 11b. This CV "signal" was divided into 4 quadrants based on whether the currents are oxidizing or reducing, and whether the currents were assigned to the Fc mediator or the $\mathrm{Ru}^{3+}$ mediator. The division of the CV-signal into four quadrants is important for analyzing the information in the signal, however assigning specific chemical activities $\left(\mathrm{Fc} / \mathrm{Ru}^{3+}\right.$ 
oxidation/reduction) to each quadrant is only an approximation of the underlying chemistries. As indicated by the equations in Figure 11c, we integrate the current to obtain the charge transfer $(Q)$ for each quadrant and these values are shown in Figure 11d. As indicated in Figure 11b and Figure 11d this calculation was performed both for the clove-chitosan film and the control chitosan film. In both cases, the calculated values for each $Q$ were observed to be reasonably constant over time.

As noted above the redox-cycling reactions of clove result in amplification of both the Fcoxidation currents and the $\mathrm{Ru}^{3+}-$ reduction current. One approach to quantify these two amplifications is shown in the lower equations in Figure 11c which are the ratios of $Q$ values between the clove-chitosan and chitosan films. Figure 11e shows these two Amplification Ratios remain constant over time. This analysis further supports the conclusion that the clove is redox active and can repeatedly be switched between redox states.

(a)

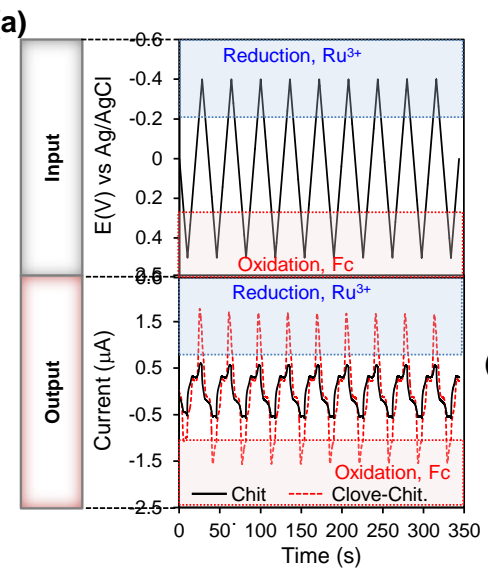

(b)

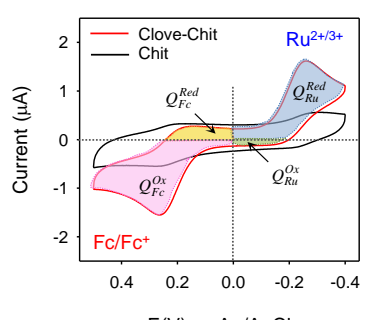

(c)

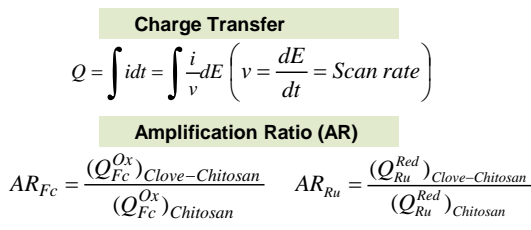

(d)

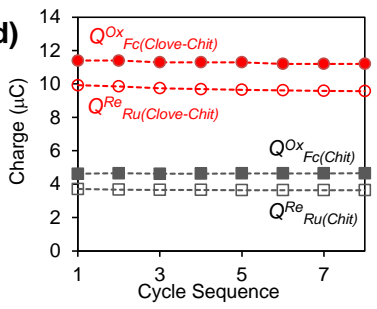

(e)

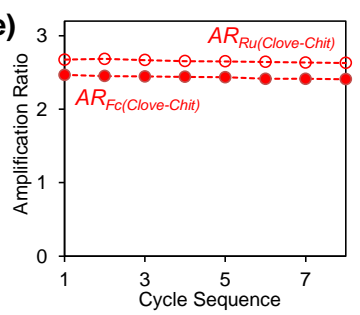

Figure 11. Analysis of the signal generated by interactive electrochemical probing of clove[276]. (a) The steady (time-invarying) input-output curves indicate that the $\mathrm{Fc} / \mathrm{Ru}^{3+}$ mediated oxidation/reduction of clove is reversible. (b) Analysis of the cyclic voltammogram (CV) signal (see text for details). (c) Calculation procedure for determining charge transfer $(\mathrm{Q})$ and amplification ratios (ARs). (d) The charge transfer (Q) for Fc oxidation and $\mathrm{Ru}^{3+}$ reduction with clove-chitosan remains relatively constant over the eight cycles tested. (e) Amplification ratios for Fc oxidation and $\mathrm{Ru}^{3+}$ reduction with clove-chitosan exceed 2 and are nearly constant over time.

\subsection{Implications of These Results}

In conclusion, we used electrochemical methods to probe the redox-activities of a model insoluble dietary antioxidant (i.e., clove)[276]. Using controlled electrical input voltages and mediators we observed output signatures characteristic of redox-cycling and these responses indicate that clove is redox-active and can be repeatedly switched between oxidized and reduced states. There are two important implications. First, redox-active 
dietary components may not be inert in the gut, rather these components may be participants in the various redox interactions in the gut. The implication is that such redox-active components may be biologically-available to exert activities even if they remain insoluble (e.g., bound to fiber) and non-absorbed. Importantly, electrochemistry provided a simple and rapid means to probe for redox-activity. Alternative methods of adding oxidants and reductants are far less convenient for detecting repeated redox switching.

The second implication is that an observation of repeated redox-switching essentially means that the clove can serve as a catalyst for transferring electrons from reductants to oxidants. Potentially, such catalytic activities may be related to observations that interactions between soluble antioxidants and dietary-fiber bound antioxidants can be synergistic (not simply additive)[273]. In addition, if redox-active dietary components can serve as catalysts, then they may act to equilibrate redox couples and thus redoxbuffer[280] the gut which can have substantial implications on redox homeostasis.

\section{Probing Bacterial Populations for Global Redox Information}

In the above example, an unconventional approach was used to probe an insoluble sample: we used complex electrical inputs and diffusible mediators to access redox "information" and the response characteristics were analyzed to infer the sample's redox-activities. In essence, this approach is analogous to the reverse engineering methods used to understand technological systems (e.g., electronic devices). As indicated by the above discussion, the redox-activities observed by this approach could be coupled with chemical intuition (e.g., the possible/likely phenolic components in clove) to assist in suggesting mechanisms for the putative health beneficial effects of antioxidant's. To date, we have used this approach to provide new insights on abiotic macromolecular systems (e.g., melanin)[280-283], and begun extending this electrochemical reverse engineering approach to probe living bacterial systems[284].

\subsection{Bio-based Redox Capacitor}

To probe a bacterial population for redox activities we use a modified approach which includes a third component (in addition to the use of complex electrical inputs and mediators). Specifically, we use a redox capacitor to purposefully engage the mediators in redox-cycling reactions. This redox capacitor is electrofabricated at an electrode surface in two steps[285,286]. First, Figure 12a shows a cathodic neutralization mechanism was used to electrodeposit a chitosan hydrogel film (using $1 \%$ chitosan

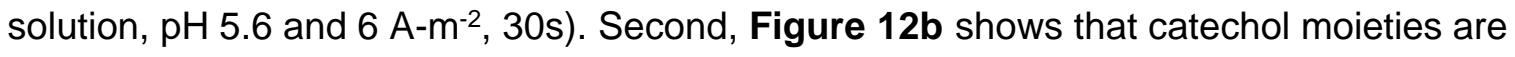
oxidatively (i.e., anodically) grafted to the electrodeposited chitosan film (5 mM catechol, $\mathrm{pH} 7.0$ and $+0.6 \mathrm{~V}, 3 \mathrm{~min}$ ). As discussed elsewhere this catechol-chitosan film possesses redox-capacitor properties that offer several important features to assist in generating interpretable signals in our reverse engineering approach[287,288]. Specifically, the redox-capacitor can engage mediators in redox-cycling reactions that generate amplified signals (i.e., currents) and the capacitor can redox-cycle with a broad range of oxidants/reductants (including biologically-relevant oxidants and 
reductants)[282,289]. Figure 12c illustrates the initial experimental system in which the electrode with a catechol-chitosan film coating was immersed in a suspension of $E$. coli in phosphate buffer (note: a counter electrode and $\mathrm{Ag} / \mathrm{AgCl}$ reference electrode were also included in this experimental system).

\subsection{Mediators}

A variety of chemical species are known to be capable of exchanging electrons with bacteria (e.g., by accepting electrons from the respiratory chain) and such electron shuttles (e.g., mediators) are routinely used for biofuel cell applications[221]. In initial studies we used two redox-active natural products as our mediators. As indicated in Figure 12d, the bacterial QS signaling molecule and virulence factor pyocyanin[290-292] $\left(E^{\circ}=-0.2 \mathrm{~V}\right)$ was used as the reductive redox-cycler, and the plant signaling molecule acetosyringone[293-295] $\left(E^{\circ}=+0.5 \mathrm{~V}\right)$ was used as the oxidative redox-cycler. Also indicated in Figure 12d is that we estimate the redox potential of the redox-capacitor to be in the range of $(-0.2 \mathrm{~V}$ to $+0.25 \mathrm{~V} \mathrm{vs} \mathrm{Ag} / \mathrm{AgCl})$.

\subsection{Electrical Inputs and Outputs}

We used the experimental system in Figure 12c, to explore responses to four different conditions. For each condition, we then imposed cyclic input potentials to the working electrode (the electrode with the redox-capacitor coating) and observed the cyclic output currents illustrated in Figure 12e. Figure 12e shows that we also integrated the current to obtain the charge transfer $(\mathrm{Q})$. Further, the same input-output information is replotted as a cyclic voltammogram in Figure $\mathbf{1 2 f}$.

The initial control condition is incubation without bacteria under anaerobic conditions (Abiotic, $\mathrm{N}_{2}$ ). This serves as a base-case in which the mediators can redox-cycle with the capacitor but there are no environmental redox-activities to probe (i.e., there are no perturbations to the mediator-capacitor-electrode redox interactions). Under these noninteracting conditions, the Q-t curve in Figure 12e shows the output $Q$ oscillates around a value of zero with the pyocyanin-reducing currents being balanced by the acetosyringone-oxidation currents.

The second condition was incubation of a population of $E$. coli under anaerobic conditions (Biotic, $\mathrm{N}_{2}$ ). The output response in Figure 12e and Figure 12f shows dramatic changes from the (Abiotic, $\mathrm{N}_{2}$ ) control condition. Under these anaerobic conditions, the E. coli are expected to transfer electrons to pyocyanin and this interaction should perturb the output response both by suppressing electrochemical pyocyanin reduction and enhancing electrochemical pyocyanin oxidation. This is consistent with observations of a peak current for pyocyanin's electrochemical oxidation that is apparent in both the output i-t curve (Figure 12e) and the CV (Figure 12f). In addition the Q-t curve in Figure 12e shows a downward slope indicating a net transfer of electrons to the electrode under this (Biotic, $\mathrm{N}_{2}$ ) condition (i.e., the electrode was serving as a terminal electron acceptor). 
The third condition involved incubation under aerobic conditions but without a bacterial population and is designated (Abiotic, $\mathrm{O}_{2}$ ). Under this condition, the i-t and CV curves show enhanced pyocyanin reducing currents, while the upward slope of the Q-t curve indicates a net transfer of electrons from the electrode under this (Abiotic, $\mathrm{O}_{2}$ ) condition. The significant perturbation in the output response is consistent with the ability of $\mathrm{O}_{2}$ to accept electrons from; (i) pyocyanin[296]; (ii) the capacitor film[282]; and (iii) the electrode when the potential is cycled to reducing conditions $(E<-0.2 \mathrm{~V})$.

In the final condition, E. coli was incubated under aerobic conditions designated (Biotic, $\mathrm{O}_{2}$ ). As expected, Figure $12 \mathrm{e}$ and Figure $12 \mathrm{f}$ the (Biotic, $\mathrm{O}_{2}$ ) condition shows intermediate responses compared to the (Biotic, $\mathrm{N}_{2}$ ) and (Abiotic, $\mathrm{O}_{2}$ ) conditions. Under this condition, the output response suggests that the reducing activities of the bacteria are partially balanced by the oxidative activities of $\mathrm{O}_{2}$.

(a) Electrodepostion

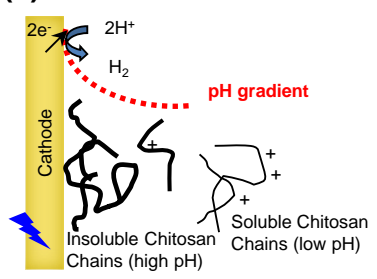

(c) Experimental System

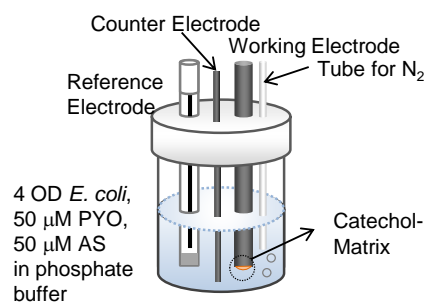

(b) Catechol Grafting

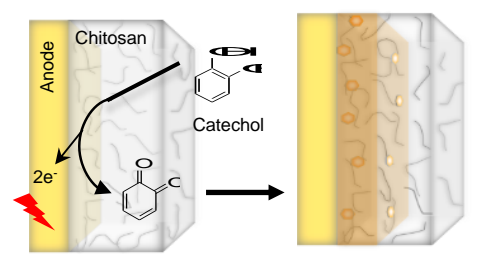

(d) Thermodynamic Plot

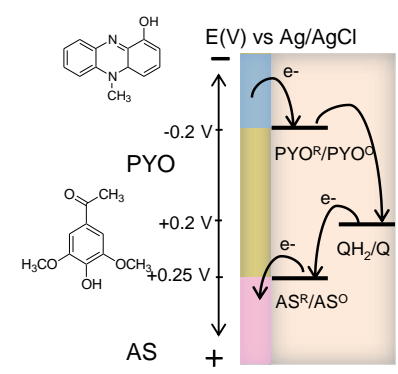

(e)

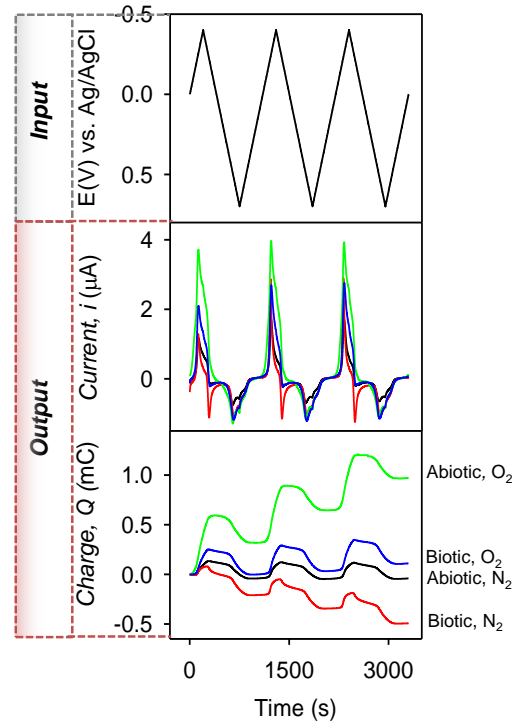

(f)

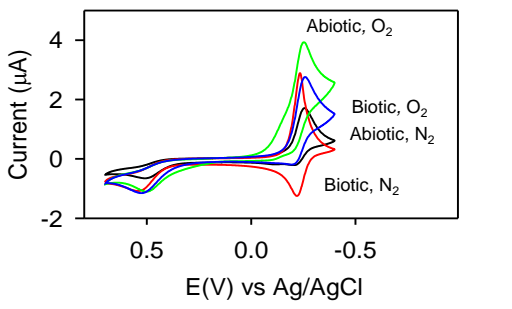

Figure 12. Probing the redox context of bacterial system[284]. Fabrication of catecholchitosan redox-capacitor by (a) cathodic electrodeposition of chitosan, and (b) anodic oxidative-grafting of catechol moieties. (c) Schematic of experimental setup. (d) Pyocyanin (PYO) and acetosyringone (AS) are natural products used as redoxmediators to charge and discharge the catechol-chitosan matrix (designated $\mathrm{QH}_{2} / \mathrm{Q}$ ). (e) Voltage input ( $E$ vs $t$ ) and output current ( $i$ vs t) and output charge ( $Q$ vs t) curves for the four conditions of aerobic $\left(\mathrm{O}_{2}\right)$, anaerobic $\left(\mathrm{N}_{2}\right)$, biotic (with $E$. coli), and abiotic (without $E$. coli). (f) Cyclic voltammograms (CVs) for four experimental conditions in (e). 


\subsection{Processing the Signal}

To analyze the signals from the above experiments, Figure 13a shows that we again: (i) divided the CV signal into quadrants; (ii) assigned each quadrant as an oxidation or reduction that is attributed to either pyocyanin (PYO) or acetosyringone (AS); and (iii) integrated the current to obtain the total charge transfer in each individual quadrant. As indicated by the representative signal of Figure 13a, only 3 of these quadrants show currents (there is no reduction currents in the acetosyringone region). Figure 13a shows that we then used two ratios to correlate the data. The first ratio is the fraction of total oxidative charge transfer attributed to pyocyanin oxidation $\left(F_{\mathrm{PYO}}\right)$. The second ratio is a rectification ratio for pyocyanin currents. Rectification refers to a preferential tendency for currents to flow in one direction. For the case of pyocyanin, the reductive redox-cycling mechanism tends to rectify currents such that pyocyanin's reduction at the electrode is greater than its oxidation (i.e., $R R_{P Y O}>1$; and $\log R_{\text {PYO }}>0$ ).

Figure 13b shows that when the data from Figure 12e are plotted as $F_{P Y O}$ vs. $\log R R_{P Y O}$, the results fall into separate groupings. To understand these groupings, it is useful to consider that pyocyanin is "sampling" the local redox-environment; it can donate electrons to $\mathrm{O}_{2}$ and accept electrons from bacteria. Under extreme conditions where $\mathrm{O}_{2}$ is abundant and no bacteria are present - the (Abiotic, $\mathrm{O}_{2}$ ) condition - $\mathrm{O}_{2}$ can quickly accept electrons from pyocyanin driving pyocyanin into its oxidized state. Under these conditions, there is little or no remaining pyocyanin in a reduced state for electrochemical oxidation and thus; Qo,PYo and FPYo approach 0, and RRPYo approaches $\infty$. This condition is shown at the lower right in Figure 13b. An alternative extreme condition is when bacteria are present and $\mathrm{O}_{2}$ is absent - the (Biotic, $\mathrm{N}_{2}$ ) condition. In this extreme, the pyocyanin can be driven into its reduced state by accepting electrons from the bacteria and the electrode serves as the terminal electron acceptor to re-oxidize the pyocyanin. Under this extreme, Qo,PYo and FPyo become large, and RRPYo becomes small. Under this condition the data trends toward the upper left in Figure 13b.

\subsection{Implications of These Results}

The redox-probing in Figure 12 and Figure $\mathbf{1 3}$ is accessing global redox information from a population of bacteria. The observation in Figure 13b shows that signals can be analyzed to discern groupings of redox context. We believe this is a promising start but many questions remain. Can this method detect meaningful dynamic information (e.g., an immune oxidative burst or disruptions in microbiome community structure)? If so, then this electrochemical reverse engineering approach could provide a simple, rapid tool for in vitro study of how the diet or therapeutics interact with the microbiome, or how the host and microbiome interact. In such applications the mediators would serve to "observe" without perturbing the biological system. However, aggressively probing with mediators may perturb the biology, and thus it may be possible to enlist electrode signals and mediators to impose controlled oxidative stresses as a means to study biological responses to such stresses. 
(a)
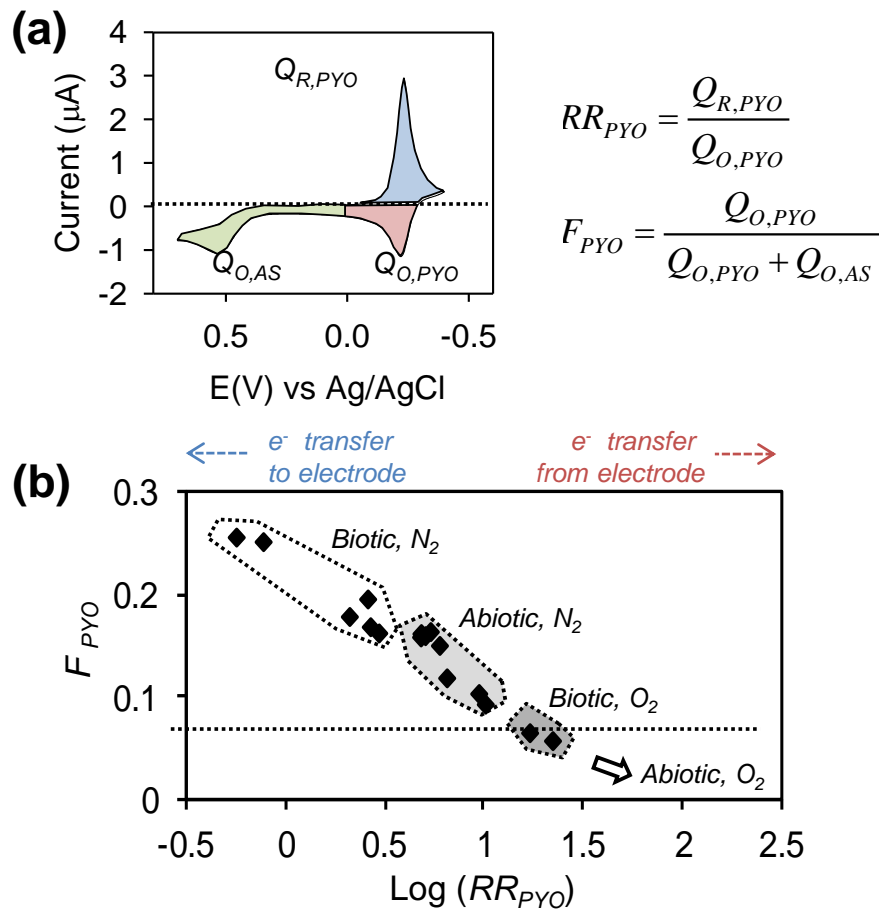

Figure 13. Signal processing to identify correlations of redox context[284]. (a) Analysis of the cyclic voltammogram (CV) signal and ratios used to correlate results (see text for details). (b) Correlations show that the four redox contexts tested could be grouped.

\section{Probing Bacterial Populations for Specific Redox Activities}

Pyocyanin (PYO) is a redox-active metabolite[297-299] produced by the opportunistic pathogen $P$. aeruginosa[154,296,300]. Pyocyanin has both antibiotic and virulence activities that rely on its redox-activity[155,301-303]. For instance, pyocyanin's virulence is believed to result from redox-cycling reactions in which pyocyanin accepts electrons from host cells (and thus disrupts host cell redox state)[155,302,304] and donates the electrons to $\mathrm{O}_{2}$ to generate reactive oxygen species (ROS). Pyocyanin is also believed to be a bacterial signaling molecule[290-292] and its redox-activity has been linked to these signaling activities[305]. Thus this redox-active extracellular metabolite appears to be a participant in extensive cell-cell interactions and this has motivated considerable effort to rapidly detect the presence of pyocyanin. Electrochemical methods are commonly considered for pyocyanin detection because of the simplicity, speed and sensitivity of these measurements[306-309].

To evaluate the capabilities of the catechol-chitosan redox-capacitor film for the in situ detection of pyocyanin synthesis, we used the electrochemical cell of Figure 14a and inoculated a $P$. aeruginosa culture into a standard bacterial growth medium (LuriaBertani Broth)[310]. For comparison, this cell was equipped with three different working electrodes (a bare gold electrode, an electrode coated with chitosan film, and an electrode coated with a catechol-chitosan film), as well as a reference electrode 
$(\mathrm{Ag} / \mathrm{AgCl})$ and a counter electrode (Pt wire). We also supplemented the medium with 50 $\mu \mathrm{M}$ of the oxidative redox-cycling mediator $\mathrm{Fc}_{\mathrm{c}}\left(\mathrm{E}_{0}=+0.25 \mathrm{~V}\right)$. Intermittently, during the course of cultivation, cyclic voltammogram measurements were made to test for redoxactivity (note prior to these measurements, $\mathrm{N}_{2}$ was bubbled through the electrochemical cell for 10 min to minimize interference from $\mathrm{O}_{2}$ reduction reactions that can occur at the same potentials as pyocyanin reduction). Figure $14 \mathrm{~b}$ shows these in situ electrochemical measurements for the bare gold electrode and for the catechol-chitosan coated electrode. For both electrodes, there is a progressive growth in the peak currents in the region for pyocyanin reduction. Growth of this pyocyanin reduction current is more significant for the electrode coated with the catechol-chitosan redox capacitor which is consistent with the reductive redox-cycling amplification of Figure 14c.

Interestingly, Figure 14b shows there is also a progressive growth in the peak currents associated with Fc oxidation and this growth is especially prominent for the electrode coated with the catechol-chitosan redox-capacitor. The thermodynamic plot in Figure $14 \mathrm{c}$ illustrates the rationale for adding the Fc mediator to this system. The pyocyanin that is synthesized can engage the catechol-chitosan redox capacitor in reductive redoxcycling mechanism of Figure 14c which can transfer electrons from the electrode to the capacitor and yield an amplified reduction current. However, because of the finite capacity of the catechol-chitosan film for accepting electrons, this pyocyanin amplification cannot be sustained indefinitely unless a mechanism is also available to deplete electrons from the capacitor. The added Fc mediator serves this discharging function: when the potential is cycled to an oxidative potential, the Fc mediator is engaged in an oxidative redox-cycling mechanism of Figure 14c that transfers electrons from the catechol-chitosan film to the electrode. Importantly, Fc's oxidative redox-cycling is coupled to pyocyanin's reductive redox-cycling such that the appearance of pyocyanin in the cultivation medium enables the catechol-chitosan film to simultaneously amplify the peak currents for pyocyanin reduction and Fc oxidation. This coupled amplification is a signature pattern for redox-cycling[311].

There is an added complication in the experiment in Figure 14: the ferrocene mediator can accept electrons from the bacterial culture and thus engage in a separate oxidative redox-cycling mechanism. This Fc-mediated bacteria-electrode redox-cycling mechanism is apparent in Figure 14b from the relatively large Fc oxidation currents measured by the bare gold electrode, and by the relatively large Fc oxidation currents observed during the initial cultivation period before the bacteria had been able to generate pyocyanin. To overcome this complexity and provide quantitative analysis, we used a different imposed voltage signal. As illustrated by the insert in Figure 14d, we imposed an initial $30 \mathrm{sec}$ oxidative potential $(+0.4 \mathrm{~V})$ to engage $\mathrm{Fc}$ is the oxidative redoxcycling with the catechol-chitosan redox-capacitor that is required to discharge electrons from this film. Next, a reducing potential $(-0.4 \mathrm{~V})$ was imposed for $60 \mathrm{sec}$ to engage pyocyanin in reductive redox-cycling with the catechol-chitosan film. Figure 14d shows the cathodic charge transfer over the $60 \mathrm{sec}$ measurement time for the various sampling times. These in situ measurements show that the electrode with the catechol-chitosan 
film shows substantially amplified reduction currents (vs. the bare gold control electrode) consistent with a redox-cycling based amplification.

Figure 14e summarizes results from these three electrode measurements. Redoxactivities associated with pyocyanin production are apparent from all three electrode measurements, however the amplified signal from the catechol-chitosan coated electrode provides a more sensitive measurement of this bacterial signaling molecule. Detection of this redox-activity appears to be somewhat selective biologically, in that a "control" E. coli culture showed the generation of negligible redox activities (compared to those observed with the $P$. aeruginosa culture)[310]. From a chemical perspective, the electrochemical measurements in Figure 14 are non-selective in that the redox-active metabolite(s) are not explicitly identified nor are their chemical concentrations quantified. In fact, further electrochemical measurements indicate that this $P$. aeruginosa culture is producing at least two different redox-active metabolites[310]. From a biological perspective, however, redox activity (and not the chemical identity and concentrations) may be the more relevant chemical information needed to characterize and understand cell-cell interactions.

(a)

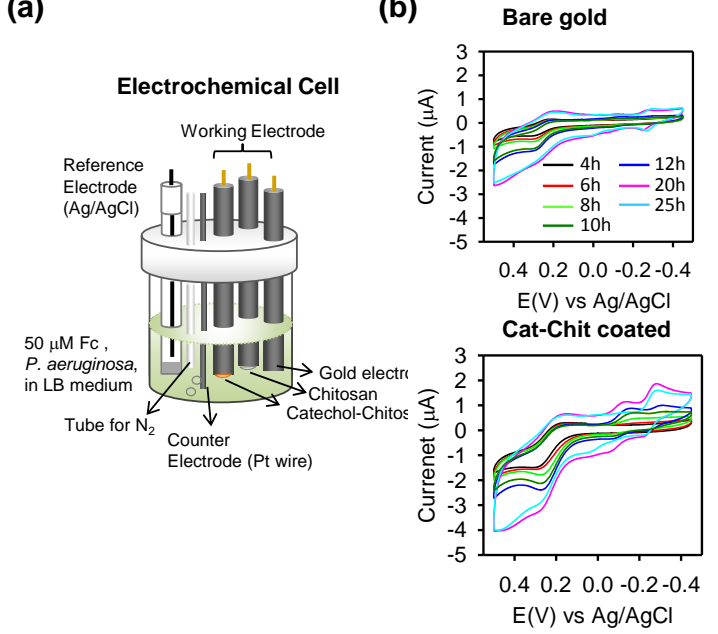

(d)
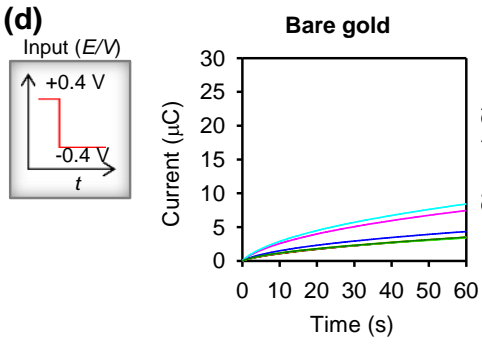

(c) Reductive Redox-Cycling

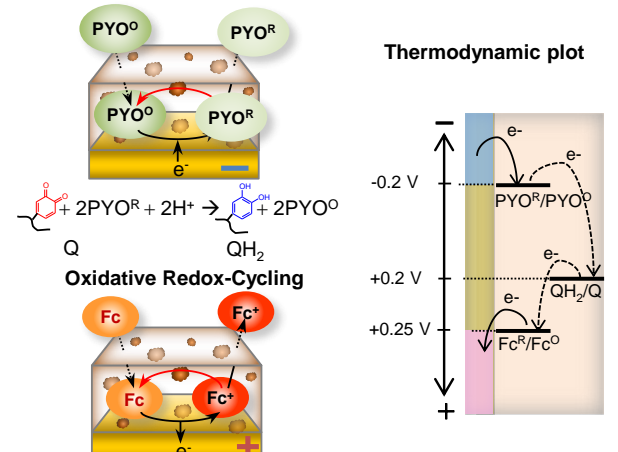

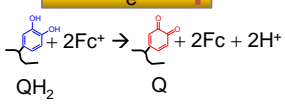

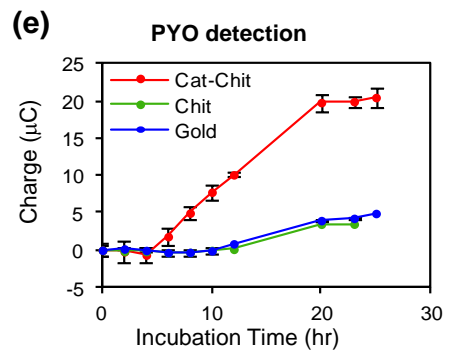

Figure 14. Probing a bacterial population for the generation of the redox-active pyocyanin (PYO) signaling molecule[310]. (a) Schematic of experimental setup. (b) Intermittent in situ cyclic voltammogram (CV) measurements of $P$. aeruginosa culture with a bare gold electrode and an eletrode coated with catechol-chitosan redoxcapacitor film. (c) Thermodynamic plot for pyocyanin-reductive redox-cycling and Fcoxidative redox-cycling with the redox-capacitor. (d) For quantitative analysis, 
intermittent in situ measurements were performed by first imposing an oxidative potential (to discharge the redox-capacitor) and then imposing a reducing potential to enable the pyocyanin-mediated charging of the capacitor for 60 seconds (charge transfer during this 60 second period provides a quantitative measure of pyocyanin). (e) Summary results show the catechol-chitosan redox-capacitor provides a sensitive means to detect the synthesis of pyocyanin.

\section{CONCLUSIONS AND PERSPECTIVES}

The intestine is a complex biological system with an extensive array of interactions within and between the host and microbiota. Many of these interactions are mediated by redox-active molecular species that in some cases are short-lived (e.g., superoxide) and in other cases form stable redox-couples (e.g., catecholics). Further, some of the redoxcouples can readily exchange electrons (e.g., pyocyanin) with their redox states tending toward equilibrium within the various gradients (e.g., $\mathrm{O}_{2}$ gradient) while other redoxcouples are kinetically insulated with their redox states controlled by the biology (e.g., biothiols). There is an increasing appreciation that redox is an important modality for regulating biological function and mediating biological communication. However, conventional tools to characterize chemical mechanisms in biological information processing (e.g., -omic methods) may be ill-equipped to discern the spatiotemporal richness of redox information that may crucially depend on whether a set of bi-stable redox species are switched to their oxidized or reduced states. We suggest that electrochemistry provides a unique set of capabilities to "eavesdrop" on redox-based biological communication and even to participate in this communication to actuate biology and guide outcomes. Further, we anticipate that electrochemical tools would be especially suitable for incorporation into emerging gut-on-a-chip platforms for in vitro studies of the intestine [312,313]. Importantly, electrochemistry provides access to the chemically-based redox modality of biology while simultaneously using inputs/outputs of an electrical modality that provides access to advanced signal processing methods for analysis. Thus, electrochemistry allows biology to be probed in new ways and allows the results to be interpreted using the vast capabilities of information technology. We envision that interactive electrochemical probing and reverse engineering could provide entirely new insights on the redox-based molecular communication of biology.

\section{ACKNOWLEDGEMENTS}

We gratefully acknowledge financial support from the United States: National Science Foundation (CBET-1435957), Defense Threat Reduction Agency (HDTRA1-13-1-0037), and USDA-National Institute of Food and Agriculture (20146702121585). 


\section{Reference:}

[1] A.M. Mowat, W.W. Agace, Regional specialization within the intestinal immune system, Nat Rev Immunol. 14 (2014) 667-685. doi:10.1038/nri3738.

[2] R.M. Jones, A.S. Neish, Redox signaling mediates symbiosis between the gut microbiota and the intestine, Gut Microbes. 5 (2014). doi:10.4161/gmic.27917.

[3] F.M. Gribble, F. Reimann, Enteroendocrine Cells: Chemosensors in the Intestinal Epithelium, Annu. Rev. Physiol. 78 (2016) annurev-physiol-021115-105439. doi:10.1146/annurev-physiol-021115-105439.

[4] H.C. Clevers, C.L. Bevins, Paneth cells: maestros of the small intestinal crypts., Annu. Rev. Physiol. 75 (2013) 289-311. doi:10.1146/annurev-physiol-030212183744.

[5] L.G. van der Flier, H. Clevers, Stem cells, self-renewal, and differentiation in the intestinal epithelium., Annu. Rev. Physiol. 71 (2009) 241-260. doi:10.1146/annurev.physiol.010908.163145.

[6] R. Sender, S. Fuchs, R. Milo, Revised estimates for the number of human and bacteria cells in the body, bioRxiv. (2016) 36103. doi:10.1101/036103.

[7] D.C. Savage, Microbial Ecology of the Gastrointestinal Tract, Annu. Rev. Microbiol. 31 (1977) 107-133. doi:10.1146/annurev.mi.31.100177.000543.

[8] I. Koboziev, C. Reinoso Webb, K.L. Furr, M.B. Grisham, Role of the enteric microbiota in intestinal homeostasis and inflammation, Free Radic. Biol. Med. 68 (2014) 122-133. doi:10.1016/j.freeradbiomed.2013.11.008.

[9] C.A. Lozupone, J.I. Stombaugh, J.I. Gordon, J.K. Jansson, R. Knight, Diversity, stability and resilience of the human gut microbiota., Nature. 489 (2012) 220-30. doi:10.1038/nature11550.

[10] S. Matamoros, C. Gras-Leguen, F. Le Vacon, G. Potel, M.F. De La Cochetiere, Development of intestinal microbiota in infants and its impact on health, Trends Microbiol. 21 (2013) 167-173. doi:10.1016/j.tim.2012.12.001.

[11] V. D'Argenio, F. Salvatore, The role of the gut microbiome in the healthy adult status., Clin. Chim. Acta. 451 (2015) 97-102. doi:10.1016/j.cca.2015.01.003.

[12] A. Moya, M. Ferrer, Functional Redundancy-Induced Stability of Gut Microbiota Subjected to Disturbance, Trends Microbiol. 24 (2016) 402-413. doi:10.1016/j.tim.2016.02.002.

[13] M. Roberfroid, Prebiotics: the concept revisited., J. Nutr. 137 (2007) 830S-837S. doi:10.3945/ajcn.114.096883.

[14] G.R. Gibson, M.B. Roberfroid, Dietary modulation of the human colonic microbiota: introducing the concept of prebiotics., J. Nutr. 125 (1995) 1401-1412. doi:10.1079/NRR200479.

[15] F.F. Duan, J.H. Liu, J.C. March, Engineered commensal bacteria reprogram intestinal cells into glucose-responsive insulin-secreting cells for the treatment of 
diabetes, Diabetes. 64 (2015) 1794-1803. doi:10.2337/db14-0635.

[16] I.Y. Hwang, M.H. Tan, E. Koh, C.L. Ho, C.L. Poh, M.W. Chang, Reprogramming microbes to be pathogen-Seeking killers, ACS Synth. Biol. 3 (2014) 228-237. doi:10.1021/sb400077j.

[17] B.O. Adamu, T.D. Lawley, Bacteriotherapy for the treatment of intestinal dysbiosis caused by Clostridium difficile infection, Curr. Opin. Microbiol. 16 (2013) 596-601. doi:10.1016/j.mib.2013.06.009.

[18] C.R. Kelly, L. de Leon, N. Jasutkar, Fecal microbiota transplantation for relapsing Clostridium difficile infection in 26 patients: methodology and results., J. Clin. Gastroenterol. 46 (2012) 145-9. doi:10.1097/MCG.0b013e318234570b.

[19] R.A. Britton, V.B. Young, Interaction between the intestinal microbiota and host in Clostridium difficile colonization resistance, Trends Microbiol. 20 (2012) 313-319. doi:10.1016/j.tim.2012.04.001.

[20] S. Angelberger, W. Reinisch, A. Makristathis, C. Lichtenberger, C. Dejaco, P. Papay, G. Novacek, M. Trauner, A. Loy, D. Berry, Temporal Bacterial Community Dynamics Vary Among Ulcerative Colitis Patients After Fecal Microbiota Transplantation, Am. J. Gastroenterol. 108 (2013) 1620-1630. doi:10.1038/ajg.2013.257.

[21] M.E. V Johansson, H. Sjövall, G.C. Hansson, The gastrointestinal mucus system in health and disease., Nat. Rev. Gastroenterol. Hepatol. 10 (2013) 352-61. doi:10.1038/nrgastro.2013.35.

[22] G.C. Hansson, Role of mucus layers in gut infection and inflammation, Curr. Opin. Microbiol. 15 (2012) 57-62. doi:10.1016/j.mib.2011.11.002.

[23] D. Ulluwishewa, R.C. Anderson, W.C. McNabb, P.J. Moughan, J.M. Wells, N.C. Roy, Regulation of tight junction permeability by intestinal bacteria and dietary components., J. Nutr. 141 (2011) 769-776. doi:10.3945/jn.110.135657.

[24] L. V Hooper, A.J. Macpherson, Immune adaptations that maintain homeostasis with the intestinal microbiota., Nat. Rev. Immunol. 10 (2010) 159-69. doi:10.1038/nri2710.

[25] a Alam, G. Leoni, C.C. Wentworth, J.M. Kwal, H. Wu, C.S. Ardita, P. a Swanson, J.D. Lambeth, R.M. Jones, a Nusrat, a S. Neish, Redox signaling regulates commensal-mediated mucosal homeostasis and restitution and requires formyl peptide receptor 1., Mucosal Immunol. 7 (2014) 645-55. doi:10.1038/mi.2013.84.

[26] M.B. Geuking, Y. K??ller, S. Rupp, K.D. McCoy, The interplay between the gut microbiota and the immune system, Gut Microbes. 5 (2014). doi:10.4161/gmic.29330.

[27] C.M. Theriot, M.J. Koenigsknecht, P.E. Carlson, G.E. Hatton, A.M. Nelson, B. Li, G.B. Huffnagle, J. Z Li, V.B. Young, Antibiotic-induced shifts in the mouse gut microbiome and metabolome increase susceptibility to Clostridium difficile infection., Nat. Commun. 5 (2014) 3114. doi:10.1038/ncomms4114. 
[28] M. Wlodarska, A.D. Kostic, R.J. Xavier, An integrative view of microbiome-host interactions in inflammatory bowel diseases, Cell Host Microbe. 17 (2015) 577591. doi:10.1016/j.chom.2015.04.008.

[29] I. Sobhani, J. Tap, F. Roudot-Thoraval, J.P. Roperch, S. Letulle, P. Langella, C. Gérard, J.T. van Nhieu, J.P. Furet, Microbial dysbiosis in colorectal cancer (CRC) patients, PLoS One. 6 (2011). doi:10.1371/journal.pone.0016393.

[30] D. Mathis, C. Benoist, The influence of the microbiota on type-1 diabetes: On the threshold of a leap forward in our understanding, Immunol. Rev. 245 (2012) 239249. doi:10.1111/j.1600-065X.2011.01084.x.

[31] P. Bhargava, E.M. Mowry, Gut Microbiome and Multiple Sclerosis, Curr. Neurol. Neurosci. Rep. 14 (2014). doi:10.1007/s11910-014-0492-2.

[32] M. Serino, V. Blasco-Baque, S. Nicolas, R. Burcelin, Far from the Eyes, Close to the Heart: Dysbiosis of Gut Microbiota and Cardiovascular Consequences, Curr. Cardiol. Rep. 16 (2014) 1-7. doi:10.1007/s11886-014-0540-1.

[33] P.J. Turnbaugh, R.E. Ley, M. a Mahowald, V. Magrini, E.R. Mardis, J.I. Gordon, An obesity-associated gut microbiome with increased capacity for energy harvest., Nature. 444 (2006) 1027-31. doi:10.1038/nature05414.

[34] J.U. Scher, S.B. Abramson, The microbiome and rheumatoid arthritis., Nat. Rev. Rheumatol. 7 (2011) 569-78. doi:10.1038/nrrheum.2011.121.

[35] T. Le Roy, M. Llopis, P. Lepage, A. Bruneau, S. Rabot, C. Bevilacqua, P. Martin, C. Philippe, F. Walker, A. Bado, G. Perlemuter, A.-M. Cassard-Doulcier, P. Gérard, Intestinal microbiota determines development of non-alcoholic fatty liver disease in mice., Gut. 62 (2013) 1787-94. doi:10.1136/gutjnl-2012-303816.

[36] M.B. Miller, B.L. Bassler, Quorum sensing in bacteria., Annu. Rev. Microbiol. 55 (2001) 165-99. doi:10.1146/annurev.micro.55.1.165.

[37] C.M. Waters, B.L. Bassler, Quorum sensing: cell-to-cell communication in bacteria, Annu. Dev.Biol. 21 (2005) 319-346. doi:10.1146/.

[38] Z. Sun, X. He, V.F. Brancaccio, J. Yuan, C.U. Riedel, Bifidobacteria exhibit LuxSdependent autoinducer 2 activity and biofilm formation, PLoS One. 9 (2014). doi:10.1371/journal.pone.0088260.

[39] C.H. Johnson, C.M. Dejea, D. Edler, L.T. Hoang, A.F. Santidrian, B.H. Felding, J. Ivanisevic, K. Cho, E.C. Wick, E.M. Hechenbleikner, W. Uritboonthai, L. Goetz, R.A. Casero, D.M. Pardoll, J.R. White, G.J. Patti, C.L. Sears, G. Siuzdak, Metabolism links bacterial biofilms and colon carcinogenesis, Cell Metab. 21 (2015) 891-897. doi:10.1016/j.cmet.2015.04.011.

[40] C.M. Dejea, E.C. Wick, E.M. Hechenbleikner, J.R. White, J.L. Mark Welch, B.J. Rossetti, S.N. Peterson, E.C. Snesrud, G.G. Borisy, M. Lazarev, E. Stein, J. Vadivelu, A.C. Roslani, A.A. Malik, J.W. Wanyiri, K.L. Goh, I. Thevambiga, K. Fu, F. Wan, N. Llosa, F. Housseau, K. Romans, X. Wu, F.M. McAllister, S. Wu, B. Vogelstein, K.W. Kinzler, D.M. Pardoll, C.L. Sears, Microbiota organization is a distinct feature of proximal colorectal cancers., Proc. Natl. Acad. Sci. U. S. A. 111 
(2014) 18321-6. doi:10.1073/pnas.1406199111.

[41] A. Deep, U. Chaudhary, V. Gupta, Quorum sensing and Bacterial Pathogenicity: From Molecules to Disease., J. Lab. Physicians. 3 (2011) 4-11. doi:10.4103/0974-2727.78553.

[42] T.B. Rasmussen, M. Givskov, Quorum sensing inhibitors: A bargain of effects, Microbiology. 152 (2006) 895-904. doi:10.1099/mic.0.28601-0.

[43] Q. Yang, T. Defoirdt, Quorum sensing positively regulates flagellar motility in pathogenic Vibrio harveyi, Environ. Microbiol. 17 (2015) 960-968. doi:10.1111/1462-2920.12420.

[44] A.S.Y. Lee, K.P. Song, LuxS/autoinducer-2 quorum sensing molecule regulates transcriptional virulence gene expression in Clostridium difficile, Biochem. Biophys. Res. Commun. 335 (2005) 659-666. doi:10.1016/j.bbrc.2005.07.131.

[45] M.J. Federle, B.L. Bassler, Interspecies communication in bacteria, J. Clin. Invest. 112 (2003) 1291-1299. doi:10.1172/JCl200320195.

[46] A.S. Ismail, J.S. Valastyan, B.L. Bassler, J.A. Thompson, R. Oliveira, A. Djukovic, C. Ubeda, K.B. Xavier, Manipulation of the quorum sensing signal Al-2 affects the antibiotic-treated gut microbiota, Cell Rep. 10 (2015) 1861-1871. doi:10.1016/j.celrep.2015.02.049.

[47] S. Gamby, V. Roy, M. Guo, J.A.I. Smith, J. Wang, J.E. Stewart, X. Wang, W.E. Bentley, H.O. Sintim, Altering the communication networks of multispecies microbial systems using a diverse toolbox of AI-2 analogues, ACS Chem. Biol. 7 (2012) 1023-1030. doi:10.1021/cb200524y.

[48] Y.-K. Lee, Effects of diet on gut microbiota profile and the implications for health and disease., Biosci. Microbiota, Food Heal. 32 (2013) 1-12. doi:10.12938/bmfh.32.1.

[49] H. Chung, S.J. Pamp, J.A. Hill, N.K. Surana, S.M. Edelman, E.B. Troy, N.C. Reading, E.J. Villablanca, S. Wang, J.R. Mora, Y. Umesaki, D. Mathis, C. Benoist, D.A. Relman, D.L. Kasper, Gut immune maturation depends on colonization with a host-specific microbiota, Cell. 149 (2012) 1578-1593. doi:10.1016/j.cell.2012.04.037.

[50] I. Semova, J.D. Carten, J. Stombaugh, L.C. MacKey, R. Knight, S.A. Farber, J.F. Rawls, Microbiota regulate intestinal absorption and metabolism of fatty acids in the zebrafish, Cell Host Microbe. 12 (2012) 277-288. doi:10.1016/j.chom.2012.08.003.

[51] J.K. Nicholson, Host-gut microbiota metabolic interactions, Science (80-. ). 336 (2012) 787-788. doi:10.1126/science.1223813.

[52] A.K. Benson, S. a Kelly, R. Legge, F. Ma, S.J. Low, J. Kim, M. Zhang, P.L. Oh, D. Nehrenberg, K. Hua, S.D. Kachman, E.N. Moriyama, J. Walter, D. a Peterson, D. Pomp, Individuality in gut microbiota composition is a complex polygenic trait shaped by multiple environmental and host genetic factors., Proc. Natl. Acad. Sci. U. S. A. 107 (2010) 18933-18938. doi:10.1073/pnas.1007028107. 
[53] F. Kong, R.P. Singh, Disintegration of solid foods in human stomach, J. Food Sci. 73 (2008). doi:10.1111/j.1750-3841.2008.00766.x.

[54] M.G. Espey, Role of oxygen gradients in shaping redox relationships between the human intestine and its microbiota, Free Radic. Biol. Med. 55 (2013) 130-140. doi:10.1016/j.freeradbiomed.2012.10.554.

[55] J.M. Campbell, G.C. Fahey, B.W. Wolf, Selected indigestible oligosaccharides affect large bowel mass, cecal and fecal short-chain fatty acids, $\mathrm{pH}$ and microflora in rats., J. Nutr. 127 (1997) 130-136. doi:10.1073/pnas.1000087107.

[56] M.A. Fischbach, J.A. Segre, Signaling in Host-Associated Microbial Communities, Cell. 164 (2016) 1288-1300. doi:10.1016/j.cell.2016.02.037.

[57] L. V. Hooper, Molecular Analysis of Commensal Host-Microbial Relationships in the Intestine, Science (80-. ). 291 (2001) 881-884.

doi:10.1126/science.291.5505.881.

[58] M. Kim, H. Ashida, M. Ogawa, Y. Yoshikawa, H. Mimuro, C. Sasakawa, Bacterial interactions with the host epithelium, Cell Host Microbe. 8 (2010) 20-35. doi:10.1016/j.chom.2010.06.006.

[59] J.M. Wong, R. de Souza, C.W. Kendall, A. Emam, D.J. Jenkins, Colonic health: fermentation and short chain fatty acids, J Clin Gastroenterol. 40 (2006) 235-243. doi:00004836-200603000-00015 [pii].

[60] P. Louis, G.L. Hold, H.J. Flint, The gut microbiota, bacterial metabolites and colorectal cancer, Nat. Rev. Microbiol. 12 (2014) 661-672. doi:10.1038/nrmicro3344.

[61] Y. Furusawa, Y. Obata, S. Fukuda, T.A. Endo, G. Nakato, D. Takahashi, Y. Nakanishi, C. Uetake, K. Kato, T. Kato, M. Takahashi, N.N. Fukuda, S. Murakami, E. Miyauchi, S. Hino, K. Atarashi, S. Onawa, Y. Fujimura, T. Lockett, J.M. Clarke, D.L. Topping, M. Tomita, S. Hori, O. Ohara, T. Morita, H. Koseki, J. Kikuchi, K. Honda, K. Hase, H. Ohno, Commensal microbe-derived butyrate induces the differentiation of colonic regulatory T cells, Nature. 504 (2013) 446-450. http://dx.doi.org/10.1038/nature12721.

[62] H. Hatayama, J. Iwashita, A. Kuwajima, T. Abe, The short chain fatty acid, butyrate, stimulates MUC2 mucin production in the human colon cancer cell line, LS174T, Biochem Biophys Res Commun. 356 (2007) 599-603. doi:10.1016/j.bbrc.2007.03.025.

[63] A. Ohata, M. Usami, M. Miyoshi, Short-chain fatty acids alter tight junction permeability in intestinal monolayer cells via lipoxygenase activation, Nutrition. 21 (2005) 838-847. doi:10.1016/j.nut.2004.12.004.

[64] D.T. Hughes, V. Sperandio, Inter-kingdom signalling: communication between bacteria and their hosts, Nat.Rev.Microbiol. 6 (2008) 111-120. doi:10.1038/nrmicro1836.

[65] A.R. Pacheco, V. Sperandio, Inter-kingdom signaling: chemical language between bacteria and host, Curr. Opin. Microbiol. 12 (2009) 192-198. 
doi:10.1016/j.mib.2009.01.006.

[66] E. Wynendaele, F. Verbeke, M. D’Hondt, A. Hendrix, C. Van De Wiele, C. Burvenich, K. Peremans, O. De Wever, M. Bracke, B. De Spiegeleer, Crosstalk between the microbiome and cancer cells by quorum sensing peptides, Peptides. 64 (2015) 40-48. doi:10.1016/j.peptides.2014.12.009.

[67] A.S. Ismail, J.S. Valastyan, B.L. Bassler, A Host-Produced Autoinducer-2 Mimic Activates Bacterial Quorum Sensing, Cell Host Microbe. 19 (2016) 470-480. doi:10.1016/j.chom.2016.02.020.

[68] T. Karlsson, M. V. Turkina, O. Yakymenko, K.E. Magnusson, E. Vikström, The Pseudomonas aeruginosa N-Acylhomoserine Lactone Quorum Sensing Molecules Target IQGAP1 and Modulate Epithelial Cell Migration, PLoS Pathog. 8 (2012). doi:10.1371/journal.ppat.1002953.

[69] S.Y. Eum, D. Jaraki, L. Bertrand, I.E. András, M. Toborek, Disruption of epithelial barrier by quorum-sensing N-3-(oxododecanoyl)-homoserine lactone is mediated by matrix metalloproteinases., Am. J. Physiol. Gastrointest. Liver Physiol. 306 (2014) G992-G1001. doi:10.1152/ajpgi.00016.2014.

[70] G.-H. Joe, M. Andoh, M. Nomura, H. Iwaya, J.-S. Lee, H. Shimizu, Y. Tsuji, H. Maseda, H. Miyazaki, H. Hara, S. Ishizuka, Acyl-homoserine lactones suppresses IEC-6 cell proliferation and increase permeability of isolated rat colon, Biosci. Biotechnol. Biochem. 78 (2014) 462-465. doi:10.1080/09168451.2014.882748.

[71] V. Sperandio, A.G. Torres, B. Jarvis, J.P. Nataro, J.B. Kaper, Bacteria-host communication: The language of hormones, Proc. Natl. Acad. Sci. 100 (2003) 8951-8956. doi:10.1073/pnas.1537100100.

[72] A. Stacy, L. McNally, S.E. Darch, S.P. Brown, M. Whiteley, The biogeography of polymicrobial infection, Nat. Rev. Microbiol. 14 (2016) 93-105. doi:10.1038/nrmicro.2015.8.

[73] K. Yasuda, K. Oh, B. Ren, T.L. Tickle, E.A. Franzosa, L.M. Wachtman, A.D. Miller, S. V. Westmoreland, K.G. Mansfield, E.J. Vallender, G.M. Miller, J.K. Rowlett, D. Gevers, C. Huttenhower, X.C. Morgan, Biogeography of the intestinal mucosal and lumenal microbiome in the rhesus macaque, Cell Host Microbe. 17 (2015) 385-391. doi:10.1016/j.chom.2015.01.015.

[74] L. Albenberg, T. V. Esipova, C.P. Judge, K. Bittinger, J. Chen, A. Laughlin, S. Grunberg, R.N. Baldassano, J.D. Lewis, H. Li, S.R. Thom, F.D. Bushman, S.A. Vinogradov, G.D. Wu, Correlation between intraluminal oxygen gradient and radial partitioning of intestinal microbiota, Gastroenterology. 147 (2014) 10551063.e8. doi:10.1053/j.gastro.2014.07.020.

[75] A. Naidoo, K. Naidoo, N. Yende-zuma, T.N. Gengiah, Correlation Between Intraluminal Oxygen Gradient and Radial Partitioning of Intestinal Microbiota in Humans and Mice, Gastroenterology. 19 (2015) 161-169. doi:10.3851/IMP2701.Changes.

[76] D. Harman, Aging: a theory based on free radical and radiation chemistry., J. Gerontol. 11 (1956) 298-300. doi:10.1093/geronj/11.3.298. 
[77] A. Kumar, H. Wu, L.S. Collier-Hyams, J.M. Hansen, T. Li, K. Yamoah, Z.-Q. Pan, D.P. Jones, A.S. Neish, Commensal bacteria modulate cullin-dependent signaling via generation of reactive oxygen species., EMBO J. 26 (2007) 4457-66. doi:10.1038/sj.emboj.7601867.

[78] R.M. Jones, J.W. Mercante, A.S. Neish, Reactive oxygen production induced by the gut microbiota: pharmacotherapeutic implications., Curr. Med. Chem. 19 (2012) 1519-29. doi:10.1016/j.biotechadv.2011.08.021.Secreted.

[79] D. Barford, The role of cysteine residues as redox-sensitive regulatory switches, Curr. Opin. Struct. Biol. 14 (2004) 679-686. doi:10.1016/j.sbi.2004.09.012.

[80] C.E. Paulsen, K.S. Carroll, Orchestrating redox signaling networks through regulatory cysteine switches, ACS Chem. Biol. 5 (2010) 47-62. doi:10.1021/cb900258z.

[81] C. Klomsiri, P.A. Karplus, L.B. Poole, Cysteine-based redox switches in enzymes., Antioxid. Redox Signal. 14 (2011) 1065-77. doi:10.1089/ars.2010.3376.

[82] M. a Wouters, S.W. Fan, N.L. Haworth, Disulfides as redox switches: from molecular mechanisms to functional significance., Antioxid. Redox Signal. 12 (2010) 53-91. doi:10.1089/ars.2009.2510.

[83] H. Antelmann, J.D. Helmann, Thiol-based redox switches and gene regulation., Antioxid. Redox Signal. 14 (2011) 1049-63. doi:10.1089/ars.2010.3400.

[84] T. Darby, R. Jones, Cell differentiation in the murine intestine requires NADPH oxidase 1, FASEB J. . 30 (2016) 57.3-57.3.

http://www.fasebj.org/content/30/1_Supplement/57.3.abstract.

[85] R.M. Jones, L. Luo, C.S. Ardita, A.N. Richardson, Y.M. Kwon, J.W. Mercante, A. Alam, C.L. Gates, H. Wu, P.A. Swanson, J.D. Lambeth, P.W. Denning, A.S. Neish, Symbiotic lactobacilli stimulate gut epithelial proliferation via Nox-mediated generation of reactive oxygen species., EMBO J. 32 (2013) 3017-3028. doi:10.1038/emboj.2013.224.

[86] P. a Swanson, A. Kumar, S. Samarin, M. Vijay-Kumar, K. Kundu, N. Murthy, J. Hansen, A. Nusrat, A.S. Neish, Enteric commensal bacteria potentiate epithelial restitution via reactive oxygen species-mediated inactivation of focal adhesion kinase phosphatases., Proc. Natl. Acad. Sci. U. S. A. 108 (2011) 8803-8808. doi:10.1073/pnas.1010042108.

[87] C.L. Bigarella, R. Liang, S. Ghaffari, Stem cells and the impact of ROS signaling., Development. 141 (2014) 4206-18. doi:10.1242/dev.107086.

[88] D. Zhou, L. Shao, D.R. Spitz, Reactive oxygen species in normal and tumor stem cells, 2014. doi:10.1016/B978-0-12-420117-0.00001-3.

[89] B. Kalyanaraman, Teaching the basics of redox biology to medical and graduate students: Oxidants, antioxidants and disease mechanisms, Redox Biol. 1 (2013) 244-257. doi:10.1016/j.redox.2013.01.014. 
[90] J.M. McCord, I. Fridovich, Superoxide dismutase. An enzymic function for erythrocuprein (hemocuprein)., J. Biol. Chem. 244 (1969) 6049-6055. doi:10.1016/0003-2697(69)90079-7.

[91] M.L. Circu, T.Y. Aw, Reactive oxygen species, cellular redox systems, and apoptosis, Free Radic. Biol. Med. 48 (2010) 749-762. doi:10.1016/j.freeradbiomed.2009.12.022.

[92] R. Brigelius-Flohé, Tissue-specific functions of individual glutathione peroxidases, Free Radic. Biol. Med. 27 (1999) 951-965. doi:10.1016/S0891-5849(99)00173-2.

[93] A. Hall, P.A. Karplus, L.B. Poole, Typical 2-Cys peroxiredoxins - Structures, mechanisms and functions, FEBS J. 276 (2009) 2469-2477. doi:10.1111/j.17424658.2009.06985.x.

[94] C. Espinosa-Diez, V. Miguel, D. Mennerich, T. Kietzmann, P. Sánchez-Pérez, S. Cadenas, S. Lamas, Antioxidant responses and cellular adjustments to oxidative stress, Redox Biol. 6 (2015) 183-197. doi:10.1016/j.redox.2015.07.008.

[95] J. Lu, A. Holmgren, The thioredoxin antioxidant system, Free Radic. Biol. Med. 66 (2014) 75-87. doi:10.1016/j.freeradbiomed.2013.07.036.

[96] C. Pereira, N.R. Ferreira, B.S. Rocha, R.M. Barbosa, J. Laranjinha, The redox interplay between nitrite and nitric oxide: From the gut to the brain, Redox Biol. 1 (2013) 276-284. doi:10.1016/j.redox.2013.04.004.

[97] J.O. Lundberg, E. Weitzberg, M.T. Gladwin, The nitrate-nitrite-nitric oxide pathway in physiology and therapeutics., Nat. Rev. Drug Discov. 7 (2008) 156-67. doi: $10.1038 /$ nrd2466.

[98] J. Vermeiren, T. Van de Wiele, W. Verstraete, P. Boeckx, N. Boon, Nitric oxide production by the human intestinal microbiota by dissimilatory nitrate reduction to ammonium., J. Biomed. Biotechnol. 2009 (2009) 284718. doi:10.1155/2009/284718.

[99] T. Sobko, C. Reinders, E. Norin, T. Midtvedt, L.E. Gustafsson, J.O. Lundberg, Gastrointestinal nitric oxide generation in germ-free and conventional rats., Am. J. Physiol. Gastrointest. Liver Physiol. 287 (2004) G993-G997. doi:10.1152/ajpgi.00203.2004.

[100] R.M. Palmer, The L-arginine: nitric oxide pathway, Curr. Opin. Nephrol. Hypertens. 2 (1993) 122-128. http://ovidsp.ovid.com/ovidweb.cgi?T=JS\&PAGE=reference\&D=emed3\&NEWS=N \&AN=7522910 \nhttp://ovidsp.ovid.com/ovidweb.cgi?T=JS\&PAGE=reference\&D= med3\&NEWS=N\&AN=7522910.

[101] M. Tiso, A.N. Schechter, Nitrate reduction to nitrite, nitric oxide and ammonia by gut bacteria under physiological conditions, PLoS One. 10 (2015) 1-18. doi:10.1371/journal.pone.0119712.

[102] R.P. Patel, J. McAndrew, H. Sellak, C.R. White, H. Jo, B.A. Freeman, V.M. Darley-Usmar, Biological aspects of reactive nitrogen species, Biochim. Biophys. Acta - Bioenerg. 1411 (1999) 385-400. doi:10.1016/S0005-2728(99)00028-6. 
[103] B.D. Paul, S.H. Snyder, H2S: A Novel Gasotransmitter that Signals by Sulfhydration, Trends Biochem. Sci. 40 (2015) 687-700. doi:10.1016/j.tibs.2015.08.007.

[104] A. Lanas, Role of nitric oxide in the gastrointestinal tract., Arthritis Res. Ther. 10 Suppl 2 (2008) S4. doi:10.1186/ar2465.

[105] A.K. Mustafa, M.M. Gadalla, S.H. Snyder, Signaling by gasotransmitters., Sci. Signal. 2 (2009) re2. doi:10.1126/scisignal.268re2.

[106] S.R. Jaffrey, N.A. Cohen, T.A. Rouault, R.D. Klausner, S.H. Snyder, The ironresponsive element binding protein: a target for synaptic actions of nitric oxide., Proc. Natl. Acad. Sci. U. S. A. 91 (1994) 12994-8. doi:10.1073/pnas.91.26.12994.

[107] J.G. Williams, K. Pappu, S.L. Campbell, Structural and biochemical studies of p21Ras S-nitrosylation and nitric oxide-mediated guanine nucleotide exchange., Proc. Natl. Acad. Sci. U. S. A. 100 (2003) 6376-6381. doi:10.1073/pnas.1037299100.

[108] M. Sasaki, S. Bharwani, P. Jordan, J.W. Elrod, M.B. Grisham, T.H. Jackson, D.J. Lefer, J.S. Alexander, Increased disease activity in eNOS-deficient mice in experimental colitis, Free Radic. Biol. Med. 35 (2003) 1679-1687. doi:10.1016/j.freeradbiomed.2003.09.016.

[109] M.B. Grisham, K.P. Pavlick, F.S. Laroux, J. Hoffman, S. Bharwani, R.E. Wolf, Nitric oxide and chronic gut inflammation: controversies in inflammatory bowel disease., J. Investig. Med. 50 (2002) 272-83. doi:10.2310/6650.2002.33281.

[110] J.B. Mannick, A. Hausladen, L. Liu, D.T. Hess, M. Zeng, Q.X. Miao, L.S. Kane, A.J. Gow, J.S. Stamler, Fas-induced caspase denitrosylation., Science. 284 (1999) 651-4. doi:10.1126/science.284.5414.651.

[111] H. Yu, E.F. Sato, K. Nagata, M. Nishikawa, M. Kashiba, T. Arakawa, K. Kobayashi, T. Tamura, M. Inoue, Oxygen-dependent regulation of the respiration and growth of Escherichia coli by nitric oxide, FEBS Lett. 409 (1997) 161-165. doi:10.1016/S0014-5793(97)00494-8.

[112] M.G. Espey, D.D. Thomas, K.M. Miranda, D.A. Wink, Focusing of nitric oxide mediated nitrosation and oxidative nitrosylation as a consequence of reaction with superoxide., Proc. Natl. Acad. Sci. U. S. A. 99 (2002) 11127-32. doi:10.1073/pnas.152157599.

[113] A. Zeida, M.C. González Lebrero, R. Radi, M. Trujillo, D.A. Estrin, Mechanism of cysteine oxidation by peroxynitrite: An integrated experimental and theoretical study, Arch. Biochem. Biophys. 539 (2013) 81-86. doi:10.1016/j.abb.2013.08.016.

[114] D. Rachmilewitz, J.S. Stamler, F. Karmeli, M.E. Mullins, D.J. Singel, J. Loscalzo, R.J. Xavier, D.K. Podolsky, Peroxynitrite-induced rat colitis--a new model of colonic inflammation., Gastroenterology. 105 (1993) 1681-1688. doi:S0016508593003920 [pii].

[115] M.L. Circu, T.Y. Aw, Redox biology of the intestine., Free Radic. Res. 45 (2011) 1245-66. doi:10.3109/10715762.2011.611509. 
[116] M.L. Circu, T.Y. Aw, Intestinal redox biology and oxidative stress, Semin. Cell Dev. Biol. 23 (2012) 729-737. doi:10.1016/j.semcdb.2012.03.014.

[117] M.A. Liebert, D.P. Jones, Redefining oxidative stress, ANTIOXIDANTS REDOX Signal. Vol. 8, Numbers. 8 (2006) 1-16. doi:10.1089/ars.2006.8.1865.

[118] R. Environment, O.F. The, C. As, V. Through, Redox environment of the cell as viewed through the redox state of the glutathione disulfide/glutathione couple, Free Radic. Biol. Med. 30 (2001) 1191-1212. doi:10.1016/S0891-5849(01)004804.

[119] Y.-M.M. Go, J.D. Chandler, D.P. Jones, The cysteine proteome, Free Radic. Biol. Med. 84 (2015) 227-245. doi:10.1016/j.freeradbiomed.2015.03.022.

[120] D. Spadaro, B.W. Yun, S.H. Spoel, C. Chu, Y.Q. Wang, G.J. Loake, The redox switch: Dynamic regulation of protein function by cysteine modifications, Physiol. Plant. 138 (2010) 360-371. doi:10.1111/j.1399-3054.2009.01307.x.

[121] H.H. Bragulla, D.G. Homberger, Structure and functions of keratin proteins in simple, stratified, keratinized and cornified epithelia, in: J. Anat., 2009: pp. 516559. doi:10.1111/j.1469-7580.2009.01066.x.

[122] R.D. Bruce Fraser, D.A.D. Parry, The role of disulfide bond formation in the structural transition observed in the intermediate filaments of developing hair, $\mathrm{J}$. Struct. Biol. 180 (2012) 117-124. doi:10.1016/j.jsb.2012.05.020.

[123] W. Jeong, S.H. Bae, M.B. Toledano, S.G. Rhee, Role of sulfiredoxin as a regulator of peroxiredoxin function and regulation of its expression, Free Radic. Biol. Med. 53 (2012) 447-456. doi:10.1016/j.freeradbiomed.2012.05.020.

[124] L.B. Poole, K.J. Nelson, Discovering mechanisms of signaling-mediated cysteine oxidation, Curr. Opin. Chem. Biol. 12 (2008) 18-24.

doi:10.1016/j.cbpa.2008.01.021.

[125] K.M. Holmström, T. Finkel, Cellular mechanisms and physiological consequences of redox-dependent signalling., Nat. Rev. Mol. Cell Biol. 15 (2014) 411-21. doi:10.1038/nrm3801.

[126] M. Zheng, F. Aslund, G. Storz, Activation of the OxyR transcription factor by reversible disulfide bond formation., Science. 279 (1998) 1718-1721. doi:10.1126/science.279.5357.1718.

[127] K. Itoh, T. Chiba, S. Takahashi, T. Ishii, K. Igarashi, Y. Katoh, T. Oyake, N. Hayashi, K. Satoh, I. Hatayama, M. Yamamoto, Y. Nabeshima, An Nrf2/Small Maf Heterodimer Mediates the Induction of Phase II Detoxifying Enzyme Genes through Antioxidant Response Elements, Biochem. Biophys. Res. Commun. 236 (1997) 313-322. doi:10.1006/bbrc.1997.6943.

[128] Y. Zuo, B. Xiang, J. Yang, X. Sun, Y. Wang, H. Cang, J. Yi, Oxidative modification of caspase- 9 facilitates its activation via disulfide-mediated interaction with Apaf1., Cell Res. 19 (2009) 449-57. doi:10.1038/cr.2009.19.

[129] Y. Jung, H. Kim, S.H. Min, S.G. Rhee, W. Jeong, Dynein light chain LC8 
negatively regulates NF-kappaB through the redox-dependent interaction with IkappaBalpha., J. Biol. Chem. 283 (2008) 23863-71.

doi:10.1074/jbc.M803072200.

[130] Y. Wang, J. Yang, J. Yi, Redox sensing by proteins: oxidative modifications on cysteines and the consequent events., Antioxid. Redox Signal. 16 (2012) 649-57. doi:10.1089/ars.2011.4313.

[131] M. Schieber, N.S. Chandel, ROS function in redox signaling and oxidative stress, Curr. Biol. 24 (2014) R453-R462. doi:10.1016/j.cub.2014.03.034.

[132] B.B.A. Simone Reuter, Oxidative stress, inflammation, and cancer: How are they linked?, Free Radic Biol Med. 49 (2011) 1603-1616. doi:10.1016/j.freeradbiomed.2010.09.006.Oxidative.

[133] F.A. Moura, K.Q. de Andrade, J.C.F. dos Santos, O.R.P. Araújo, M.O.F. Goulart, Antioxidant therapy for treatment of inflammatory bowel disease: Does it work?, Redox Biol. 6 (2015) 617-639. doi:10.1016/j.redox.2015.10.006.

[134] R. Banerjee, D.F. Becker, M.B. Dickman, V.N. Gladyshev, S.W. Ragsdale, Redox Biochemistry, John Wiley \& Sons, Inc., Hoboken, NJ, USA, 2007. doi:10.1002/9780470177334.

[135] S. Lu, S.-B. Fan, B. Yang, Y.-X. Li, J.-M. Meng, L. Wu, P. Li, K. Zhang, M.-J. Zhang, Y. Fu, J. Luo, R.-X. Sun, S.-M. He, M.-Q. Dong, Mapping native disulfide bonds at a proteome scale, Nat. Methods. advance on (2015) 1-8. doi:10.1038/nmeth.3283.

[136] M.P. DeLisa, J.J. Valdes, W.E. Bentley, Mapping stress-induced changes in autoinducer Al-2 production in chemostat-cultivated Escherichia coli K-12, J. Bacteriol. 183 (2001) 2918-2928. doi:10.1128/JB.183.9.2918-2928.2001.

[137] F. Sun, H. Liang, X. Kong, S. Xie, H. Cho, X. Deng, Q. Ji, H. Zhang, S. Alvarez, L.M. Hicks, T. Bae, C. Luo, H. Jiang, C. He, Quorum-sensing agr mediates bacterial oxidation response via an intramolecular disulfide redox switch in the response regulator AgrA, Proc. Natl. Acad. Sci. U. S. A. 109 (2012) 9095-9100. doi:10.1073/pnas.1200603109.

[138] C.E. Hochmuth, B. Biteau, D. Bohmann, H. Jasper, Redox regulation by keap1 and Nrf2 controls intestinal stem cell proliferation in drosophila, Cell Stem Cell. 8 (2011) 188-199. doi:10.1016/j.stem.2010.12.006.

[139] N. Coant, S. Ben Mkaddem, E. Pedruzzi, C. Guichard, X. Tréton, R. Ducroc, J.-N. Freund, D. Cazals-Hatem, Y. Bouhnik, P.-L. Woerther, D. Skurnik, A. Grodet, M. Fay, D. Biard, T. Lesuffleur, C. Deffert, R. Moreau, A. Groyer, K.-H. Krause, F. Daniel, E. Ogier-Denis, NADPH oxidase 1 modulates WNT and NOTCH1 signaling to control the fate of proliferative progenitor cells in the colon., Mol. Cell. Biol. 30 (2010) 2636-2650. doi:10.1128/MCB.01194-09.

[140] S. Sart, S.N. Agathos, Y. Li, Process engineering of stem cell metabolism for large scale expansion and differentiation in bioreactors, Biochem. Eng. J. 84 (2014) 74-82. doi:10.1016/j.bej.2014.01.005. 
[141] C. Stringari, R.A. Edwards, K.T. Pate, M.L. Waterman, P.J. Donovan, E. Gratton, Metabolic trajectory of cellular differentiation in small intestine by Phasor Fluorescence Lifetime Microscopy of NADH., Sci. Rep. 2 (2012) 568. doi:10.1038/srep00568.

[142] C.R. Jonas, T.R. Ziegler, L.H. Gu, D.P. Jones, Extracellular thiol/disulfide redox state affects proliferation rate in a human colon carcinoma (Caco2) cell line, Free Radic. Biol. Med. 33 (2002) 1499-1506. doi:10.1016/S0891-5849(02)01081-X.

[143] A. Alam, G. Leoni, M. Quiros, H. Wu, C. Desai, H. Nishio, R.M. Jones, A. Nusrat, A.S. Neish, The microenvironment of injured murine gut elicits a local prorestitutive microbiota, Nat. Microbiol. 1 (2016) 1-8. doi:10.1038/nmicrobiol.2015.21.

[144] G. Leoni, A. Alam, P. Alexander Neumann, J.D. Lambeth, G. Cheng, J. McCoy, R.S. Hilgarth, K. Kundu, N. Murthy, D. Kusters, C. Reutelingsperger, M. Perretti, C.A. Parkos, A.S. Neish, A. Nusrat, Annexin A1, formyl peptide receptor, and NOX1 orchestrate epithelial repair, J. Clin. Invest. 123 (2013) 443-454. doi:10.1172/JCI65831.

[145] S.E. Winter, M.G. Winter, M.N. Xavier, P. Thiennimitr, V. Poon, A.M. Keestra, R.C. Laughlin, G. Gomez, J. Wu, S.D. Lawhon, I.E. Popova, S.J. Parikh, L.G. Adams, R.M. Tsolis, V.J. Stewart, A.J. Bäumler, Host-Derived Nitrate Boosts Growth of E. coli in the Inflamed Gut, Science (80-. ). 339 (2013) 708-711. doi:10.1126/science.1232467.

[146] S.E. Winter, P. Thiennimitr, M.G. Winter, B.P. Butler, D.L. Huseby, R.W. Crawford, J.M. Russell, C.L. Bevins, L.G. Adams, R.M. Tsolis, J.R. Roth, A.J. Bäumler, Gut inflammation provides a respiratory electron acceptor for Salmonella., Nature. 467 (2010) 426-9. doi:10.1038/nature09415.

[147] J.-P. Motta, K.L. Flannigan, T. a Agbor, J.K. Beatty, R.W. Blackler, M.L. Workentine, G.J. Da Silva, R. Wang, A.G. Buret, J.L. Wallace, Hydrogen Sulfide Protects from Colitis and Restores Intestinal Microbiota Biofilm and Mucus Production., Inflamm. Bowel Dis. 21 (2015) 1006-1017. doi:10.1097/MIB.0000000000000345.

[148] G. Yang, K. Zhao, Y. Ju, S. Mani, Q. Cao, S. Puukila, N. Khaper, L. Wu, R. Wang, Hydrogen Sulfide Protects Against Cellular Senescence via S-Sulfhydration of Keap1 and Activation of Nrf2, Antioxid. Redox Signal. 18 (2013) 1906-1919. doi:10.1089/ars.2012.4645.

[149] M. Bhatia, Hydrogen sulfide as a vasodilator., IUBMB Life. 57 (2005) 603-606. doi:10.1080/15216540500217875.

[150] B.D. Paul, S.H. Snyder, H2S signalling through protein sulfhydration and beyond, Nat. Rev. Mol. Cell Biol. 13 (2012) 499-507. doi:10.1038/nrm3391.

[151] M. Magierowski, K. Magierowska, S. Kwiecien, T. Brzozowski, Gaseous mediators nitric oxide and hydrogen sulfide in the mechanism of gastrointestinal integrity, protection and ulcer healing, Molecules. 20 (2015) 9099-9123. doi:10.3390/molecules20059099. 
[152] J.O. Lundberg, E. Weitzberg, Biology of nitrogen oxides in the gastrointestinal tract, Gut. 62 (2012) 616-629. doi:10.1136/gutjnl-2011-301649.

[153] L.S. Gloyne, G.D. Grant, A. V. Perkins, K.L. Powell, C.M. McDermott, P. V. Johnson, G.J. Anderson, M. Kiefel, S. Anoopkumar-Dukie, Pyocyanin-induced toxicity in A549 respiratory cells is causally linked to oxidative stress, Toxicol. Vitr. 25 (2011) 1353-1358. doi:10.1016/j.tiv.2011.05.004.

[154] G.W. Lau, D.J. Hassett, H. Ran, F. Kong, The role of pyocyanin in Pseudomonas aeruginosa infection, Trends Mol. Med. 10 (2004) 599-606. doi:10.1016/j.molmed.2004.10.002.

[155] S.S. Baron, J.J. Rowe, Antibiotic action of pyocyanin, Antimicrob. Agents Chemother. 20 (1981) 814-820. doi:10.1128/AAC.20.6.814.

[156] E. Khare, N.K. Arora, Dual activity of pyocyanin from Pseudomonas aeruginosa antibiotic against phytopathogen and signal molecule for biofilm development by rhizobia., Can. J. Microbiol. 57 (2011) 708-713. doi:10.1139/w11-055.

[157] J. Kim, W. Park, Indole: a signaling molecule or a mere metabolic byproduct that alters bacterial physiology at a high concentration?, J. Microbiol. 53 (2015) 421428. doi:10.1007/s12275-015-5273-3.

[158] T. Bansal, R.C. Alaniz, T.K. Wood, A. Jayaraman, The bacterial signal indole increases epithelial-cell tight-junction resistance and attenuates indicators of inflammation, Proc. Natl. Acad. Sci. 107 (2009) 228-233. doi:10.1073/pnas.0906112107.

[159] Y. Shimada, M. Kinoshita, K. Harada, M. Mizutani, K. Masahata, H. Kayama, K. Takeda, Commensal bacteria-dependent indole production enhances epithelial barrier function in the colon, PLoS One. 8 (2013). doi:10.1371/journal.pone.0080604.

[160] C. Chimerel, E. Emery, D.K. Summers, U. Keyser, F.M. Gribble, F. Reimann, Bacterial Metabolite Indole Modulates Incretin Secretion from Intestinal Enteroendocrine L Cells, Cell Rep. 9 (2014) 1202-1208. doi:10.1016/j.celrep.2014.10.032.

[161] M. Karbownik, R.J. Reiter, J.J. Garcia, J. Cabrera, S. Burkhardt, C. Osuna, A. Lewiski, Indole-3-propionic acid, a melatonin-related molecule, protects hepatic microsomal membranes from iron-induced oxidative damage: Relevance to cancer reduction, J. Cell. Biochem. 81 (2001) 507-513. doi:10.1002/10974644(20010601)81:3<507::AID-JCB1064>3.0.CO;2-M.

[162] K.A. Lee, S.H. Kim, E.K. Kim, E.M. Ha, H. You, B. Kim, M.J. Kim, Y. Kwon, J.H. Ryu, W.J. Lee, Bacterial-derived uracil as a modulator of mucosal immunity and gut-microbe homeostasis in drosophila, Cell. 153 (2013) 797-811. doi:10.1016/j.cell.2013.04.009.

[163] K.A. Lee, B. Kim, J. Bhin, D.H. Kim, H. You, E.K. Kim, S.H. Kim, J.H. Ryu, D. Hwang, W.J. Lee, Bacterial uracil modulates drosophila DUOX-dependent Gut immunity via hedgehog-induced signaling endosomes, Cell Host Microbe. 17 (2015) 191-204. doi:10.1016/j.chom.2014.12.012. 
[164] M.E. V Johansson, D. Ambort, T. Pelaseyed, A. Schütte, J.K. Gustafsson, A. Ermund, D.B. Subramani, J.M. Holmén-Larsson, K.A. Thomsson, J.H. Bergström, S. Van Der Post, A.M. Rodriguez-Piñeiro, H. Sjövall, M. Bäckström, G.C. Hansson, Composition and functional role of the mucus layers in the intestine, Cell. Mol. Life Sci. 68 (2011) 3635-3641. doi:10.1007/s00018-011-0822-3.

[165] A. Herrmann, J.R. Davies, G. Lindell, S. M??rtensson, N.H. Packer, D.M. Swallow, I. Carlstedt, Studies on the "insoluble" glycoprotein complex from human colon: Identification of reduction-insensitive MUC2 oligomers and C-terminal cleavage, J. Biol. Chem. 274 (1999) 15828-15836. doi:10.1074/jbc.274.22.15828.

[166] G.F. Rushworth, I.L. Megson, Existing and potential therapeutic uses for Nacetylcysteine: The need for conversion to intracellular glutathione for antioxidant benefits, Pharmacol. Ther. 141 (2014) 150-159. doi:10.1016/j.pharmthera.2013.09.006.

[167] R. Tirouvanziam, C.K. Conrad, T. Bottiglieri, L.A.L.A. Herzenberg, R.B. Moss, L.A.L.A. Herzenberg, High-dose oral $\mathrm{N}$-acetylcysteine, a glutathione prodrug, modulates inflammation in cystic fibrosis., Proc. Natl. Acad. Sci. U. S. A. 103 (2006) 4628-4633. doi:10.1073/pnas.0511304103.

[168] S. Yuan, M. Hollinger, M.E. Lachowicz-Scroggins, S.C. Kerr, E.M. Dunican, B.M. Daniel, S. Ghosh, S.C. Erzurum, B. Willard, S.L. Hazen, X. Huang, S.D. Carrington, S. Oscarson, J. V Fahy, Oxidation increases mucin polymer crosslinks to stiffen airway mucus gels., Sci. Transl. Med. 7 (2015) 276 ra27. doi:10.1126/scitranslmed.3010525.

[169] M.-L. Kleme, E. Levy, Cystic fibrosis-related oxidative stress and intestinal lipid disorders., Antioxid. Redox Signal. 22 (2015) 614-31. doi:10.1089/ars.2014.6012.

[170] T.S. Cohen, A. Prince, Cystic fibrosis: a mucosal immunodeficiency syndrome., Nat. Med. 18 (2012) 509-19. doi:10.1038/nm.2715.

[171] S.M. Kreda, C.W. Davis, M.C. Rose, CFTR, mucins, and mucus obstruction in cystic fibrosis, Cold Spring Harb. Perspect. Med. 2 (2012). doi:10.1101/cshperspect.a009589.

[172] M.C. Rose, Respiratory Tract Mucin Genes and Mucin Glycoproteins in Health and Disease, Physiol. Rev. 86 (2006) 245-278. doi:10.1152/physrev.00010.2005.

[173] N. ljssennagger, C. Belzer, G.J. Hooiveld, J. Dekker, S.W.C. van Mil, M. Müller, M. Kleerebezem, R. van der Meer, Gut microbiota facilitates dietary hemeinduced epithelial hyperproliferation by opening the mucus barrier in colon, Proc. Natl. Acad. Sci. 112 (2015) 201507645. doi:10.1073/pnas.1507645112.

[174] R. Nuri, T. Shprung, Y. Shai, Defensive remodeling: How bacterial surface properties and biofilm formation promote resistance to antimicrobial peptides, Biochim. Biophys. Acta - Biomembr. 1848 (2015) 3089-3100. doi:10.1016/j.bbamem.2015.05.022.

[175] B.O. Schroeder, Z. Wu, S. Nuding, S. Groscurth, M. Marcinowski, J. Beisner, J. Buchner, M. Schaller, E.F. Stange, J. Wehkamp, Reduction of disulphide bonds unmasks potent antimicrobial activity of human $\beta$-defensin 1., Nature. 469 (2011) 
419-423. doi:10.1038/nature09674.

[176] F. Biasi, G. Leonarduzzi, P.I. Oteiza, G. Poli, Inflammatory bowel disease: mechanisms, redox considerations, and therapeutic targets., Antioxid. Redox Signal. 19 (2013) 1711-47. doi:10.1089/ars.2012.4530.

[177] K.P. Pavlick, F.S. Laroux, J. Fuseler, R.E. Wolf, L. Gray, J. Hoffman, M.B. Grisham, Role of reactive metabolites of oxygen and nitrogen in inflammatory bowel disease, Free Radic.Biol.Med. 33 (2002) 311-322.

[178] C.F. Krieglstein, W.H. Cerwinka, F.S. Laroux, J.W. Salter, J.M. Russell, G. Schuermann, M.B. Grisham, C.R. Ross, D.N. Granger, Regulation of murine intestinal inflammation by reactive metabolites of oxygen and nitrogen: Divergent roles of superoxide and nitric oxide, J. Exp. Med. 194 (2001) 1207-1218. doi:10.1084/jem.194.9.1207.

[179] O. Miralles-Barrachina, G. Savoye, L. Belmonte-Zalar, P. Hochain, P. Ducrotté, B. Hecketsweiler, E. Lerebours, P. Déchelotte, Low levels of glutathione in endoscopic biopsies of patients with Crohn's colitis: The role of malnutrition, Clin. Nutr. 18 (1999) 313-317. doi:10.1016/S0261-5614(98)80030-7.

[180] E.W. Holmes, S.L. Yong, D. Eiznhamer, A. Keshavarzian, Glutathione content of colonic mucosa: evidence for oxidative damage in active ulcerative colitis, Dig Dis Sci. 43 (1998) 1088-1095.

http://www.ncbi.nlm.nih.gov/entrez/query.fcgi?cmd=Retrieve\&db=PubMed\&dopt= Citation\&list_uids=9590426.

[181] G.D. Buffinton, W.F. Doe, Depleted mucosal antioxidant defences in inflammatory bowel disease, Free Radic. Biol. Med. 19 (1995) 911-918. doi:10.1016/08915849(95)94362-H.

[182] S. Blau, R. Kohen, P. Bass, A. Rubinstein, Relation between colonic inflammation severity and total low-molecular- weight antioxidant profiles in experimental colitis, Dig. Dis. Sci. 45 (2000) 1180-1187. doi:10.1023/A:1005510321278.

[183] M. Million, M. Tidjani Alou, S. Khelaifia, D. Bachar, J.-C. Lagier, N. Dione, S. Brah, P. Hugon, V. Lombard, F. Armougom, J. Fromonot, C. Robert, C. Michelle, A. Diallo, A. Fabre, R. Guieu, C. Sokhna, B. Henrissat, P. Parola, D. Raoult, Increased Gut Redox and Depletion of Anaerobic and Methanogenic Prokaryotes in Severe Acute Malnutrition, Sci. Rep. 6 (2016) 26051. doi:10.1038/srep26051.

[184] T.Y. Aw, Intestinal glutathione: Determinant of mucosal peroxide transport, metabolism, and oxidative susceptibility, Toxicol. Appl. Pharmacol. 204 (2005) 320-328. doi:10.1016/j.taap.2004.11.016.

[185] S.K. Biswas, Does the Interdependence between Oxidative Stress and Inflammation Explain the Antioxidant Paradox?, Oxid. Med. Cell. Longev. 2016 (2016). doi:10.1155/2016/5698931.

[186] F. Saura-Calixto, Concept and Health-Related Properties of Nonextractable Polyphenols: The Missing Dietary Polyphenols, J. Agric. Food Chem. 60 (2012) 11195-11200. doi:10.1021/jf303758j. 
[187] F.J. Pérez-Cano, M. Massot-Cladera, À. Franch, C. Castellote, M. Castell, The effects of cocoa on the immune system, Front. Pharmacol. 4 JUN (2013) 1-12. doi:10.3389/fphar.2013.00071.

[188] H.P. Ciolino, P.J. Daschner, G.C. Yeh, Resveratrol inhibits transcription of CYP1A1 in vitro by preventing activation of the aryl hydrocarbon receptor, Cancer Res. 58 (1998) 5707-5712.

[189] D.A. Martin, B.W. Bolling, A review of the efficacy of dietary polyphenols in experimental models of inflammatory bowel diseases., Food Funct. 6 (2015) 1773-86. doi:10.1039/c5fo00202h.

[190] B. Romier, Y.J. Schneider, Y. Larondelle, A. During, Dietary polyphenols can modulate the intestinal inflammatory response, Nutr. Rev. 67 (2009) 363-378. doi:10.1111/j.1753-4887.2009.00210.x.

[191] C. Nunes, N. Teixeira, D. Serra, V. Freitas, L. Almeida, J. Laranjinha, Red wine polyphenol extract efficiently protects intestinal epithelial cells from inflammation via opposite modulation of JAK/STAT and Nrf2 pathways, Toxicol. Res. 5 (2016) 53-65. doi:10.1039/C5TX00214A.

[192] R. Landberg, Q. Sun, E.B. Rimm, A. Cassidy, A. Scalbert, C.S. Mantzoros, F.B. Hu, R.M. Van Dam, Selected Dietary Flavonoids Are Associated with Markers of Inflammation and Endothelial, J. Nutr. (2011) 618-625. doi:10.3945/jn.110.133843.).

[193] Q. Ma, K. Kinneer, J. Ye, B.J. Chen, Inhibition of nuclear factor KB by phenolic antioxidants: Interplay between antioxidant signaling and inflammatory cytokine expression, Mol. Pharmacol. 64 (2003) 211-219. doi:10.1124/mol.64.2.211.

[194] C.G. Fraga, M. Galleano, S. V. Verstraeten, P.I. Oteiza, Basic biochemical mechanisms behind the health benefits of polyphenols, Mol. Aspects Med. 31 (2010) 435-445. doi:10.1016/j.mam.2010.09.006.

[195] H.C. Lee, A.M. Jenner, C.S. Low, Y.K. Lee, Effect of tea phenolics and their aromatic fecal bacterial metabolites on intestinal microbiota, Res. Microbiol. 157 (2006) 876-884. doi:10.1016/j.resmic.2006.07.004.

[196] X. Tzounis, Flavanol monomer-induced changes to the human faecal microflora, Br. J. Nutr. 99 (2008) 782-792. doi:10.1017/S0007114507853384.

[197] D. Bosscher, A. Breynaert, L. Pieters, N. Hermans, FOOD-BASED STRATEGIES TO MODULATE THE COMPOSITION OF THE INTESTINAL, J. Physiol. Pharmacol. 6 (2009) 5-11.

[198] R.R. McCarthy, F. O'Gara, The impact of phytochemicals present in the diet on microbial signalling in the human gut, J. Funct. Foods. 14 (2015) 684-691. doi:10.1016/j.jff.2015.02.032.

[199] F. Cardona, C. Andres-Lacueva, S. Tulipani, F.J. Tinahones, M.I. Queipo-Ortuno, Benefits of polyphenols on gut microbiota and implications in human health, $\mathrm{J}$. Nutr. Biochem. 24 (2013) 1415-1422. doi:10.1016/j.jnutbio.2013.05.001. 
[200] A. Duda-Chodak, T. Tarko, P. Satora, P. Sroka, Interaction of dietary compounds, especially polyphenols, with the intestinal microbiota: a review, Eur. J. Nutr. 54 (2015) 325-341. doi:10.1007/s00394-015-0852-y.

[201] T. Ozdal, D.A. Sela, J. Xiao, D. Boyacioglu, F. Chen, E. Capanoglu, The reciprocal interactions between polyphenols and gut microbiota and effects on bioaccessibility, Nutrients. 8 (2016) 1-36. doi:10.3390/nu8020078.

[202] F. Rouaki, A. Mazari, A. Kanane, M.B. Errahmani, A. Ammouche, Cardiotoxicity induced by dietary oxidized sunfl ower oil in rats: Pro- and antioxidant effects of ??-Tocopherol, Int. J. Vitam. Nutr. Res. 83 (2013) 367-376. doi:10.1024/03009831/a000178.

[203] G. Bjelakovic, D. Nikolova, L.L. Gluud, R.G. Simonetti, C. Gluud, Mortality in randomized trials of antioxidant supplements for primary and secondary prevention: systematic review and meta-analysis., JAMA. 297 (2007) 842-857. doi:10.1016/S0093-3619(08)70874-8.

[204] S.-K. Myung, Y. Kim, W. Ju, H.J. Choi, W.K. Bae, Effects of antioxidant supplements on cancer prevention: meta-analysis of randomized controlled trials., Ann. Oncol. 21 (2010) 166-79. doi:10.1093/annonc/mdp286.

[205] A.L. Hodgkin, A.F. Huxley, Action Potentials Recorded from Inside a Nerve Fibre, Nature. 144 (1939) 710-711. doi:10.1038/144710a0.

[206] H.M. Hudson, D.M. Griffin, A. Belhaj-Saïf, S.P. Lee, P.D. Cheney, Methods for chronic recording of EMG activity from large numbers of hindlimb muscles in awake rhesus macaques, J. Neurosci. Methods. 189 (2010) 153-161. doi:10.1016/j.jneumeth.2010.03.011.

[207] A.K. Shah, S. Mittal, Invasive electroencephalography monitoring: Indications and presurgical planning., Ann. Indian Acad. Neurol. 17 (2014) S89--94. doi:10.4103/0972-2327.128668.

[208] N. Edvardsson, V. Frykman, R. Van Mechelen, P. Mitro, A. Mohii-Oskarsson, J.L. Pasqui, H. Ramanna, F. Schwertfeger, R. Ventura, D. Voulgaraki, C. Garutti, P. Stolt, N.J. Linker, Use of an implantable loop recorder to increase the diagnostic yield in unexplained syncope: Results from the PICTURE registry, Europace. 13 (2011) 262-269. doi:10.1093/europace/euq418.

[209] D. a Gough, L.S. Kumosa, T.L. Routh, J.T. Lin, J.Y. Lucisano, Function of an implanted tissue glucose sensor for more than 1 year in animals., Sci. Transl. Med. 2 (2010) 42ra53. doi:10.1126/scitranslmed.3001148.

[210] D.M. Russell, E.M. Garry, A.J. Taberner, C.J. Barrett, J.F.R. Paton, D.M. Budgett, S.C. Malpas, A fully implantable telemetry system for the chronic monitoring of brain tissue oxygen in freely moving rats, J. Neurosci. Methods. 204 (2012) 242248. doi:10.1016/j.jneumeth.2011.11.019.

[211] J. Zhou, L. Zhang, Y. Tian, Micro Electrochemical pH Sensor Applicable for RealTime Ratiometric Monitoring of pH Values in Rat Brains, Anal. Chem. 88 (2016) 2113-2118. doi:10.1021/acs.analchem.5b03634. 
[212] D.S. Bilan, V. V. Belousov, HyPer Family Probes: State of the Art., Antioxid. Redox Signal. 24 (2016) 731-51. doi:10.1089/ars.2015.6586.

[213] N.S. Ferreira, M.G.F. Sales, Disposable immunosensor using a simple method for oriented antibody immobilization for label-free real-time detection of an oxidative stress biomarker implicated in cancer diseases, Biosens. Bioelectron. 53 (2014) 193-199. doi:10.1016/j.bios.2013.09.056.

[214] a Valavanidis, K. Fiotakis, E. Bakeas, T. Vlahogianni, Electron paramagnetic resonance study of the generation of reactive oxygen species catalysed by transition metals and quinoid redox cycling by inhalable ambient particulate matter., Redox Rep. 10 (2005) 37-51. doi:10.1179/135100005X21606.

[215] U. Bussy, M. Delaforge, C. El-Bekkali, V. Ferchaud-Roucher, M. Krempf, I. Tea, N. Galland, D. Jacquemin, M. Boujtita, Acebutolol and alprenolol metabolism predictions: comparative study of electrochemical and cytochrome P450catalyzed reactions using liquid chromatography coupled to high-resolution mass spectrometry, Anal Bioanal Chem. 405 (2013) 6077-6085. doi:10.1007/s00216013-7050-7.

[216] A. Baumann, T. Pfeifer, D. Melles, U. Karst, Investigation of the biotransformation of melarsoprol by electrochemistry coupled to complementary LC/ESI-MS and LC/ICP-MS analysis, Anal Bioanal Chem. 405 (2013) 5249-5258. doi:10.1007/s00216-013-6929-7.

[217] A. Baumann, U. Karst, Online electrochemistry/mass spectrometry in drug metabolism studies: principles and applications, Expert Opin. Drug Metab. Toxicol. 6 (2010) 715-731. doi:10.1517/17425251003713527.

[218] S. Jahn, A. Baumann, J. Roscher, K. Hense, R. Zazzeroni, U. Karst, Investigation of the biotransformation pathway of verapamil using electrochemistry/liquid chromatography/mass spectrometry - A comparative study with liver cell microsomes, J. Chromatogr. A. 1218 (2011) 9210-9220. doi:10.1016/j.chroma.2011.10.052.

[219] M.E.A. Zaki, A. Paula Bettencourt, F.M. Fernandes, M. Fernanda Proença, Synthesis and electrochemical evaluation of substituted imidazo[4,5-d]pyrrolo[3,2f][1,3] diazepine scaffolds, Tetrahedron. 68 (2012) 4628-4634. doi:10.1016/j.tet.2012.04.030.

[220] M.L. Lavaggi, M. Nieves, M. Cabrera, C. Olea-Azar, A. López de Ceráin, A. Monge, $\mathrm{H}$. Cerecetto, M. González, Structural modifications on the phenazine N,N'-dioxide-scaffold looking for new selective hypoxic cytotoxins, Eur. J. Med. Chem. 45 (2010) 5362-5369. doi:10.1016/j.ejmech.2010.08.061.

[221] B.E. Logan, Exoelectrogenic bacteria that power microbial fuel cells, Nat. Rev. Microbiol. 7 (2009) 375-381. doi:10.1038/nrmicro2113.

[222] K. Macounova, C.R. Cabrera, M.R. Holl, P. Yager, Generation of natural pH gradients in microfluidic channels for use in isoelectric focusing, Anal. Chem. 72 (2000) 3745-3751. doi:10.1021/ac000237d.

[223] C. Ulrich, O. Andersson, L. Nyholm, F. Björefors, Formation of molecular 
gradients on bipolar electrodes, Angew. Chemie - Int. Ed. 47 (2008) 3034-3036. doi:10.1002/anie.200705824.

[224] Y.-M. Go, D.P. Jones, The Redox Proteome, J. Biol. Chem. 288 (2013) 2651226520. doi:10.1074/jbc.r113.464131.

[225] C. Nathan, A. Cunningham-Bussel, Beyond oxidative stress: an immunologist's guide to reactive oxygen species., Nat. Rev. Immunol. 13 (2013) 349-61. doi:10.1038/nri3423.

[226] P.D. Ray, B.-W. Huang, Y. Tsuji, Reactive oxygen species (ROS) homeostasis and redox regulation in cellular signaling, Cell. Signal. 24 (2012) 981-990. doi:10.1016/j.cellsig.2012.01.008.

[227] Y.-M. Go, D.P. Jones, Cysteine/cystine redox signaling in cardiovascular disease, Free Radic. Biol. Med. 50 (2011) 495-509. doi:10.1016/j.freeradbiomed.2010.11.029.

[228] Y.-M. Go, D.P. Jones, Thiol/disulfide redox states in signaling and sensing, Crit. Rev. Biochem. Mol. Biol. 48 (2013) 173-181. doi:10.3109/10409238.2013.764840.

[229] H.-K. Na, Y.-J. Surh, Modulation of Nrf2-mediated antioxidant and detoxifying enzyme induction by the green tea polyphenol EGCG, Food Chem. Toxicol. 46 (2008) 1271-1278. doi:10.1016/j.fct.2007.10.006.

[230] M. Kemp, Y.-M. Go, D.P. Jones, Nonequilibrium thermodynamics of thiol/disulfide redox systems: A perspective on redox systems biology, Free Radic. Biol. Med. 44 (2008) 921-937. doi:10.1016/j.freeradbiomed.2007.11.008.

[231] S.E. Moriarty-Craige, D.P. Jones, EXTRACELLULAR THIOLS AND THIOL/DISULFIDE REDOX IN METABOLISM, Annu. Rev. Nutr. 24 (2004) 481509. doi:10.1146/annurev.nutr.24.012003.132208.

[232] F. Lisdat, D. Schäfer, The use of electrochemical impedance spectroscopy for biosensing, Anal Bioanal Chem. 391 (2008) 1555-1567. doi:10.1007/s00216-0081970-7.

[233] A. Bogomolova, E. Komarova, K. Reber, T. Gerasimov, O. Yavuz, S. Bhatt, M. Aldissi, Challenges of Electrochemical Impedance Spectroscopy in Protein Biosensing, Anal. Chem. 81 (2009) 3944-3949. doi:10.1021/ac9002358.

[234] K. Heileman, J. Daoud, M. Tabrizian, Dielectric spectroscopy as a viable biosensing tool for cell and tissue characterization and analysis, Biosens. Bioelectron. 49 (2013) 348-359. doi:10.1016/j.bios.2013.04.017.

[235] D. Hyun Jo, R. Lee, J. Hyoung Kim, H. Oh Jun, T. Geol Lee, J. Hun Kim, Realtime estimation of paracellular permeability of cerebral endothelial cells by capacitance sensor array, Sci. Rep. 5 (2015) 11014. doi:10.1038/srep11014.

[236] Y. Van Ingelgem, E. Tourwé, O. Blajiev, R. Pintelon, A. Hubin, Advantages of Odd Random Phase Multisine Electrochemical Impedance Measurements, Electroanalysis. 21 (2009) 730-739. doi:10.1002/elan.200804471. 
[237] L. Fernández Macía, M. Petrova, T. Hauffman, T. Muselle, T. Doneux, A. Hubin, A study of the electron transfer inhibition on a charged self-assembled monolayer modified gold electrode by odd random phase multisine electrochemical impedance spectroscopy, Electrochim. Acta. 140 (2014) 266-274. doi:10.1016/j.electacta.2014.05.027.

[238] E. Van Gheem, R. Pintelon, J. Vereecken, J. Schoukens, A. Hubin, P. Verboven, O. Blajiev, Electrochemical impedance spectroscopy in the presence of non-linear distortions and non-stationary behaviour, Electrochim. Acta. 49 (2004) 47534762. doi:10.1016/j.electacta.2004.05.039.

[239] J.J. Giner-Sanz, E.M. Ortega, V. Pérez-Herranz, Total harmonic distortion based method for linearity assessment in electrochemical systems in the context of EIS, Electrochim. Acta. 186 (2015) 598-612. doi:10.1016/j.electacta.2015.10.152.

[240] B. Sanchez, G. Vandersteen, R. Bragos, J. Schoukens, Basics of broadband impedance spectroscopy measurements using periodic excitations, Meas. Sci. Technol. 23 (2012) 105501. doi:10.1088/0957-0233/23/10/105501.

[241] E. Kim, Y. Liu, H. Ben-Yoav, T.E. Winkler, K. Yan, X. Shi, J. Shen, D.L. Kelly, R. Ghodssi, W.E. Bentley, G.F. Payne, Fusing Sensor Paradigms to Acquire Chemical Information: An Integrative Role for Smart Biopolymeric Hydrogels, Adv. Healthc. Mater. (2016). doi:10.1002/adhm.201600516.

[242] Z. Liu, Y. Liu, E. Kim, W.E. Bentley, G.F. Payne, Electrochemical Probing through a Redox Capacitor To Acquire Chemical Information on Biothiols, Anal. Chem. 88 (2016) 7213-7221.

[243] C.T. Chou, A markovian approach to the optimal demodulation of diffusion-based molecular communication networks, IEEE Trans. Commun. 63 (2015) 3728-3743. doi:10.1109/TCOMM.2015.2469784.

[244] T. Nakano, M.J. Moore, F. Wei, A. V Vasilakos, J. Shuai, Molecular communication and networking: opportunities and challenges., IEEE Trans. Nanobioscience. 11 (2012) 135-48. doi:10.1109/TNB.2012.2191570.

[245] I. Akyildiz, J. Jornet, The Internet of nano-things, IEEE Wirel. Commun. 17 (2010) 58-63. doi:10.1109/MWC.2010.5675779.

[246] M. Pierobon, I.F. Akyildiz, Capacity of a diffusion-based molecular communication system with channel memory and molecular noise, IEEE Trans. Inf. Theory. 59 (2013) 942-954. doi:10.1109/TIT.2012.2219496.

[247] W. Weber, S. Luzi, M. Karlsson, C.D. Sanchez-Bustamante, U. Frey, A. Hierlemann, M. Fussenegger, A synthetic mammalian electro-genetic transcription circuit, Nucleic Acids Res. 37 (2009) 1-8. doi:10.1093/nar/gkp014.

[248] Y. Song, J. Wang, S.-T. Yau, Controlled glucose consumption in yeast using a transistor-like device., Sci. Rep. 4 (2014) 5429. doi:10.1038/srep05429.

[249] T. Gordonov, E. Kim, Y. Cheng, H. Ben-Yoav, R. Ghodssi, G. Rubloff, J.-J. Yin, G.F. Payne, W.E. Bentley, Electronic modulation of biochemical signal generation, Nat. Nanotechnol. 9 (2014) 605-610. doi:10.1038/nnano.2014.151. 
[250] Tanya Tschirhart, Eunkyoung Kim, Ryan McKay, Hana Ueda, Hsuan-chen Wu, Alex Pottash, Amin Zargar, Alejandro Negrete, Joseph Shiloach, Gregory Payne, Electronic control of gene expression and cell behavior in Escherichia coli through redox signaling, Nat. Commun. (In press)

[251] Y. Liu, C.-Y. Tsao, E. Kim, T. Tschirhart, J.L. Terrell, W.E. Bentley, G.F. Payne, Using a Redox Modality to Connect Synthetic Biology to Electronics: HydrogelBased Chemo-Electro Signal Transduction for Molecular Communication, Adv. Healthc. Mater. (2016) n/a-n/a. doi:10.1002/adhm.201600908.

[252] R. Zamora-Ros, V. Fedirko, A. Trichopoulou, C.A. González, C. Bamia, E. Trepo, U. Nöthlings, T. Duarte-Salles, M. Serafini, L. Bredsdorff, K. Overvad, A. Tjønneland, J. Halkjaer, G. Fagherazzi, F. Perquier, M.-C. Boutron-Ruault, V. Katzke, A. Lukanova, A. Floegel, H. Boeing, P. Lagiou, D. Trichopoulos, C. Saieva, C. Agnoli, A. Mattiello, R. Tumino, C. Sacerdote, H.B. Bueno-deMesquita, P.H.M. Peeters, E. Weiderpass, D. Engeset, G. Skeie, M.V. Argüelles, E. Molina-Montes, M. Dorronsoro, M.J. Tormo, E. Ardanaz, U. Ericson, E. Sonestedt, M. Sund, R. Landberg, K.-T. Khaw, N.J. Wareham, F.L. Crowe, E. Riboli, M. Jenab, Dietary flavonoid, lignan and antioxidant capacity and risk of hepatocellular carcinoma in the European prospective investigation into cancer and nutrition study, Int. J. Cancer. 133 (2013) 2429-2443. doi:10.1002/ijc.28257.

[253] J.W. Finley, A.-N. Kong, K.J. Hintze, E.H. Jeffery, L.L. Ji, X.G. Lei, Antioxidants in Foods: State of the Science Important to the Food Industry, J. Agric. Food Chem. 59 (2011) 6837-6846. doi:10.1021/jf2013875.

[254] S.R. Steinhubl, Why Have Antioxidants Failed in Clinical Trials?, Am. J. Cardiol. 101 (2008) S14-S19. doi:10.1016/j.amjcard.2008.02.003.

[255] N.R. Madamanchi, A. Vendrov, M.S. Runge, Oxidative stress and vascular disease, Arterioscler. Thromb. Vasc. Biol. 25 (2005) 29-38. doi:10.1161/01.ATV.0000150649.39934.13.

[256] A. Scalbert, C. Manach, C. Morand, C. Rémésy, L. Jiménez, Dietary Polyphenols and the Prevention of Diseases, Crit. Rev. Food Sci. Nutr. 45 (2005) 287-306. doi:10.1080/1040869059096.

[257] P.-G. Pietta, Flavonoids as Antioxidants, J. Nat. Prod. 63 (2000) 1035-1042. doi:10.1021/np9904509.

[258] F.A. Tomás-Barberán, C. Andrés-Lacueva, Polyphenols and Health: Current State and Progress, J. Agric. Food Chem. 60 (2012) 8773-8775. doi:10.1021/jf300671j.

[259] S. Quideau, D. Deffieux, C. Douat-Casassus, L. Pouységu, Plant Polyphenols: Chemical Properties, Biological Activities, and Synthesis, Angew. Chemie Int. Ed. 50 (2011) 586-621. doi:10.1002/anie.201000044.

[260] J.A. Baur, D.A. Sinclair, Therapeutic potential of resveratrol: the in vivo evidence, Nat. Rev. Drug Discov. 5 (2006) 493-506. doi:10.1038/nrd2060.

[261] H.R. El-Seedi, A.M.A. El-Said, S.A.M. Khalifa, U. Göransson, L. Bohlin, A.-K. Borg-Karlson, R. Verpoorte, Biosynthesis, Natural Sources, Dietary Intake, Pharmacokinetic Properties, and Biological Activities of Hydroxycinnamic Acids, J. 
Agric. Food Chem. 60 (2012) 10877-10895. doi:10.1021/jf301807g.

[262] J.A. Ross, C.M. Kasum, DIETARYFLAVONOIDS: Bioavailability, Metabolic Effects, and Safety, Annu. Rev. Nutr. 22 (2002) 19-34.

doi:10.1146/annurev.nutr.22.111401.144957.

[263] B. Halliwell, Are polyphenols antioxidants or pro-oxidants? What do we learn from cell culture and in vivo studies?, Arch. Biochem. Biophys. 476 (2008) 107-112. doi:10.1016/j.abb.2008.01.028.

[264] B. Halliwell, J. Rafter, A. Jenner, Health promotion by flavonoids, tocopherols, tocotrienols, and other phenols: direct or indirect effects? Antioxidant or not?, Am. J. Clin. Nutr. 81 (2005). doi:81/1/268S [pii].

[265] F. Saura-Calixto, Dietary fiber as a carrier of dietary antioxidants: An essential physiological function, J. Agric. Food Chem. 59 (2011) 43-49. doi:10.1021/jf1036596.

[266] J. Pérez-Jiménez, J.L. Torres, Analysis of Nonextractable Phenolic Compounds in Foods: The Current State of the Art, J. Agric. Food Chem. 59 (2011) 1271312724. doi:10.1021/jf203372w.

[267] E.E. Çelik, V. Gökmen, V. Fogliano, Soluble Antioxidant Compounds Regenerate the Antioxidants Bound to Insoluble Parts of Foods, J. Agric. Food Chem. 61 (2013) 10329-10334. doi:10.1021/jf402523k.

[268] L. Bravo, Polyphenols: Chemistry, Dietary Sources, Metabolism, and Nutritional Significance, Nutr. Rev. 56 (2009) 317-333. doi:10.1111/j.17534887.1998.tb01670.x.

[269] M. Carocho, I.C.F.R. Ferreira, A review on antioxidants, prooxidants and related controversy: Natural and synthetic compounds, screening and analysis methodologies and future perspectives, Food Chem. Toxicol. 51 (2013) 15-25. doi:10.1016/j.fct.2012.09.021.

[270] P.N. Denev, C.G. Kratchanov, M. Ciz, A. Lojek, M.G. Kratchanova, Bioavailability and Antioxidant Activity of Black Chokeberry (Aronia melanocarpa) Polyphenols: in vitro and in vivo Evidences and Possible Mechanisms of Action: A Review, Compr. Rev. Food Sci. Food Saf. 11 (2012) 471-489. doi:10.1111/j.15414337.2012.00198.x.

[271] B. Halliwell, K. Zhao, M. Whiteman, The gastrointestinal tract: A major site of antioxidant action?, Free Radic. Res. 33 (2000) 819-830.

doi:10.1080/10715760000301341.

[272] R. Del Pino-García, M.L. González-SanJosé, M.D. Rivero-Pérez, J. GarcíaLomillo, P. Muñiz, Total antioxidant capacity of new natural powdered seasonings after gastrointestinal and colonic digestion, Food Chem. 211 (2016) 707-714. doi:10.1016/j.foodchem.2016.05.127.

[273] E.E. Çelik, V. Gökmen, L.H. Skibsted, Synergism between Soluble and Dietary Fiber Bound Antioxidants, J. Agric. Food Chem. 63 (2015) 2338-2343. doi:10.1021/acs.jafc.5b00009. 
[274] E.E. Çelik, V. Gökmen, Investigation of the interaction between soluble antioxidants in green tea and insoluble dietary fiber bound antioxidants, Food Res. Int. 63 (2014) 266-270. doi:10.1016/j.foodres.2014.02.026.

[275] E. Doğan, V. Gökmen, Mechanism of the interaction between insoluble wheat bran and polyphenols leading to increased antioxidant capacity, Food Res. Int. 69 (2015) 189-193. doi:10.1016/j.foodres.2014.12.037.

[276] M.E. Lee, E. Kim, Y. Liu, J.C. March, W.E. Bentley, G.F. Payne, Rapid and repeatable redox cycling of an insoluble dietary antioxidant: Electrochemical analysis, J. Agric. Food Chem. 62 (2014) 9760-9768. doi:10.1021/jf503479d.

[277] J. Pérez-Jiménez, V. Neveu, F. Vos, A. Scalbert, Identification of the 100 richest dietary sources of polyphenols: an application of the Phenol-Explorer database, Eur. J. Clin. Nutr. 64 (2010) S112-S120. doi:10.1038/ejcn.2010.221.

[278] L. Jirovetz, G. Buchbauer, I. Stoilova, A. Stoyanova, A. Krastanov, E. Schmidt, Chemical Composition and Antioxidant Properties of Clove Leaf Essential Oil, J. Agric. Food Chem. 54 (2006) 6303-6307. doi:10.1021/jf060608c.

[279] X. Lin, Y. Ni, S. Kokot, Electrochemical mechanism of eugenol at a Cu doped gold nanoparticles modified glassy carbon electrode and its analytical application in food samples, Electrochim. Acta. 133 (2014) 484-491. doi:10.1016/j.electacta.2014.04.065.

[280] E. Kim, L. Panzella, R. Micillo, W.E. Bentley, A. Napolitano, G.F. Payne, Reverse Engineering Applied to Red Human Hair Pheomelanin Reveals Redox-Buffering as a Pro-Oxidant Mechanism, Sci. Rep. 5 (2015) 18447. doi:10.1038/srep18447.

[281] E. Kim, Y. Liu, W.T. Leverage, J.-J.J. Yin, I.M. White, W.E. Bentley, G.F. Payne, Context-Dependent Redox Properties of Natural Phenolic Materials, Biomacromolecules. 15 (2014) 1653-1662. doi:10.1021/bm500026x.

[282] E. Kim, Y. Liu, C.J. Baker, R. Owens, S. Xiao, W.E. Bentley, G.F. Payne, Redoxcycling and $\mathrm{H} 2 \mathrm{O} 2$ generation by fabricated catecholic films in the absence of enzymes., Biomacromolecules. 12 (2011) 880-8. doi:10.1021/bm101499a.

[283] E. Kim, W.T. Leverage, Y. Liu, L. Panzella, M.L. Alfieri, A. Napolitano, W.E. Bentley, G.F. Payne, Paraquat-Melanin Redox-Cycling: Evidence from Electrochemical Reverse Engineering, ACS Chem. Neurosci. 7 (2016) 10571067. doi:10.1021/acschemneuro.6b00007.

[284] E. Kim, T. Gordonov, Y. Liu, W.E. Bentley, G.F. Payne, Reverse engineering to suggest biologically relevant redox activities of phenolic materials, ACS Chem. Biol. 8 (2013) 716-724. doi:10.1021/cb300605s.

[285] E. Kim, Y. Liu, X.-W.W. Shi, X. Yang, W.E. Bentley, G.F. Payne, Biomimetic Approach to Confer Redox Activity to Thin Chitosan Films, Adv. Funct. Mater. 20 (2010) 2683-2694. doi:10.1002/adfm.200902428.

[286] E. Kim, Y. Xiong, Y. Cheng, H.-C. Wu, Y. Liu, B. Morrow, H. Ben-Yoav, R. Ghodssi, G. Rubloff, J. Shen, W. Bentley, X. Shi, G. Payne, Chitosan to Connect Biology to Electronics: Fabricating the Bio-Device Interface and Communicating 
Across This Interface, Polymers (Basel). 7 (2014) 1-46.

doi:10.3390/polym7010001.

[287] E. Kim, W.T. Leverage, Y. Liu, I.M. White, W.E. Bentley, G.F. Payne, Redoxcapacitor to connect electrochemistry to redox-biology, Analyst. 139 (2014) 3243. doi:10.1039/c3an01632c.

[288] K.M. Gray, E. Kim, L.-Q. Wu, Y. Liu, W.E. Bentley, G.F. Payne, Biomimetic fabrication of information-rich phenolic-chitosan films, Soft Matter. 7 (2011) 9601. doi:10.1039/c1sm05293d.

[289] E. Kim, Y. Liu, W.E. Bentley, G.F. Payne, Redox Capacitor to Establish BioDevice Redox-Connectivity, Adv. Funct. Mater. 22 (2012) 1409-1416. doi:10.1002/adfm.201101946.

[290] N.C. Cady, K.A. McKean, J. Behnke, R. Kubec, A.P. Mosier, S.H. Kasper, D.S. Burz, R.A. Musah, Inhibition of Biofilm Formation, Quorum Sensing and Infection in Pseudomonas aeruginosa by Natural Products-Inspired Organosulfur Compounds, PLoS One. 7 (2012) e38492. doi:10.1371/journal.pone.0038492.

[291] A.E. Clatworthy, E. Pierson, D.T. Hung, Targeting virulence: a new paradigm for antimicrobial therapy, Nat. Chem. Biol. 3 (2007) 541-548. doi:10.1038/nchembio.2007.24.

[292] L.R.R. Perez, A.L.P. de Freitas, A.L. Barth, Cystic and Non-Cystic Fibrosis Pseudomonas aeruginosa Isolates are not Differentiated by the Quorum-Sensing Signaling and Biofilm Production, Curr. Microbiol. 64 (2011) 81-84. doi:10.1007/s00284-011-0041-z.

[293] E.-M. Lai, H.-W. Shih, S.-R. Wen, M.-W. Cheng, H.-H. Hwang, S.-H. Chiu, Proteomic analysis ofAgrobacterium tumefaciens response to thevir gene inducer acetosyringone, Proteomics. 6 (2006) 4130-4136. doi:10.1002/pmic.200600254.

[294] C.J. Baker, B.D. Whitaker, D.P. Roberts, N.M. Mock, C.P. Rice, K.L. Deahl, A.A. Aver'yanov, Induction of redox sensitive extracellular phenolics during plantbacterial interactions, Physiol. Mol. Plant Pathol. 66 (2005) 90-98. doi:10.1016/j.pmpp.2005.05.002.

[295] C.J. Baker, N.M. Mock, B.D. Whitaker, D.P. Roberts, C.P. Rice, K.L. Deahl, A.A. Aver'yanov, Involvement of acetosyringone in plant-pathogen recognition, Biochem. Biophys. Res. Commun. 328 (2005) 130-136. doi:10.1016/j.bbrc.2004.12.153.

[296] A. Price-Whelan, L.E.P. Dietrich, D.K. Newman, Rethinking "secondary" metabolism: physiological roles for phenazine antibiotics, Nat. Chem. Biol. 2 (2006) 71-78. doi:10.1038/nchembio764.

[297] J. Davies, K.S. Ryan, Introducing the Parvome: Bioactive Compounds in the Microbial World, ACS Chem. Biol. 7 (2012) 252-259. doi:10.1021/cb200337h.

[298] S. Romero, G.T. Van Nhieu, A bacterial virulence factor that dissipates tension, Nat. Cell Biol. 11 (2009) 1174-1175. doi:10.1038/ncb1009-1174. 
[299] P.D. Straight, R. Kolter, Interspecies Chemical Communication in Bacterial Development, Annu. Rev. Microbiol. 63 (2009) 99-118. doi:10.1146/annurev.micro.091208.073248.

[300] L.E.P. Dietrich, A. Price-Whelan, A. Petersen, M. Whiteley, D.K. Newman, The phenazine pyocyanin is a terminal signalling factor in the quorum sensing network of Pseudomonas aeruginosa, Mol. Microbiol. 61 (2006) 1308-1321. doi:10.1111/j.1365-2958.2006.05306.x.

[301] C. Okegbe, H. Sakhtah, M.D. Sekedat, A. Price-Whelan, L.E.P. Dietrich, Redox Eustress: Roles for Redox-Active Metabolites in Bacterial Signaling and Behavior, Antioxid. Redox Signal. 16 (2012) 658-667. doi:10.1089/ars.2011.4249.

[302] A. V Armstrong, D.E.S. Stewart-Tull, The Site Of The Activity Of Extracellular Products Of Pseudomonas Aeruginosa In The Electron-Transport Chain In Mammalian Cell Respiration, J. Med. Microbiol. 4 (1971) 263-270. doi:10.1099/00222615-4-2-263.

[303] D.J. Hassett, L. Charniga, K. Bean, D.E. Ohman, M.S. Cohen, Response of Pseudomonas aeruginosa to pyocyanin: Mechanisms of resistance, antioxidant defenses, and demonstration of a manganese-cofactored superoxide dismutase, Infect. Immun. 60 (1991) 328-336.

[304] K.L. Palmer, L.M. Mashburn, P.K. Singh, M. Whiteley, Cystic Fibrosis Sputum Supports Growth and Cues Key Aspects of Pseudomonas aeruginosa Physiology, J. Bacteriol. 187 (2005) 5267-5277. doi:10.1128/jb.187.15.5267-5277.2005.

[305] D. Koley, M.M. Ramsey, A.J. Bard, M. Whiteley, Discovery of a biofilm electrocline using real-time 3D metabolite analysis, Proc. Natl. Acad. Sci. 108 (2011) 1999620001. doi:10.1073/pnas.1117298108.

[306] D. V Vukomanovic, D.E. Zoutman, G.S. Marks, J.F. Brien, G.W. van Loon, K. Nakatsu, Analysis of pyocyanin from Pseudomonas aeruginosa by adsorptive stripping voltammetry, J. Pharmacol. Toxicol. Methods. 36 (1996) 97-102. doi:10.1016/s1056-8719(96)00104-9.

[307] O. Bukelman, N. Amara, R. Mashiach, P. Krief, M.M. Meijler, L. Alfonta, Electrochemical analysis of quorum sensing inhibition, Chem. Commun. (2009) 2836. doi:10.1039/b901125k.

[308] D. Sharp, P. Gladstone, R.B. Smith, S. Forsythe, J. Davis, Approaching intelligent infection diagnostics: Carbon fibre sensor for electrochemical pyocyanin detection, Bioelectrochemistry. 77 (2010) 114-119. doi:10.1016/j.bioelechem.2009.07.008.

[309] J.L. Connell, J. Kim, J.B. Shear, A.J. Bard, M. Whiteley, Real-time monitoring of quorum sensing in 3D-printed bacterial aggregates using scanning electrochemical microscopy., Proc. Natl. Acad. Sci. U. S. A. 111 (2014) 1825560. doi:10.1073/pnas.1421211111.

[310] E. Kim, T. Gordonov, W.E. Bentley, G.F. Payne, Amplified and in Situ Detection of Redox-Active Metabolite Using a Biobased Redox Capacitor, Anal. Chem. 85 (2013) 2102-2108. doi:10.1021/ac302703y. 
[311] Y. Liu, E. Kim, I.M. White, W.E. Bentley, G.F. Payne, Information processing through a bio-based redox capacitor: Signatures for redox-cycling, Bioelectrochemistry. 98 (2014) 94-102. doi:10.1016/j.bioelechem.2014.03.012.

[312] J. Yu, R.L. Carrier, J.C. March, L.G. Griffith, Three dimensional human small intestine models for ADME-Tox studies, Drug Discov. Today. 19 (2014) 15871594. doi:10.1016/j.drudis.2014.05.003.

[313] H.J. Kim, H. Li, J.J. Collins, D.E. Ingber, Contributions of microbiome and mechanical deformation to intestinal bacterial overgrowth and inflammation in a human gut-on-a-chip, Proc. Natl. Acad. Sci. 113 (2015) 201522193. doi:10.1073/pnas.1522193112. 